\section{Pacific Northwest}

National Laboratory

Operated by Battelle for the

U.S. Department of Energy

\section{Oxidation of K-West Basin Spent Nuclear Fuel In Moist Helium Atmosphere}

J. Abrefah

R. L. Sell

RECEU:

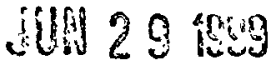

os 1

May 1999

Prepared for the U.S. Department of Energy under Contract DE-AC06-76RLO 1830 


\section{DISCLAIMER}

This report was prepared as an account of work sponsored by an agency of the United States Government. Reference herein to any specific commercial product, process, or service by trade name, trademark, manufacturer, or otherwise does not necessarily constitute or imply its endorsement, recommendation, or favoring by the United States Government or any agency thereof, or Battelle Memorial Institute.

\section{PACIFIC NORTHWEST NATIONAL LABORATORY \\ operated by \\ BATTELLE \\ for the \\ UNITED STATES DEPARTMENT OF ENERGY \\ under Contract DE-AC06-76RLO 1830}

Printed in the United States of America

Available to DOE and DOE contractors from the

Office of Scientific and Technical Information, P.O. Box 62, Oak Ridge, TN 37831;

prices available from $(615)$ 576-8401.

Available to the public from the National Technical Information Service,

U.S. Department of Commerce, 5285 Port Royal Rd., Springfield, VA 22161 
PNNL-12167

UC-602

\title{
Oxidation of K-West Basin Spent Nuclear Fuel In Moist Helium Atmosphere
}

\author{
J. Abrefah \\ R. L. Sell
}

May 1999

Prepared for

the U.S. Department of Energy

under Contract DE-AC06-76RLO 1830

Pacific Northwest National Laboratory

Richland, Washington 99352 


\section{DISCLAIMER}

This report was prepared as an account of work sponsored by an agency of the United States Government. Neither the United States Government nor any agency thereof, nor any of their employees, make any warranty, express or implied, or assumes any legal liability or responsibility for the accuracy, completeness, or usefulness of any information, apparatus, product, or process disclosed, or represents that its use would not infringe privately owned rights. Reference herein to any specific commercial product, process, or service by trade name, trademark, manufacturer, or otherwise does not necessarily constitute or imply its endorsement, recommendation, or favoring by the United States Government or any agency thereof. The views and opinions of authors expressed herein do not necessarily state or reflect those of the United States Government or any agency thereof. 


\section{DISCLAIMER}

Portions of this document may be illegible in electronic image products. Images are produced from the best available original document. 


\section{Summary}

The oxidation rate of the 105-K West (KW) Basin spent nuclear fuel (SNF) in a moist helium atmosphere was investigated using a thermogravimetric analysis (TGA) system at the Pacific Northwest National Laboratory (PNNL). As part of the study and for the purpose of comparison of the SNF data with literature oxidation rates, unirradiated metallic uranium samples were taken from unirradiated $\mathrm{N}$-Reactor fuel and tested using the TGA system. The limited experimental measurements for both the unirradiated N-Reactor fuel and the KW SNF samples have been completed. This report summarizes the results obtained for these measurements.

The TGA system was modified for the moist-inert operation with the addition of a gas bubbler and gas handling system to introduce the proper atmosphere for the measurements. The approved test matrix included both unirradiated and irradiated fuel sample measurements to verify expected behavior based on published literature rates for uranium (Sellers 1998). ${ }^{1}$ Tests were to focus on temperatures at and below $150^{\circ} \mathrm{C}$, and a constant water vapor partial pressure was to be used for all tests. However, during the investigation the decision was made to do two additional tests at about $200^{\circ} \mathrm{C}$ because of the difficulty in measuring the small weight changes at temperatures below $75^{\circ} \mathrm{C}$. A vapor partial pressure of approximately $7 \mathrm{kPa}$ was used for these tests to have conditions similar to the expected processing conditions at the cold vacuum drying facility. The test samples were sectioned from an inner unirradiated $\mathrm{N}$-Reactor fuel element and from an outer KW Basin damaged/corroded fuel element 4378. The KW Basin damaged/corroded fuel element was the same one used for the bulk of the measurements in dry air (Abrefah et al. 1998a). ${ }^{2}$ These samples had regular geometrical shapes with masses between 1.5 and 3.5 grams. The dimensions of the samples were measured with a calibrated caliper and the initial exposed uranium surface areas were calculated from these dimensions.

Five unirradiated N-Reactor fuel sample tests were conducted to add credence to the measured oxidation rate of the SNF using the same TGA system. For the initial three unirradiated samples, gas flow rates were between 160 and $200 \mathrm{cc} / \mathrm{min}$ to ensure an adequate supply of reactants to the reaction zone of the sample and to minimize any potential leakage of air into the system. Measurements started at about $160^{\circ} \mathrm{C}$ and proceeded to lower temperatures and longer test times to obtain measurable weight gains. The low-temperature measurement in the series at $75^{\circ} \mathrm{C}$ resulted in no measurable weight gain after approximately 100 hours; therefore, $75^{\circ} \mathrm{C}$ was judged as the limiting temperature for the moist

\footnotetext{
' Sellers, E.D., 1998, Letter to H M Hatch, "Contract No. DE-AC06-96RL13200, Action on Baseline Change Request SNF-BCR-98-04 Complete Thermogravimetric Analysis Measurements" 98-SFD-094, Department of Energy Richland Operations Office, Richland, Washington.

${ }^{2}$ Abrefah, J., H.C. Buchanan, W.M. Gerry, W.J. Gray, and S.C. Marschman. 1998a. Dry Air Oxidation Kinetics of K Basin Spent Nuclear Fuel. PNNL-11786, Pacific Northwest National Laboratory, Richland, Washington.
} 
helium tests. During the last test in the initial series of tests involving the unirradiated uranium samples at an intermediate temperature of $132^{\circ} \mathrm{C}$, there was some sample weight loss after the first 150 minutes. Rates derived from the weight gain over the first 150 minutes were, however, similar to expected results based on the literature.

Seventeen irradiated samples have been tested over a temperature range of approximately $75^{\circ} \mathrm{C}$ to $210^{\circ} \mathrm{C}$. Blank runs were also performed at various temperatures to establish the system baseline. During the first eight tests, the SNF samples showed material loss. The material loss was ascribed to the formation of very fine particles, probably less than a micron in size. These particles were removed by reactant gas flow from the sample crucible and deposited on the heat shields directly underneath. Visual examination of the test chamber after the test showed the presence of the dark uranium oxide particles on the alumina heat shields. Earlier experiments in another test furnace and metallographic examinations of reacted SNF have shown that the oxide layers formed on the irradiated fuel surfaces fracture and break off after reaching a thickness of approximately 3 microns (Marschman et al. 1997). ${ }^{1}$ Examinations of some of these powders formed during furnace oxidation tests showed them to be less than a micron in diameter. A scanning electron microscope (SEM) analysis was performed on some of the oxides produced in this study. The results indicate that the particle sizes are similar to those reported in Marschman et al. (1997). Additionally, it was observed that a fraction of the oxidation product has sizes that are so small that they could be dispersed by a gas flow rate of 75 to $200 \mathrm{cc} / \mathrm{min}$ resulting in the measurement of a weight loss by the electrobalance.

The material loss problem was resolved by (a) reducing the gas flow velocity and (b) adding a platinum screen as a cover for the sample crucible. Two tests (TGA Runs 87 and 90) with an unirradiated $\mathrm{N}$-Reactor sample were performed using a platinum screen and reduced gas flow to verify that no mass transfer effects were observed by adopting these changes to the test. The weight traces for these unirradiated samples were similar to an earlier run with a higher flow rate and no platinum gauze cover. A test was conducted using a KW SNF sample (TGA Run 89) to verify that these procedural changes solved the mass loss problem. Both the weight trace and visual inspection of the alumina heat shield indicated minimal mass loss: Because of the success in minimizing the mass loss, the testing of the KW SNF samples was resumed using the same configuration and flow rate.

The oxidation behavior of KW SNF in the moist helium atmosphere showed linear oxidation kinetics throughout the temperature range studied. Thus, the unnormalized oxidation rate (weight gain/elapsed time) was computed using the least square regression fit to the weight trace data with an equation of the form

$$
\Delta W=a+r t
$$

\footnotetext{
${ }^{1}$ Marschman S.C., T.D. Pyecha, and J. Abrefah. 1997. Metallographic Examination of Damaged N-Reactor Spent Nuclear Fuel Element SFEC5,4378. PNNL-1 1438, Pacific Northwest National Laboratory, Richland, Washington.
} 
where $\Delta \mathrm{W}$ is the weight gain, $\boldsymbol{a}$ is the intercept on the weight gain axis, $t$ is the time in minutes and $r$, the slope of the fit, is the rate of weight gain in $\mathrm{mg} / \mathrm{min}$. The calculated rate of weight gain was normalized to the exposed uranium surface area and the square root of the vapor pressure in the gas stream in kiloPascal $(\mathrm{kPa})$ to give a rate constant, $\mathrm{k}$,

$$
k=r / A \sqrt{P_{\mathrm{H}_{2} \mathrm{O}}} m g / \mathrm{cm}^{2} / \mathrm{hr} / \sqrt{\mathrm{kPa}}
$$

The calculated reaction rates, $\mathrm{k}$, are compared to similar literature data in Figure S.1. The rate constants for the KW SNF are plotted in Figure S.1 as two groups of data. The first group is the SNF samples that experienced significant mass loss for which only the initial weight gain or weight gain segment with the longest duration of time was used. Their rate constants are represented as open circles in the figure. Complete weight gain traces were used in estimating the rate constants for the second group of KW SNF samples that did not experience significant mass loss. The oxidation rates for this latter group are represented by the filled squares in the figure. The weight change data for the unirradiated $\mathrm{N}$-Reactor fuel samples were treated similarly to estimate the rate constants represented by filled triangles in Figure S.1.

The oxidation rates for the unirradiated N-Reactor fuel samples in Figure S.1 fall slightly below the regression fit to the literature values for unirradiated metallic uranium but generally agree with the literature within the $95 \%$ prediction interval. Such an agreement between the two unirradiated materials (i.e., N-Reactor fuel and metallic uranium) proved the TGA system configuration could reproduce the literature data for metallic uranium.

The calculated oxidation rates for the KW SNF, however, fall consistently below the mean of the literature rates for unirradiated metallic uranium. Nevertheless, most of the individual rates for the KW SNF still fall on the lower band of the $95 \%$ predicted interval. In other words, the oxidation rates of the KW SNF samples tested were not higher than the oxidation rates of unirradiated metallic uranium. This inference is supported by statistical analysis comparing the SNF data with the literature data (Appendix C). A linear regression line was fitted to a selection of the KW SNF oxidation data (the complete weight gain group except the runs at about $75^{\circ} \mathrm{C}$ ) using an Arrhenius expression

$$
k=k_{0} \exp \left(-E_{a} / R T\right)
$$

where $\mathrm{k}_{0}$ is the pre-exponential factor, $\mathrm{E}_{\mathrm{a}}$ is the activation energy, $\mathrm{R}$ is the gas constant $(=1.987 \mathrm{cal} / \mathrm{g}$ mole/K), and $T$ is absolute temperature in Kelvin. The regression fit yielded a rate constant

$$
k=4.53 \times 10^{5} \exp (-13.3 / R T) m g / c m^{2} / h r / \sqrt{k P a}
$$

where the activation energy of $13.3 \mathrm{kcal} / \mathrm{mole}$ compares very well with similar fit to the literature data which gave an activation energy of $11.1 \mathrm{kcal} / \mathrm{mole}$. The agreement in activation energies for the SNF with metallic uranium supports a conclusion that the reactivity of the KW SNF is similar to the literature 
data. The observed lowering of the KW SNF oxidation rate may be ascribed to an experimental difficulty in controlling oxygen and a second property that is intrinsic to the $\mathrm{N}$-Reactor fuel. These effects are

1. Oxygen impurity in the reactant gas stream that could poison the moisture reaction with uranium as indicated in the report by Colmenares (1984) ${ }^{1}$.

2. Alloy addition to the $\mathrm{N}$-Reactor Fuel material that was also shown in the same report by Colmenares (1984) to influence metallic uranium reactivity.

The potential for the oxygen poisoning effect was confirmed by monitoring the oxygen concentration in the outlet gas stream using an Alfa/Omega Series 3000 Trace Oxygen Analyzer. Results of the scoping experiment suggest that during the oxidation test the oxygen in the gas stream could be as high as about $80 \mathrm{vppm}$. The actual oxygen concentration at the test sample zone could not be accurately measured, but may be lower than the measured value. The maximum theoretical multiplication factor due to the oxygen poison can be estimated from the literature data of Colmenares (1984) if the assumption is made that the response of KW SNF to the oxygen poisoning is similar to what was reported by Colmenares. Multiplying the calculated oxidation rates for the KW SNF by the maximum poisoning factor will move the KW SNF data up but most of rates will still be enveloped by the $95 \%$ prediction interval in Figure S.1.

\footnotetext{
1 Colmenares, C.A. 1984. "Oxidation Mechanisms and Catalytic Properties of the Actinides." Prog. Solid State Chemistry, 15: 257-364.
} 


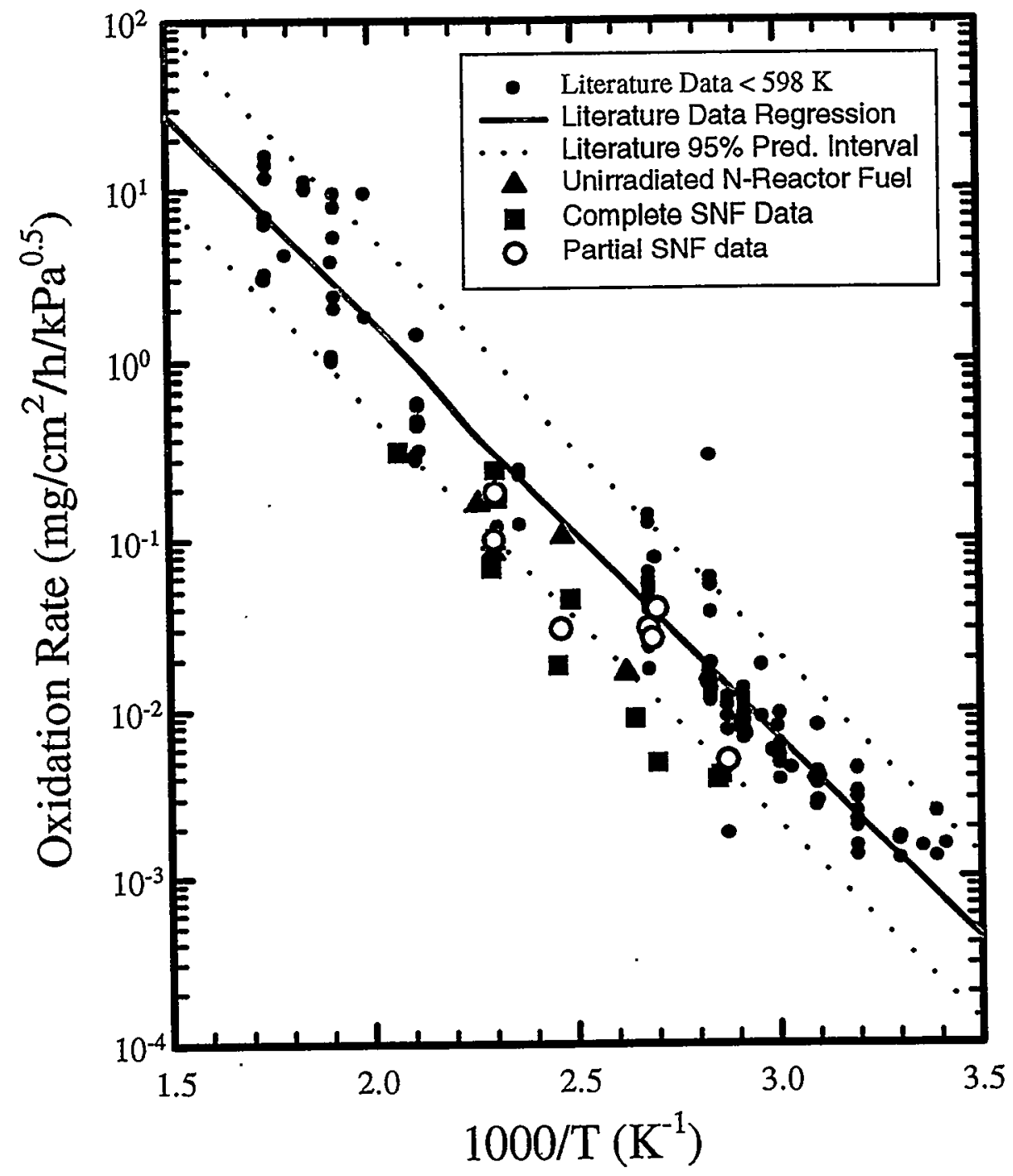

Figure S.1. Comparison of KW Basin SNF and Unirradiated N-Reactor Fuel Oxidation Rates with Literature Data for Uranium in Oxygen-Free Water Vapor 


\section{Acknowledgments}

The campaign to ship SNF samples from the K-Basin to Pacific Northwest National Laboratory for characterization activities was made possible through the dedicated efforts of the operations staff at the K-Basin and Duke Engineering and Services, Hanford SNF characterization group under the management of Ronald Omberg and his associates, Bruce Makenas, David Bergmann, and Leo Lawrence. The authors also extend our appreciation and thanks to the hot cell technicians of the Postirradiation Testing

Laboratory (PTL) and the Radiochemistry Processing Laboratory (Shielded Analytical Laboratory), who were involved in preparation of the TGA test samples. 


\section{Quality Assurance}

This work was conducted under the Quality Assurance Program, Pacific Northwest National Laboratory (PNNL) SNF-70-001, SNF Quality Assurance Program, as implemented by the PNNL SNF Characterization Project Operation Manual. This QA program has been evaluated and determined to effectively implement the requirements of DOE/RW-0333P, Office of Civilian Radioactive Waste Management Quality Assurance Requirements and Description (QARD). Compliance with the QARD requirements is mandatory for projects that generate data used to support the development of a permanent High-Level Nuclear Waste repository. Further, the U.S. Department of Energy has determined that the testing activities that generated the results documented in this report shall comply with the QARD.

Supporting records for the data in this report are located in the permanent PNNL SNF Characterization Project records (Oxidation of K-West Basin Spent Nuclear Fuel In Moist Helium Atmosphere). 



\section{Acronyms}

$\begin{array}{ll}\text { CVD } & \text { cold vacuum drying } \\ \text { DSC } & \text { differential scanning calorimeter } \\ \text { IPS } & \text { Integrated Process Strategy } \\ \text { kPa } & \text { kiloPascal } \\ \text { KW } & \text { 105-K West } \\ \text { MS } & \text { mass spectrometer } \\ \text { MWd } & \text { megawatts-days } \\ \text { PTL } & \text { Postirradiation Testing Laboratory } \\ \text { QA } & \text { Quality Assurance } \\ \text { QARD } & \text { Quality Assurance Requirement Description } \\ \text { QMS } & \text { quadrupole mass spectrometer } \\ \text { SFEC } & \text { single fuel element canister } \\ \text { SNF } & \text { spent nuclear fuel } \\ \text { SEM } & \text { scanning electron microscope } \\ \text { TGA } & \text { thermogravimetric analysis } \\ \text { UHP } & \text { ultra high purity } \\ \text { XRD } & \text { X-ray diffraction } \\ \text { vppm } & \text { volume parts per million } \\ \text { wppm } & \end{array}$




\section{Contents}

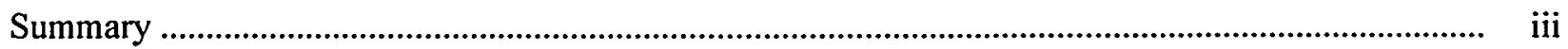

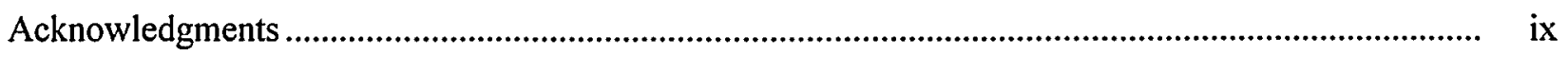

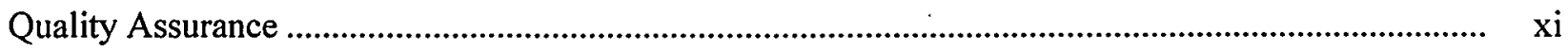

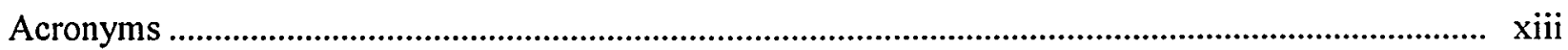

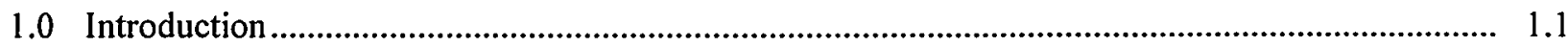

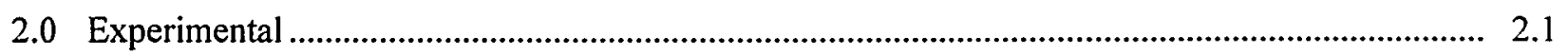

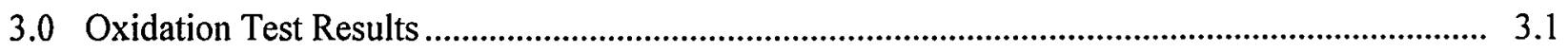

3.1 Oxidation of KW Basin SNF ........................................................................................ 3.1

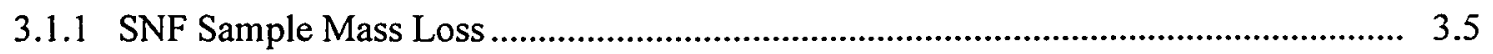

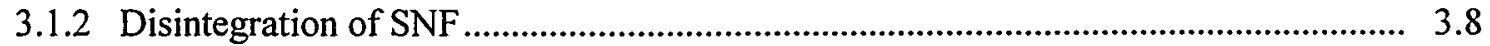

3.1.3 SEM/XRD Examinations of Oxidation Products .............................................. 3.8

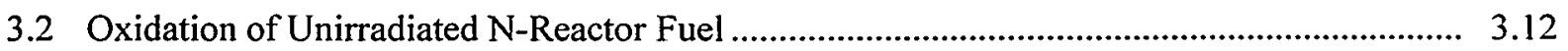

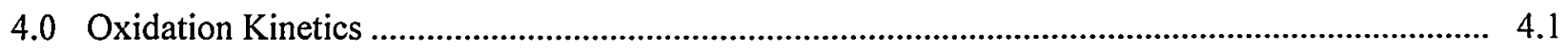

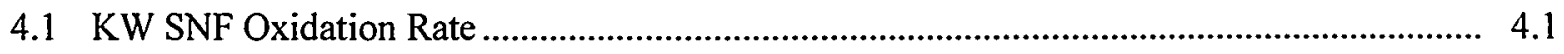

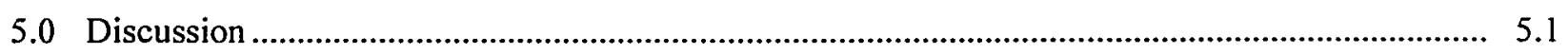

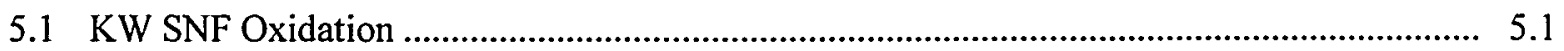

5.1.1 SNF Sample Mass Loss .................................................................................. 5.1

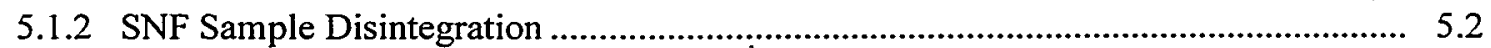

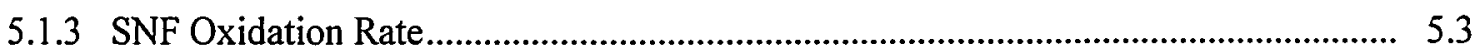

5.2 Oxidation of Unirradiated N-Reactor Fuel ...................................................................... 5.4

5.2.1 Unirradiated N-Reactor Fuel Oxidation Rate ........................................................ 5.4 
6.0 Conclusions.

7.0 Future Work

8.0 References.

8.1

Appendix A - SNF and Unirradiated N-Reactor Fuel Oxidation Results in

Helium/Water Vapor Atmosphere

Appendix B - SEM/XRD Photomicrographs of SNF Oxidation Products and

Results of Drying Calcium Oxalate

B. 1

Appendix C - Statistical Analyses of SNF Oxidation Data.

Appendix D - Data Integrity Review Team (DIRT) Activity Summary

D. 1 


\section{Figures}

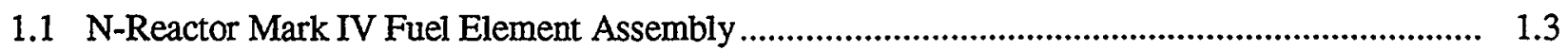

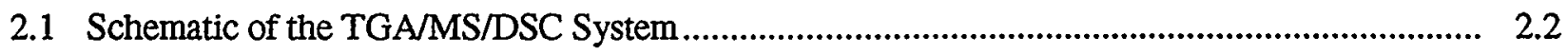

2.2 SNF Sample in Quartz Crucible without Platinum Mesh ................................................. 2.3

2.3 SNF Sample in Quartz Crucible Covered with Platinum Mesh ............................................. 2.3

2.4 End View of the Damaged Region of the SNF Element 4378. The S1A-J came from the $90 \mathrm{o}$ Sector shown by the two arrows............................................................................. 2.5

2.5 Sectioning Diagram of SNF Element 4378 Showing Test Samples...................................... 2.5

3.1 Oxidation Rate of KW SNF in Moist Helium at Different Temperatures:

TGA Run 96 at $211^{\circ} \mathrm{C}$, TGA Run 89 at $163^{\circ} \mathrm{C}$, TGA Run 98 at $129^{\circ} \mathrm{C}$,

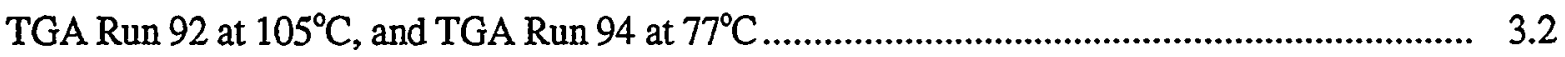

3.2 Plots of SNF Weight Change versus Time in Varying Moist Helium Gas Flow Rates:

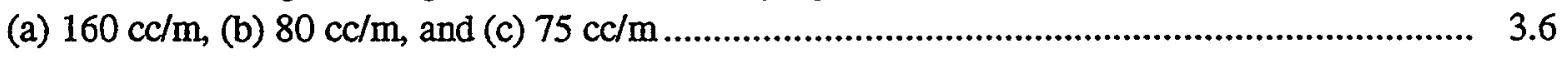

3.3 Photograph of the TGA System Showing the Top Heat Shield Covered with

Uranium Oxide Particulates from the Oxidation of SNF.................................................. 3.7

3.4 Results of TGA Run 80 Showing Photograph of Disintegrated SNF Sample 5-S1A-J2B1 after

Oxidation in Moist Helium ..............................................................................................

3.5. Results of TGA Run 81 Showing Photograph of Disintegrated SNF Sample 5-S1A-J2A2 after Oxidation in Moist Helium

3.6 Results of TGA Run 82 Showing Photograph of Disintegrated SNF Sample 5-S1A-J4B after

Oxidation in Moist Helium

3.7 Photomicrograph of SNF Oxidation Product Showing Ranges of Particle Sizes from Submicron to about 50 Microns

3.8 Photomicrograph of Unirradiated N-Reactor Fuel Oxidation Product

4.1 Regression Analysis of the Initial Segment of SNF Weight Change versus Time Data, TGA 81 Unirradiated N-Reactor Fuel Oxidation Rate 
4.2 Regression Analysis of KW Basin SNF Complete Weight Change Versus Time Data, TGA 82

4.3 Regression Analysis of KW Basin SNF Complete Weight Change Versus Time Data, TGA 96

4.4 Oxidation Rate of KW SNF and Unirradiated N-Reactor Fuel in Moist Helium

4.5 Comparison of KW SNF and Unirradiated N-Reactor Fuel Oxidation Rates with Literature Data for Uranium in "Oxygen Free" Water Vapor.

5.1. SNF Sample 5-S1A-A1A with Microcracks Filled with $\mathrm{UH}^{3}$ Precipitates (i.e... black regions with "Halo")

\section{Tables}

1.1 Alloy Composition of N-Reactor Fuel

3.1 Summary Results for KW SNF Oxidation in Moist Helium

3.2 Summary Results for Unirradiated N-Reactor Fuel Oxidation in Moist Helium 


\subsection{Introduction}

The N-Reactor spent nuclear fuel (SNF) stored at the Hanford 100-Area K-Basins comprises fuel assemblies made of a metallic uranium core that was co-extruded with an inner and outer sleeve of Zircaloy-2 under high pressure and elevated temperature (Figure 1.1). The co-extrusion formed a diffusion weld between the uranium core and the Zircaloy- 2 cladding. The metallic uranium core of the fuel was not pure uranium but contained alloy elements to yield the alloy 601 whose composition is listed in Table 1.1. Uranium alloy 601 was developed to improve the irradiation performance of the N-Reactor fuel in the core of the reactor. The major impurities in alloy 601 that may influence the reaction kinetics of the N-Reactor fuel are aluminum, carbon, iron, silicon, nickel, copper, and chromium. The inner and outer elements were assembled (Figure 1.1) and irradiated in the N-Reactor to an averaged burnup in the range of about 0.9 to $2.7 \mathrm{MWd} / \mathrm{kgU}$ (Abrefah et al.1994). After discharge, the SNF materials were put into the water-filled K-Basins (i.e., 105-K West and 105-K East), where they have been stored for periods ranging from 12 to 28 years. Storing the discharged fuel assemblies in a water basin resulted in severe corrosion in some of the uranium cores. This was due to various breaches (created during discharge and subsequent handling in the basins) in the cladding material. The corrosion damage due to the reaction of metallic uranium with water,

$$
\mathrm{U}+(2+\mathrm{x}) \mathrm{H}_{2} \mathrm{O}=\mathrm{UO}_{2+\mathrm{x}}+(2+\mathrm{x}) \mathrm{H}_{2}
$$

has generated SNF material whose subsequent oxidation kinetics could be significantly different from the initial uranium alloy 601 material. Several factors could influence the SNF reactivity (Pearce 1989) but the two important factors consequential to the severe corrosion that may affect its oxidation kinetics are the increased surface area due to roughening of the exposed uranium surface and the potential generation of uranium hydride inclusions in the uranium matrix.

Corrosion of metallic uranium by water forms uranium oxide(s), which is non-adherent and spalls due to the large volume change associated with the transformation. The volume change of the surface oxide film sets up stresses in the substrate material that cause the substrate uranium matrix to develop cracks (Baker et al. 1966). The embrittlement of the uranium material by irradiation is likely influencing crack formation in the SNF material and creating additional surface area. The spalling oxide also creates a rough uranium surface, which further increases the reaction surface area of the exposed uranium.

A fraction of the hydrogen generated by the corrosion reaction of water with uranium migrates into the uranium matrix and precipitates out as uranium hydride. The high surface area of the uranium hydride inclusions can significantly change the oxidation behavior of the corroded uranium matrix. In fact, the enhanced reactivity of metallic uranium in moist air has been ascribed to probable formation of a transitory uranium hydride phase ahead of the oxidation front (Bennett et al. 1975). It is therefore expected that a uranium matrix having a sufficient concentration of the hydride phase may show significant enhancement in reactivity. 
Table 1.1. Alloy Composition of N-Reactor Fuel

\begin{tabular}{|l|c|}
\hline \multicolumn{1}{|c|}{ Element } & $\begin{array}{c}\text { Uranium Alloy 601 } \\
\text { (wppm }{ }^{\text {(a) }} \text { ) }\end{array}$ \\
\hline Aluminum & $700-900$ \\
\hline Beryllium & 10 \\
\hline Boron & 0.25 \\
\hline Cadmium & 0.25 \\
\hline Carbon & $365-735$ \\
\hline Chromium & 65 \\
\hline Copper & 75 \\
\hline Hydrogen & 2.0 \\
\hline Iron & $300-400$ \\
\hline Magnesium & 25 \\
\hline Manganese & 25 \\
\hline Nickel & 100 \\
\hline Nitrogen & 75 \\
\hline Silicon & 124 \\
\hline Zirconium & 65 \\
\hline Uranium & Balance \\
\hline (a) wppm = weight parts per million \\
\hline
\end{tabular}

The proposed drying process (Gerber 1996), cold vacuum drying (CVD), for the K-Basin fuel, will subject the degraded SNF to an environment of helium mixed with water vapor. Hence the reactivity of uranium in the moist helium atmosphere is crucial information for safety analysis and process control of the CVD process. The SNF project has reviewed the literature to establish the reaction rate equation to be used in their analyses. The experimental program reported here, using samples taken from one of the $\mathrm{K}$-West Basin SNF is to validate the rate expressions for SNF developed using literature results. Consequently, only limited experiments within the CVD process temperature and vapor pressure regime were performed to compare with the available literature database. This report summarizes the observations for the completed tests. The limited SNF data are compared with the reviewed literature data for the temperature range of interest. 


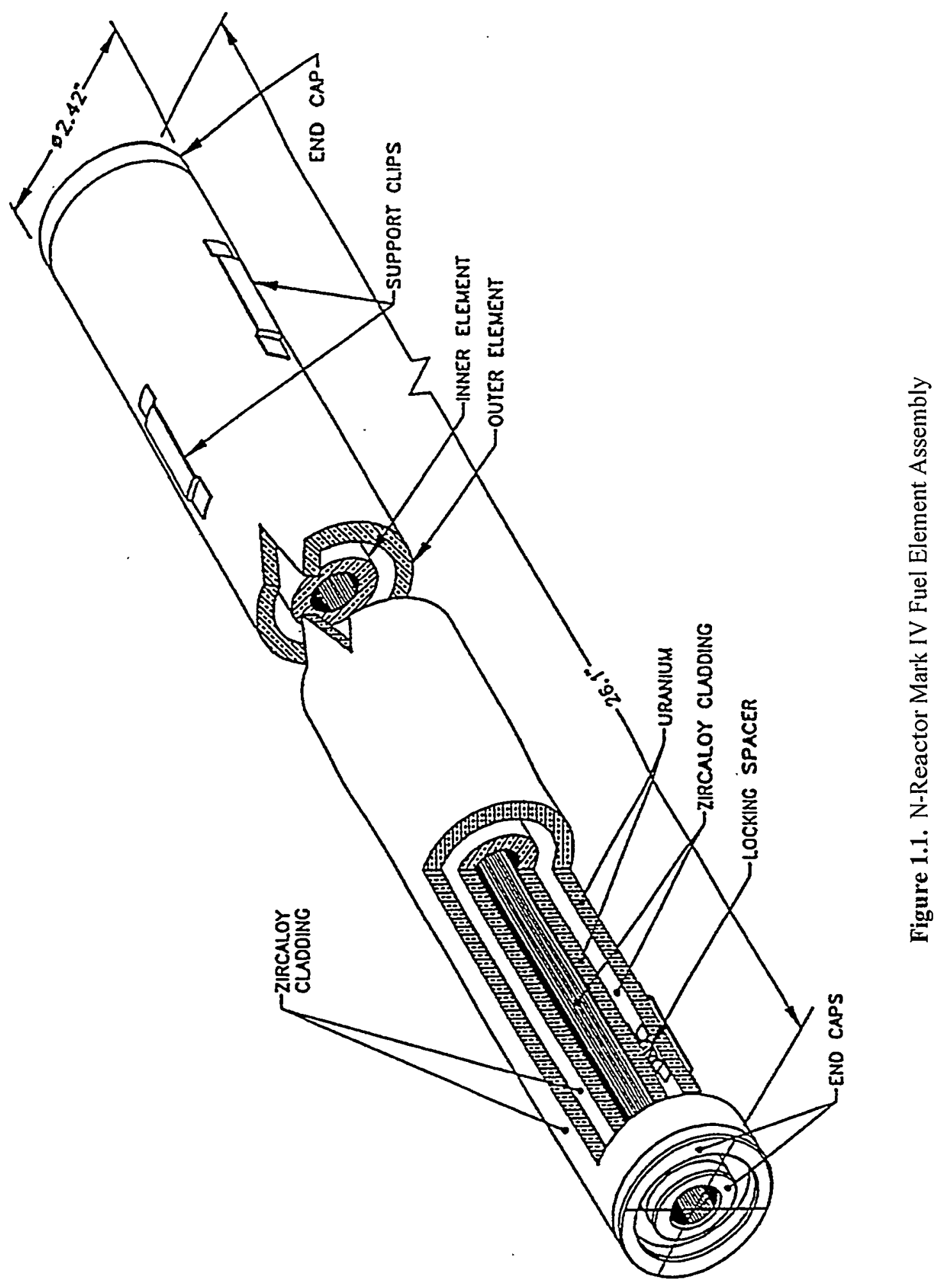




\subsection{Experimental}

The testing was conducted using a Netzsch STA 409 Thermogravimetric/Differential Scanning Calorimeter/Mass Spectrometer (TGA/DSC/MS) skimmer graphite furnace system in a glove box. A schematic representation of the testing system is shown in Figure 2.1. The system is made up of four chambers; a MS chamber, an intermediate chamber, a sample reaction chamber, and a balance chamber. The MS chamber houses the quadrupole mass spectrometer (QMS), and it is pumped by a turbomolecular pump to a baseline pressure of about $10^{-7}$ Torr. The intermediate chamber separates the MS chamber from the atmospheric reaction chamber and is pumped by a mechanical pump to a base pressure of about $10^{-3}$ Torr without a load. The sample chamber houses the thermogravimetric sample carrier, which has the sample thermocouple (i.e., S-type) and connects to the analytical balance. Gas inlet and outlet lines are connected to this chamber for supplying the reactant gas. The sample crucible, with dimensions of 15 $\mathrm{mm}$ outside diameter, $12 \mathrm{~mm}$ inside diameter, a depth of $5.2 \mathrm{~mm}$, and a height of $7 \mathrm{~mm}$, is mounted at the end of the sample carrier (Figure 2.1). The material for the crucible is quartz. Some of the experiments were conducted with an open crucible as shown in Figure 2.2.

The SNF sample was loaded with one surface (i.e., either a uranium cut surface or the attached Zircaloy) in contact with the bottom of the quartz crucible. To minimize an observed sample loss during the oxidation reaction in the first few experiments, a crucible cover constructed from 52-mesh and 100-mesh platinum gauze was used in all subsequent tests. A photograph showing a test sample covered with the platinum gauze in shown in Figure 2.3. The sample chamber was resistively heated by graphite elements that are protected by a vacuum of about $10^{-3}$ Torr. The analytical balance chamber houses the electrobalance and a gas inlet to the chamber that allows it to be purged by ultra high purity (UHP) helium. The temperature of the analytical chamber was maintained at ambient conditions by a series of heat shields in the sample chamber and water cooling at the joint that separates this chamber from the heated sample chamber.

The reactant gas mixture of UHP helium and water vapor was generated using a bubbler system. This consists of a cylindrical stainless steel reservoir filled with de-ionized water and heated by a Neslab RTE 111 constant temperature bath. The temperature of the bubbler water is measured by a type-K thermocouple. Routing the moist-helium gas mixture through the normal inlet of the TGA system resulted in operational problems with the mechanical portion of the balance. These problems were caused by the premature condensation of water vapor that subsequently damaged the balance compensation mechanism. The gas system was reconfigured to enter the test chamber at a different location with the balance protected from the moisture atmosphere with a dry UHP helium gas. The balance was repaired and completely realigned and calibrated. Measurements were conducted using a material with well-known waters of hydration to verify balance operations and sample temperatures. Measurements with calcium oxalate (Appendix B) duplicated the expected behavior for the known waters of hydration. The gas handling system was protected with heat tape at approximately $100^{\circ} \mathrm{C}$ to minimize moisture condensation from the gas bubbler operating at approximately $50^{\circ} \mathrm{C}$. The partial pressure of the water vapor in the gas mixture was measured by a moisture monitor. The output of the moisture probe was stored by HP Data Acquisition/Switch Unit 34970A. 


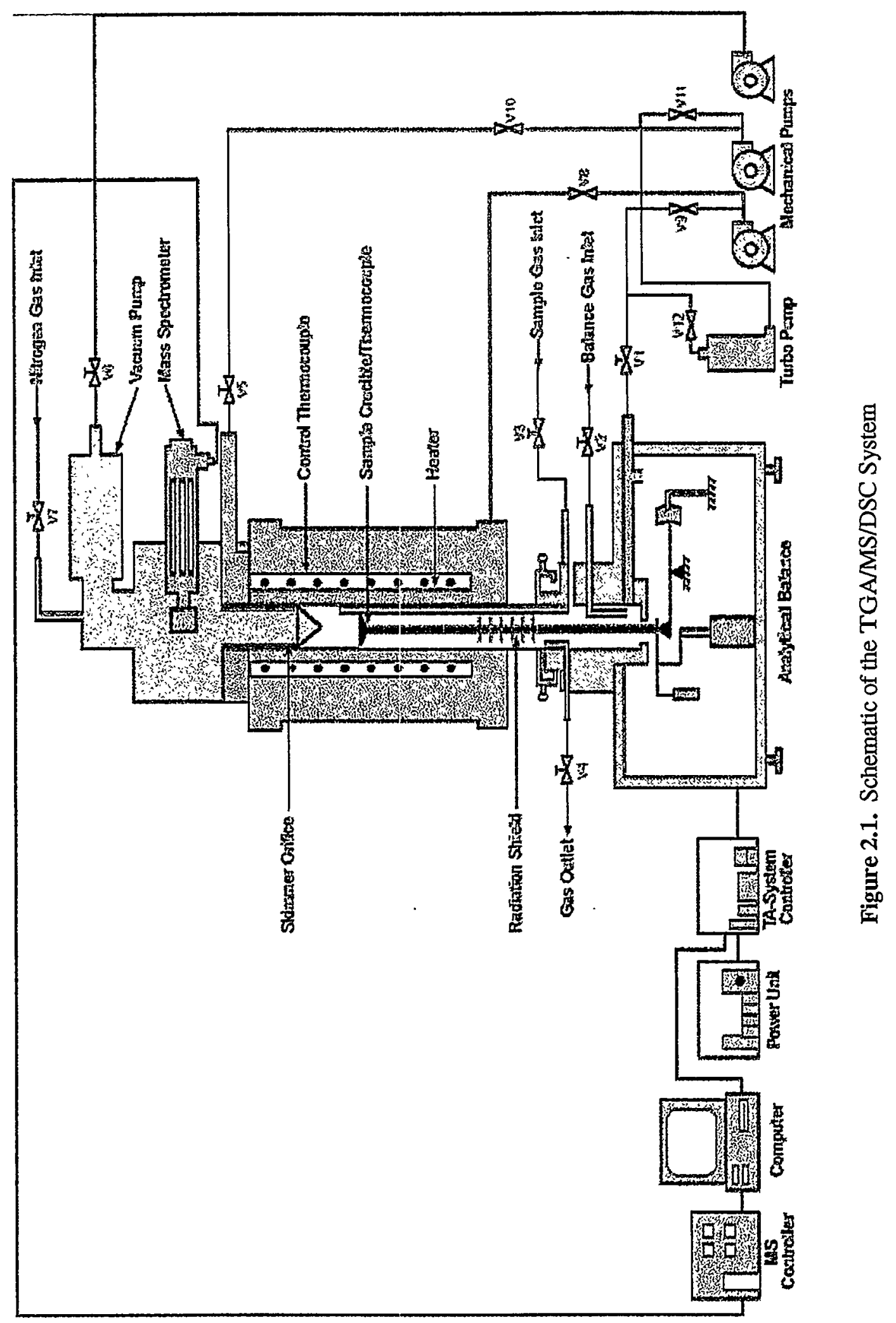




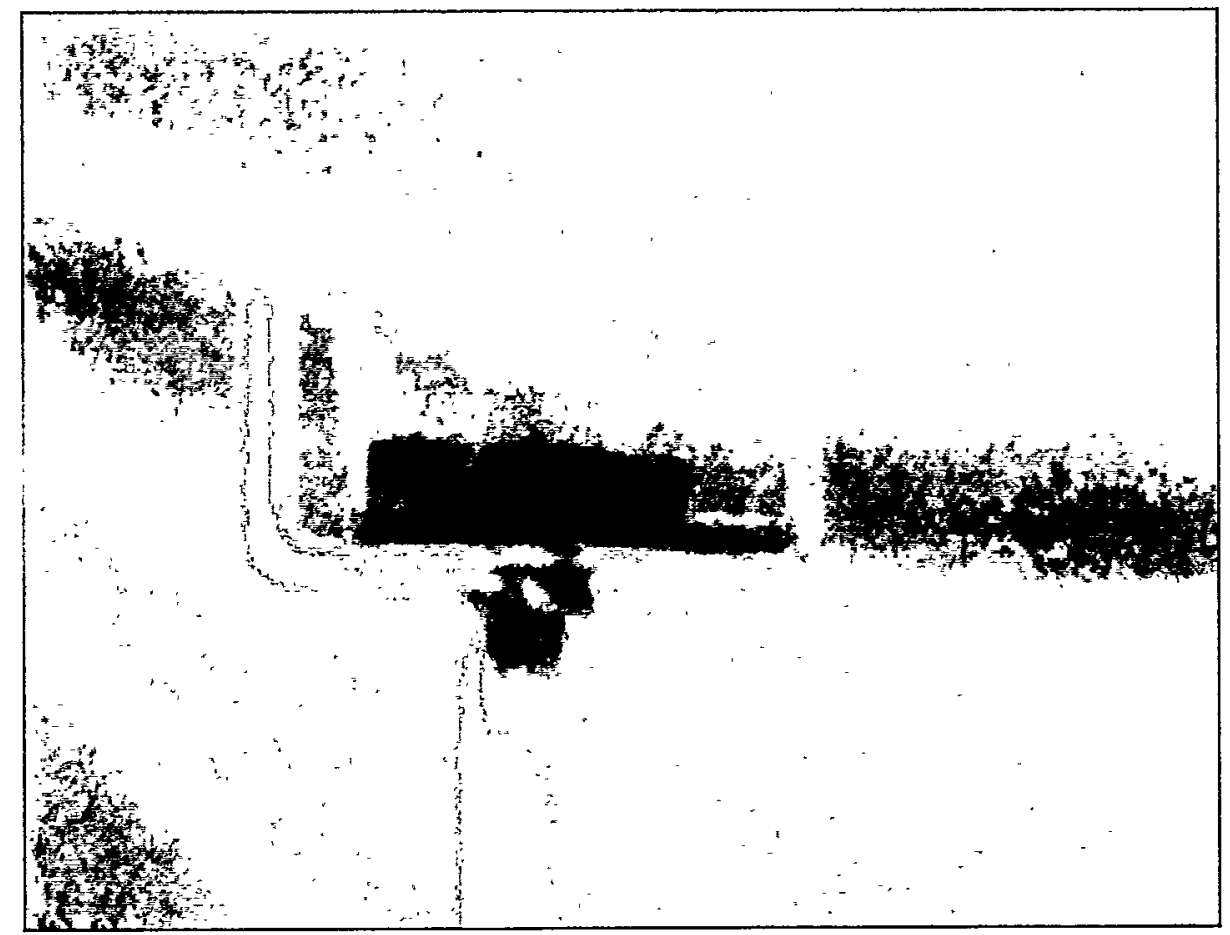

Figure 2.2. SNF Sample in Quartz Crucible without Platinum Mesh

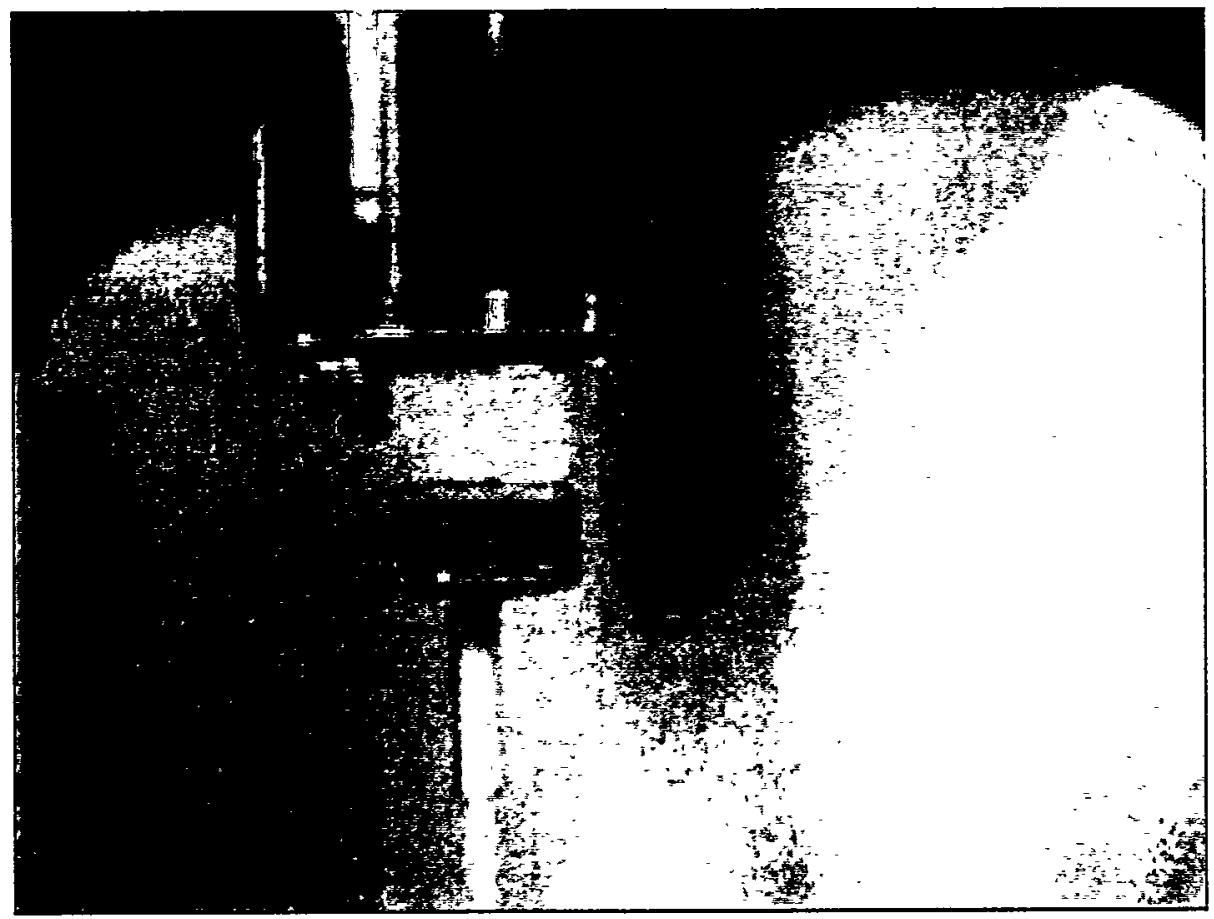

Figure 2.3. SNF Sample in Quartz Crucible Covered with Platinum Mesh 
The SNF samples used for the oxidation studies were sectioned from the damaged region of a damaged/corroded end of SNF element SFEC5,4378 shown in Figure 2.4. In this figure, the end cap has been removed to show the remaining metallic fuel material after corrosion. The $90^{\circ}$ sector SFEC $5,4378-$ S1A-J (henceforth referred to as "5-S1A-J") which was subsectioned to generate the small TGA test samples was partly attached to the end cap as indicated in Figure 2.4. The sectioning diagram of the sector 5-S1A-J for the TGA test samples is shown in Figure 2.5. The $90^{\circ}$ sector was first subsectioned longitudinally into four pieces of approximately $22.5^{\circ}$ sector angles. The $22.5^{\circ}$ sector piece identified as one of 5-S1A-J1 was slit longitudinally in between the inner and outer cladding as shown in Figure 2.5. The fuel bonded to the outer cladding was then identified as $5-\mathrm{S} 1 \mathrm{~A}-\mathrm{J} 1 \mathrm{~A}$ and the other bonded to the inner cladding as 5-S1A-J1B. The slitted pieces were finally cut into the TGA test pieces and were identified as 5-S1A-J1A1, -J1A2....J1A6, and 5-S1A-J1B1, -J1B2....J1B6. The 22.5 sector piece 5-S1A-J2 was similarly subsectioned. Sector piece 5-S1A-J3 was stored in UHP argon as an archive sample. The last piece, 5-S1 A-J4, was cut into five samples, 5-S1A-J4A, -J4B, -J4C, -J4D, and -J4E, and only the three middle pieces were considered for TGA testing.

The regular-geometrical-shaped SNF samples were used in the as-cut condition without any further preparation. The samples used were weighed before and after testing and their dimensional measurements were recorded. Before- and after-test photographs of the test samples were also taken. The samples were oxidized under the flowing gas mixture of helium/water vapor at a constant temperature and approximate system pressure of one atmosphere. The temperature was constant for each run but varied from run to run. Prior to each oxidation test, the sample chamber was purged with the UHP helium for more than an hour after loading the sample. The sample was then heated at a constant rate (i.e., either $10^{\circ} \mathrm{C} / \mathrm{min}$ or $5^{\circ} \mathrm{C} / \mathrm{min}$ ) to the desired temperature while flowing UHP helium at a rate of about 75 to $200 \mathrm{~cm}^{3} / \mathrm{min}$ through the sample chamber. After heating the sample to the isothermal temperature, the UHP helium gas was reconfigured to pass through the bubbler to pick up water vapor and supply the moist helium to the sample. The water in the bubbler had been sparged with helium for more than 2 hours at about $50^{\circ} \mathrm{C}$ to remove most of the dissolved oxygen. The sample temperature was then maintained at isothermal condition for the duration of the test, which ranged between 8 hours and 6 days. This isothermal condition was followed by cooling to ambient temperature. The sample weight change was continuously monitored by the electrobalance throughout the test. The off-gas stream, however, was not monitored by the attached QMS due to the high background of moisture in the system. The samples had either four or five cut uranium surfaces and the other surface(s) was bonded with cladding (Zircaloy-2) material.

Unirradiated $\mathrm{N}$-Reactor fuel samples were also oxidized in the moist helium atmosphere using the same experimental steps. The unirradiated samples were sectioned from an inner unirradiated N-Reactor fuel element. Unlike the SNF test samples, these unirradiated samples were polished using 600 -grit sandpaper to give shining metallic surfaces before testing. The pre-test characterization of these samples were weight and dimensional measurements. These unirradiated samples were not photographed. 


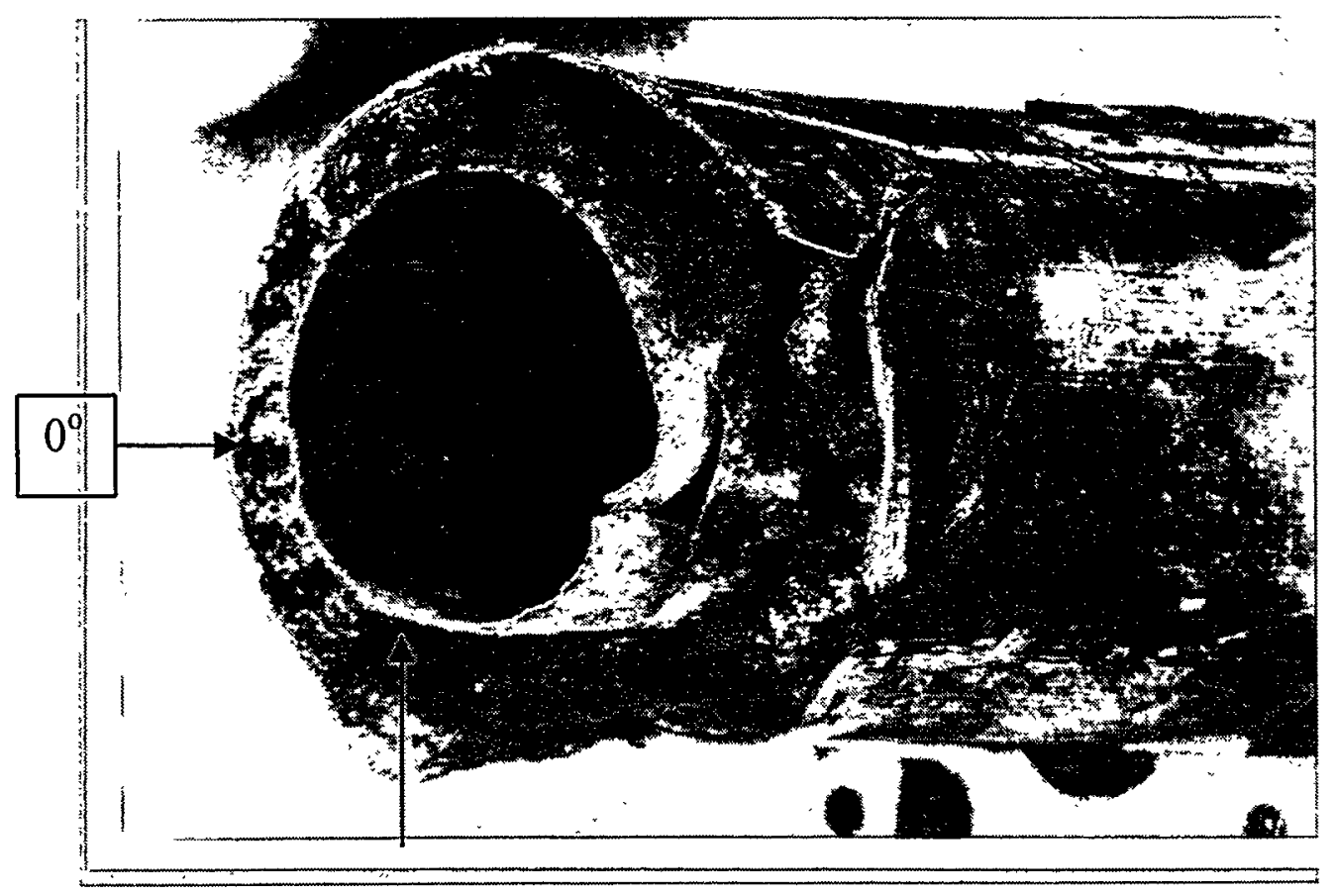

Figure 2.4. End View of the Damaged Region of the SNF Element 4378. The SlA-J came from the $90^{\circ}$ Sector shown by the two arrows.

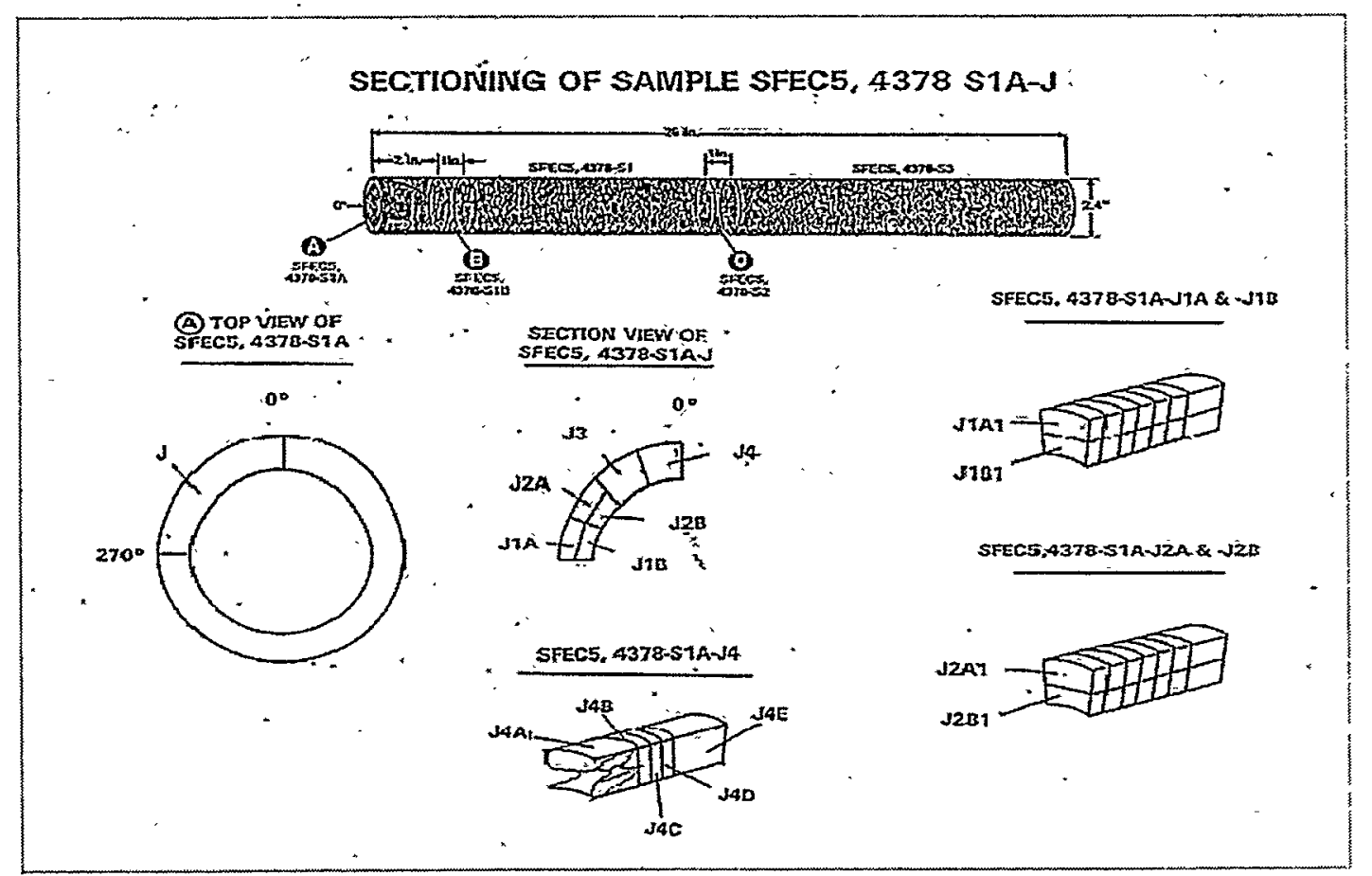

Figure 2.5. Sectioning Diagram of SNF Element 4378 Showing Test Samples 


\subsection{Oxidation Test Results}

\subsection{Oxidation of KW Basin SNF}

The oxidation results of all the K-West SNF samples in helium-water vapor atmosphere showing the rate of weight change behavior together with before- and after-test photographs of the samples are given in Appendix A, Figures A.1 through A.17. The temperature range studied was between 76 and $211^{\circ} \mathrm{C}$ and can be classified as five temperature groups. The groups in decreasing order of temperature are

a) two tests at about $210^{\circ} \mathrm{C}$ shown in Figures A.15 and A.16 (TGA Runs 96 and 97)

b) five tests around $160^{\circ} \mathrm{C}$ shown in Figures A.1 to A.3 and A.8 and A.9 (TGA Runs 80 to 82 and 88 and 89$)$

c) three tests at an approximate temperature of $130^{\circ} \mathrm{C}$ shown in Figures A.7, A.10, and A.17 (TGA Runs 86, 91, and 98)

d) four experiments (TGA Runs 83 to 85 and 92) were performed at approximately $100^{\circ} \mathrm{C}$ and are shown in Figures A.4 to A.6 and A.11

e) three tests were performed at about $75^{\circ} \mathrm{C}$ (TGA Runs 93, 94, and 95) and are shown in Figures A.12 through A.14.

The rate of weight gain by the KW SNF in the moist helium for one sample in each temperature group listed above is shown in Figure 3.1. For these selected runs, the rate of weight change (i.e., slope of the weight change versus time plot) follows linear oxidation kinetics. Other tests that gave similar linear rate of weight change but are not shown in Figure 3.1 are TGA Runs 82 (Figure A.3) and TGA Run 96 (Figure A.15). The plots in Figure 3.1 also show that the rate of weight gain by the KW SNF decreases with decreasing temperature suggesting an Arrhenius behavior for the reactivity of KW SNF material with moist helium. For cases where the weight change versus time plots showed erratic behavior (Figures A.2, A.4, A.5 A.7, and A.8), only segments of the data where the sample gained weight will be considered in determining the oxidation kinetics, and a linear kinetics will be assumed. In most cases, the weight gain segment of the data occurred at the initial stages of the tests. There is also a group of the weight change versus time plots (Figure A.1, A.6, A.10, and A.11) where the samples showed weight gains throughout the tests but the weight traces were affected by mass losses. For the latter group, the entire weight change versus time was analyzed realizing that the error associated with the estimated rate of change was higher. The portions of the weight change versus time data analyzed are indicated in the plots shown at Appendix A.

The testing parameters and the summary results of all the runs for the KW SNF are listed in Table 3.1. The tabulation is in an increasing order of the TGA Run numbers. The missing consecutive TGA Run numbers were tests using the unirradiated fuel samples and they are included in TGA Runs 


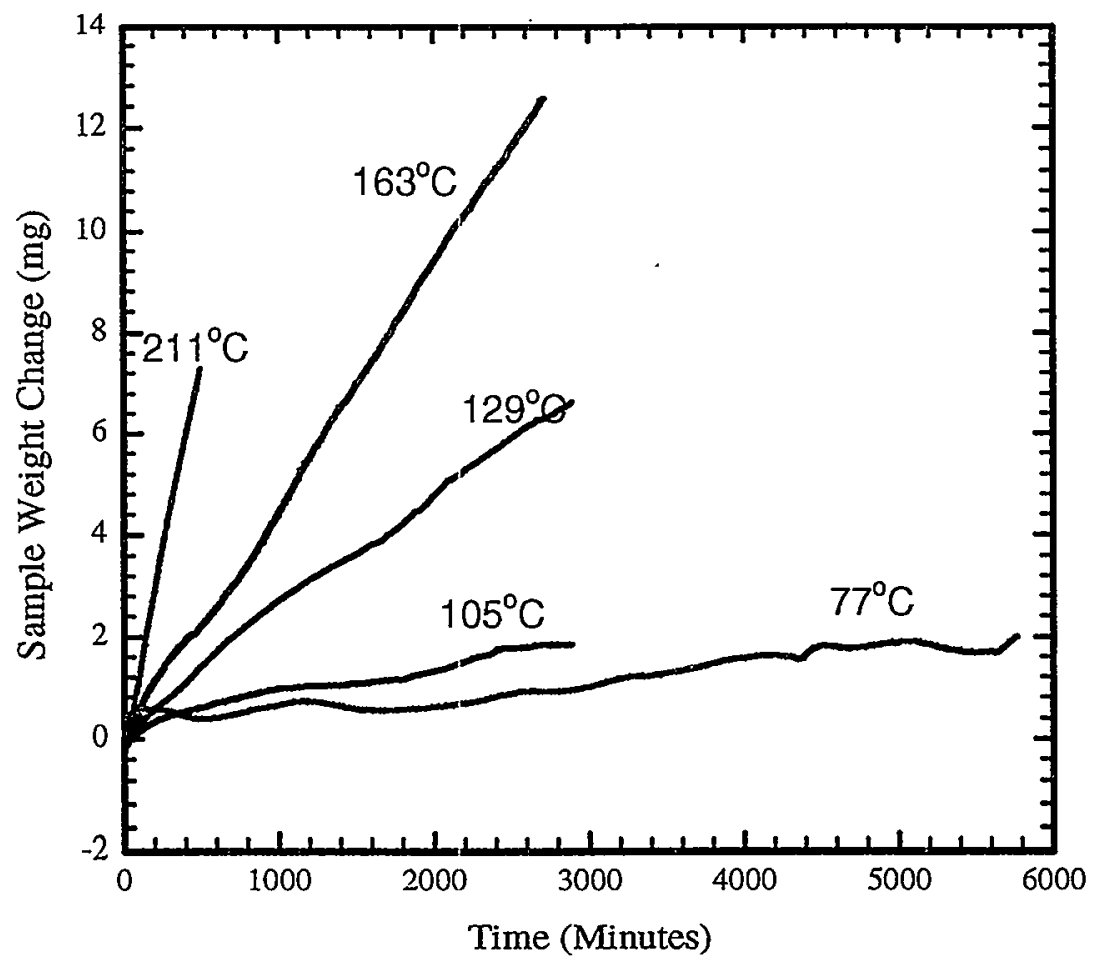

Figure 3.1. Oxidation Rate of KW SNF in Moist Helium at Different Temperatures: TGA Run 96 at $211^{\circ} \mathrm{C}$, TGA Run 89 at $163^{\circ} \mathrm{C}$, TGA Run 98 at $129^{\circ} \mathrm{C}$, TGA Run 92 at $105^{\circ} \mathrm{C}$, and TGA Run 94 at $77^{\circ} \mathrm{C}$

listed in Table 3.2. The sample identifications (ID) in Table 3.1 trace each sample to a specific location of the SNF element 4378 as was discussed in Section 2.0. The digit ' 5 ' in all the IDs traces these samples to the single fuel element canister (SFEC) that was used in shipping the SNF element from the KW Basin to the PTL facility for destructive characterization. The before-test weights of the SNF samples in Table 3.1 range between $1526 \mathrm{mg}$ and $3516 \mathrm{mg}$. These sample sizes are smaller than those used in the dry air oxidation campaign (Abrefah et al. 1998a), and they were cut smaller to minimize some of the experimental difficulties that were experienced during the dry air oxidation studies. The after-test sample weights in Table 3.1 were measured knowing there were difficulties in keeping all the oxidation products together with the sample. The sample control difficulties were due to (a) the spallation of the oxides formed by the reaction and (b) the dispersibility of the oxide formed by the reaction of KW SNF with the moist helium. Additionally, sample transfer activities from the glove box to the hot cell where the weight measurements were performed increased the potential of sample loss and the uncertainty in the after-test weight measurement data; therefore, the after-test weighing data in Table 3.1 should only be considered as qualitative information. The consequence of the after-test sample loss was an indication of no weight changes in Table 3.1 for SNF samples tested at low temperatures (TGA Runs 83, 84, 85, and 93). 
Table 3.1. Summary Results for KW SNF Oxidation in Moist Helium

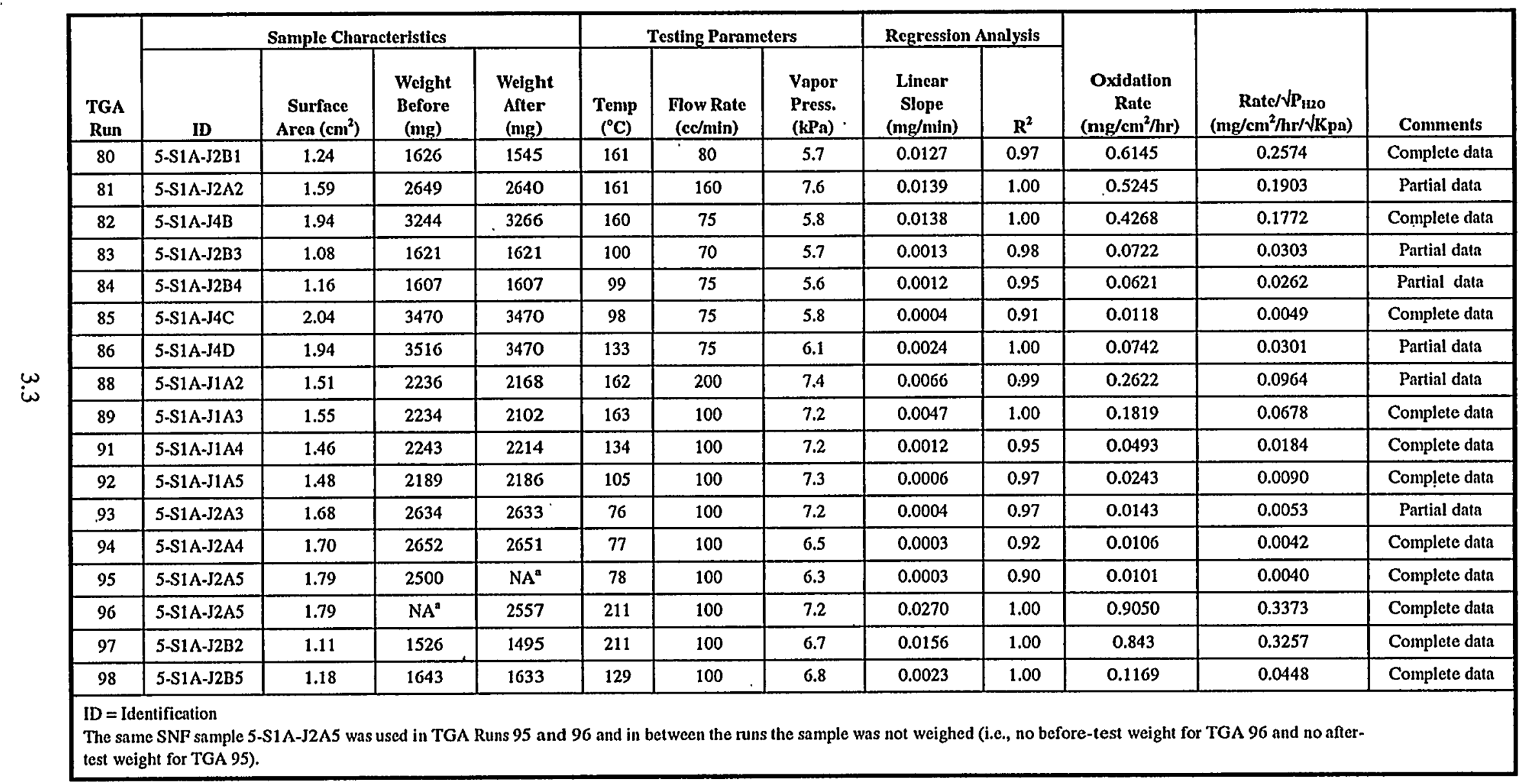


Table 3.2. Summary Results for Unirradiated N-Reactor Fuel Oxidation in Moist Helium

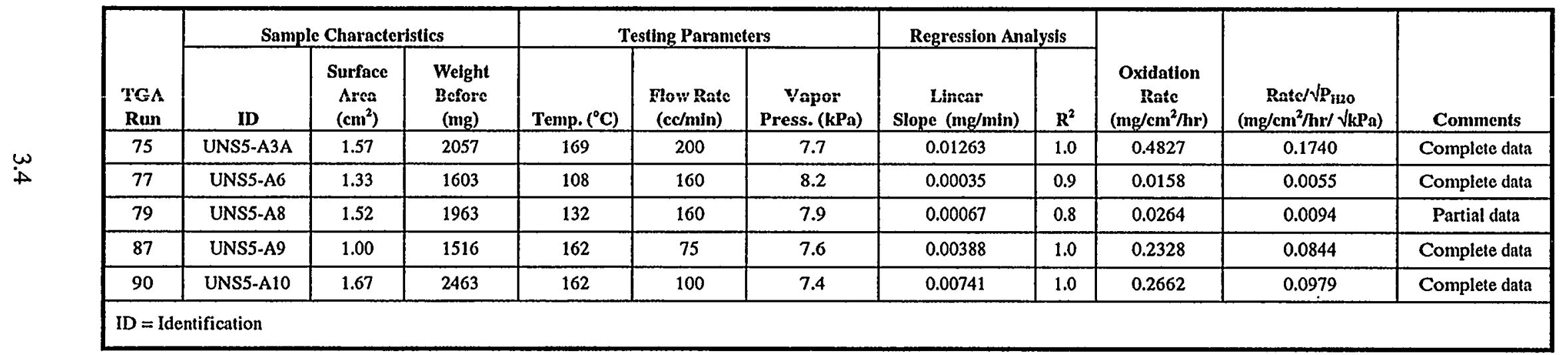


The initial geometric surface areas of the SNF samples in the third column of Table 3.1 range from $1.08 \mathrm{~cm}^{2}$ to $2.04 \mathrm{~cm}^{2}$. These areas were estimated from dimensional measurements that excluded the surfaces that were still attached to the Zircaloy cladding. Any irregularities associated with the cut surfaces were not considered in the estimate of the surface areas. The sample temperature and the gas stream water vapor partial pressure for each run are listed in Table 3.1. These data are the averaged values measured over the range of the isothermal period of the test. Typical variations from the mean of these two parameters were very small as shown in the statistical analyses report (Table C.1 of Appendix C).

The weight change plots for some of the tests involving the KW SNF such as Figure A.2 showed a behavior that can best be described as erratic response of the system. This erratic response was due to the nature of the oxidation product and will be discussed in Section 3.1.1. Another important observation is the breakup or disintegration of the SNF sample after oxidation and that will be discussed in Section 3.1.2. The scanning electron microscope (SEM) and the X-ray diffraction (XRD) analyses of the oxidation product, and the disintegrated SNF sample will be discussed in Section 3.1.3.

\subsubsection{SNF Sample Mass Loss}

The first seven SNF sample tests were performed with a quartz crucible that had an open top. The oxidation of the SNF generated a black oxide and a substantial fraction of the powder was readily dispersible by very low flows such that when the TGA furnace was opened to unload samples the oxidation product was easily blown by the flow of air through the glove box. The dispersible behavior of the oxidation product resulted in weight measurement difficulties during the testing. The open crucible configuration resulted in mass losses during the oxidation process, even for tests where the gas flow rate was low. Consequently, an erratic weight trace was measured for the tests with the open crucible top as shown in Figure 3.2a (TGA Run 81). The total mass loss estimated from the decreasing slopes of Figure $3.2 \mathrm{a}$ yielded about $11.4 \mathrm{mg}$. This suggests that a minimum of about $11.4 \mathrm{mg}$ of the oxidation product was entrained in the gas stream and was carried away from the sample crucible. If the oxide product is assumed to be mainly uranium dioxide, $\mathrm{UO}_{2}$, then this calculated mass loss constitutes about 4 weight \% of the total oxidation product. The total weight of the oxidation product for TGA Run 81 was estimated from a linear extrapolation of the initial slope of the weight change in Figure 3.2a. The extrapolated weight gain by the sample is given by the equation

$$
\Delta W=\left(\frac{\Delta w}{\Delta t}\right)_{\text {inizial }} \times \Delta t_{\text {elapsed }}
$$

where $(\Delta \mathrm{w} / \Delta \mathrm{t})_{\text {initial }}$ is the initial slope $(=0.0139 \mathrm{mg} / \mathrm{min})$ and $\Delta \mathrm{t}_{\text {elapsed }}$ is the total elapsed time $(=2536 \mathrm{~min})$. The total weight of the uranium oxide product is then given by $\Delta W / 32 \times 270$, which is about $280 \mathrm{mg}$.

The mass loss was strongly dependent on the reactant gas flow as shown in the decreasing gas flow plots of Figures 3.2 (TGA Runs 80 through 82). By decreasing the reactant gas flow rate from $160 \mathrm{cc} / \mathrm{min}$ (TGA Run 81) to $75 \mathrm{cc} / \mathrm{min}$ (TGA Run 82), we were able to decrease significantly the mass 


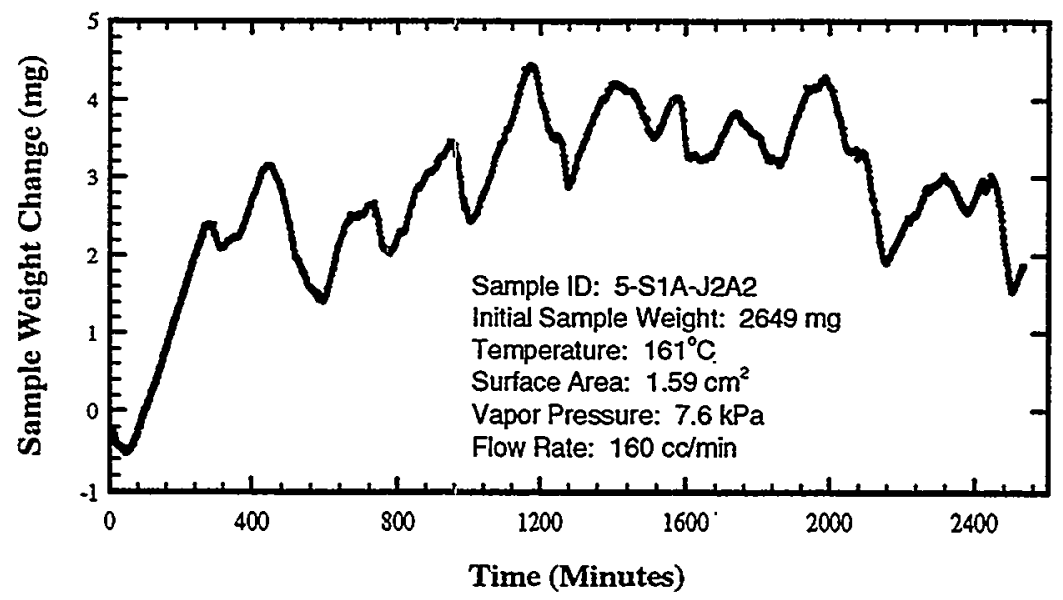

(a)

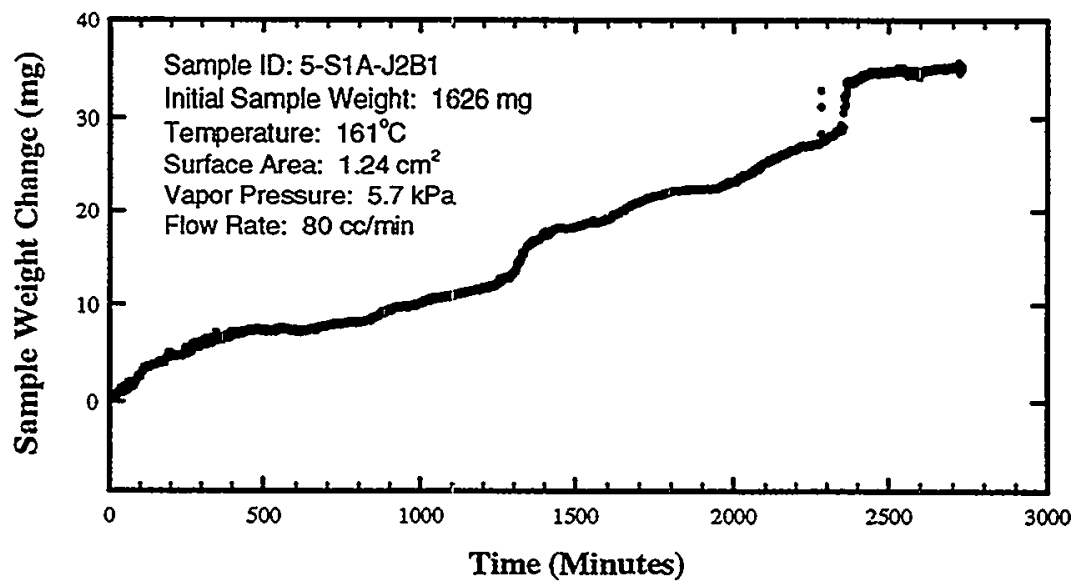

(b)

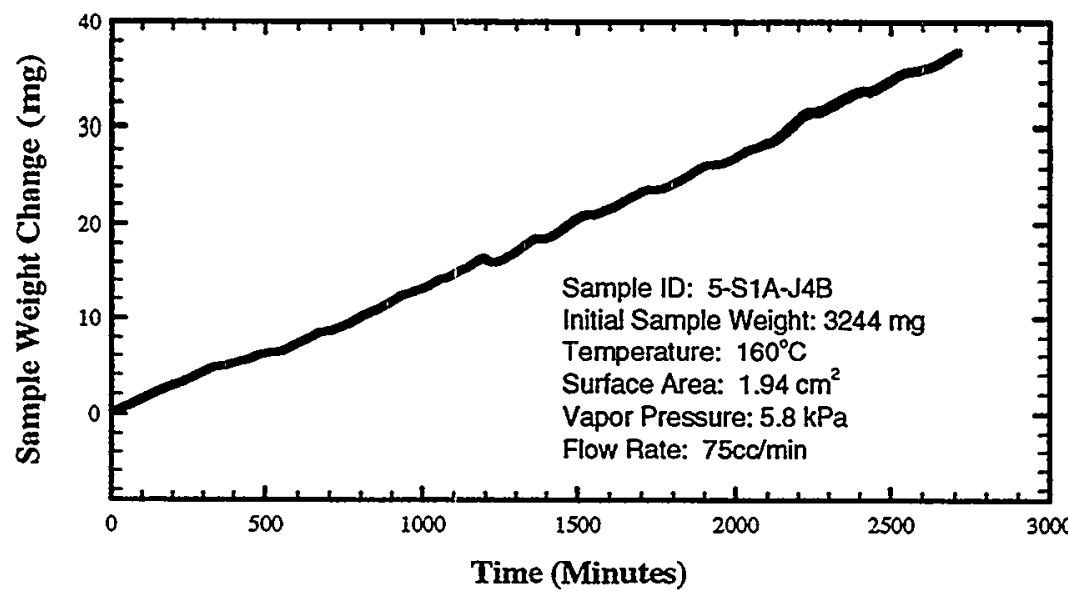

(c)

Figure 3.2. Plots of SNF Weight Change versus Time in Varying Moist Helium Gas Flow Rates: (a) $160 \mathrm{cc} / \mathrm{m}$, (b) $80 \mathrm{cc} / \mathrm{m}$, and (c) $75 \mathrm{cc} / \mathrm{m}$ 
loss to improve the weight trace measurement. Most of the oxidation product that was blown out of the crucible ended up on the heat shields below the sample crucible and some ended up in the balance chamber. Figure 3.3 shows a photograph of alumina heat shields covered with uranium oxide particulates. Most of the oxidation product in Figure 3.3 was collected on the first heat shield. The mass loss for TGA Run 82 showed significant improvement compared to TGA Run 80 even though the flow rate was decreased slightly from 80 to $75 \mathrm{cc} / \mathrm{min}$. This improvement may also be due to the increased sample size (i.e., $3.3 \mathrm{~g}$ for TGA Run 82 compared to $1.5 \mathrm{~g}$ for TGA Run 80 ).

A single 52-mesh platinum cover was used in TGA Run 88 (Figure A.8) with a gas flow of about $200 \mathrm{cc} / \mathrm{min}$ to determine whether that could prevent the mass loss and the results were negative. However, combining 52-mesh and 100-mesh platinum covers and folding them to generate a four-layered (i.e., two of 52-mesh and two of 100-mesh) platinum gauze plus lowering the reactant gas flow rate to $100 \mathrm{cc} / \mathrm{min}$ yielded a minimum particulate loss and reliable weight trace as shown in Figure A.9 (TGA Run 89). This configuration was used in all the subsequent tests (TGA Runs 89 through 98) and the gas flow rate was fixed at $100 \mathrm{cc} / \mathrm{min}$ to augment the containment of the particulates in the sample crucible. The potential for mass transfer effect for the platinum gauze cover and the low reactant gas flow was evaluated by testing an unirradiated N-Reactor fuel sample in TGA Run 90 . The oxidation results, Figure A.22, for the unirradiated run (TGA Run 90) using the new configuration and the low gas flow rate was within the experimental spread with a test (TGA Run 75) performed at $200 \mathrm{cc} / \mathrm{min}$ without the platinum cover.

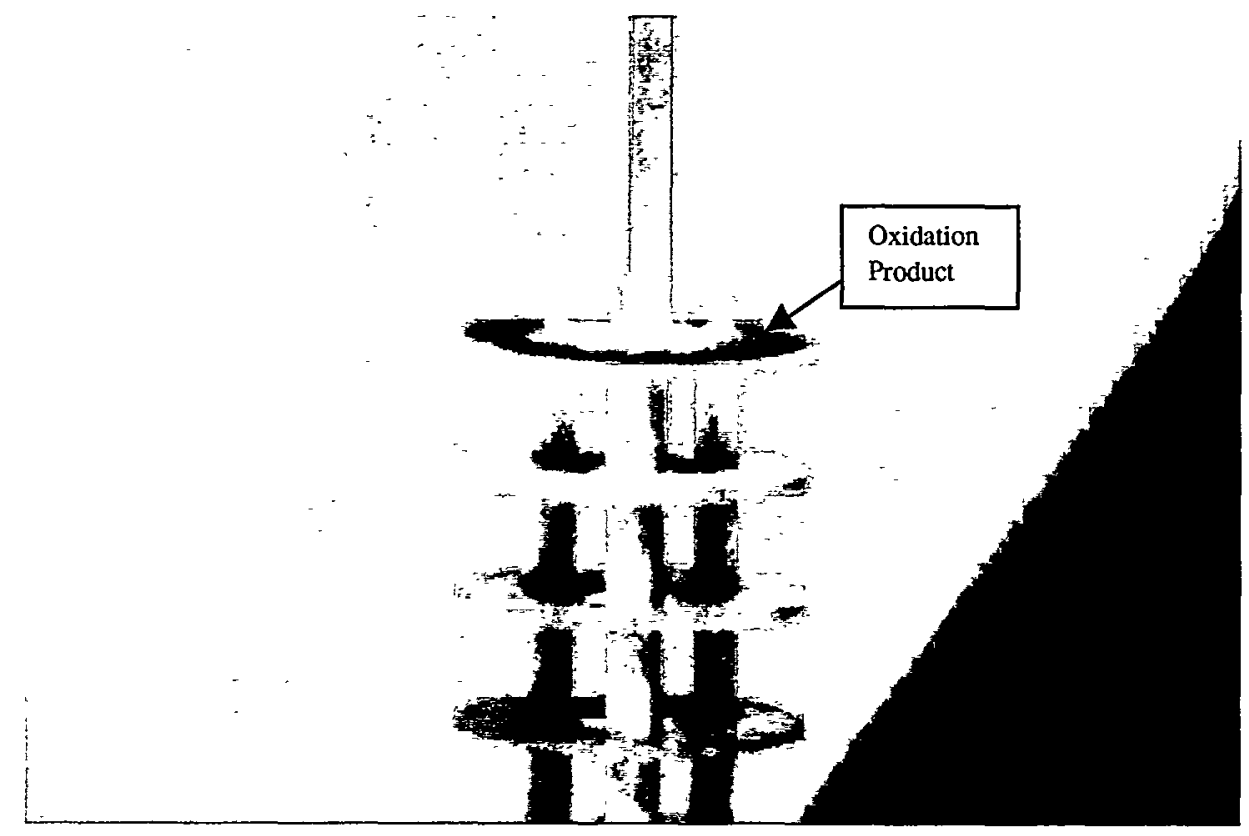

Figure 3.3. Photograph of the TGA System Showing the Top Heat Shield Covered with Uranium Oxide Particulates from the Oxidation of SNF 


\subsubsection{Disintegration of SNF}

Three of the KW SNF samples disintegrated after oxidation in the moist helium atmosphere. The before- and after-test photographs of these samples are shown in Figures 3.4 through 3.6 together with the respective weight versus time traces for these samples. In Figure 3.4 the after-test photograph shows a large piece of the sample with the cladding still attached, a smaller piece and a powdery fraction that was generated by the sample breakup, and the oxide from the oxidation reaction. The particle size distribution of the powder has not been determined, but a particle size as large as a millimeter or higher was observed. The only evidence of potential sample disintegration from the weight trace measurement is the weight spike at a time of about 2200 minutes followed by a relative sudden weight increase at a time of about 2300 minutes into the run. The observed irregularity of the weight trace throughout the run, however, was mainly due to mass loss effects described in Section 3.1.1.

The unique property of the three samples that disintegrated was that they all came from the SNF element location (Figure 2.5) very close to the corrosion front. Sample 5-S1A-J2B1 for TGA Run 80 (Figure 3.4) was the first piece under the rough corrosion surface; sample 5-S1A-J2A2 for TGA Run 81 (Figure 3.5) was the second piece after sample 5-S1A-J2A1 which broke into pieces in storage and therefore could not be tested, ${ }^{1}$ and sample 5-S1A-J4B for TGA Run 82 (Figure 3.6) was the next closest piece to rough surface corroded piece 5-S1A-J4A.

\subsubsection{SEM/XRD Examinations of Oxidation Products}

Some of the oxidation product generated by the KW SNF reaction with moist helium were analyzed by SEM to determine morphological features of the spalled oxide and the size of the particles. Some selected SEM photomicrographs are shown in Figures B.1 through B.11 of Appendix B. There are two different morphological forms of oxidation products: 1) rock-type particles shown in Figures B.2, B.3, and B.7; and 2) sheet-like particles which are laminar flakes, reminiscent of scales (Figures B.1, B.8, and B.11). The particle sizes ranges from the very fine submicron particles (Figure 3.7) which contributed to the observed mass loss during the tests to the flakes larger than one hundred microns in diameter.

The XRD spectra of the disintegrated SNF products from TGA Runs 80 and 82 are shown in Figures B.12 through B.15. Both the unprocessed intensity plots (Figures B.12 and B.14) and the background subtracted plots (Figures B.13 and B.15) identified metallic uranium as part of the disintegrated powder for the two samples analyzed. The high background signal of the intensity plots (Figures B.12 and B.14) was due to changes in the XRD sample preparation. The XRD slide was covered with transparent tape to prevent spreading of the powdered sample in the system and the large peak was due to the transparent tape material. Usually, the method used to prevent spreading of contamination in the XRD has been mixing a fine crushed powder sample in a collodian. This will have increased the potential of oxidizing any metallic component of the SNF powder. The covering of the samples with the tape substantially reduced the intensity of the peaks of the samples. Hence the subtracted spectra (Figures B.13 and B.15) are noisy but still showed the identified peaks for metallic uranium.

\footnotetext{
${ }^{1}$ The broken pieces of 5-S1A-J2A1 could not be used because we wanted to use regular geometrical shaped samples whose initial surface area could be calculated from dimensional measurements.
} 

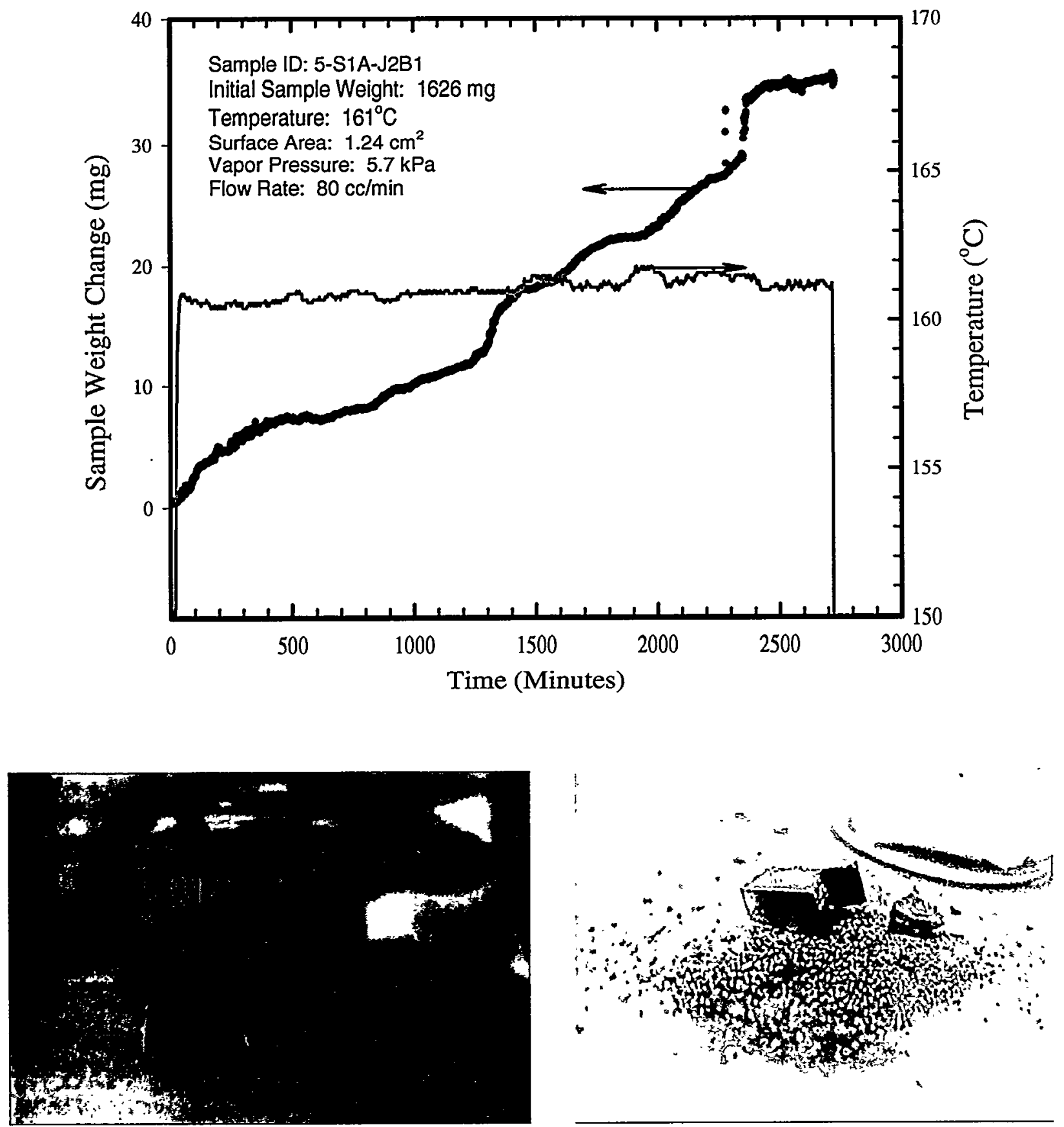

Figure 3.4. Results of TGA Run 80 Showing Photograph of Disintegrated SNF Sample 5-S1A-J2B1 after Oxidation in Moist Helium 

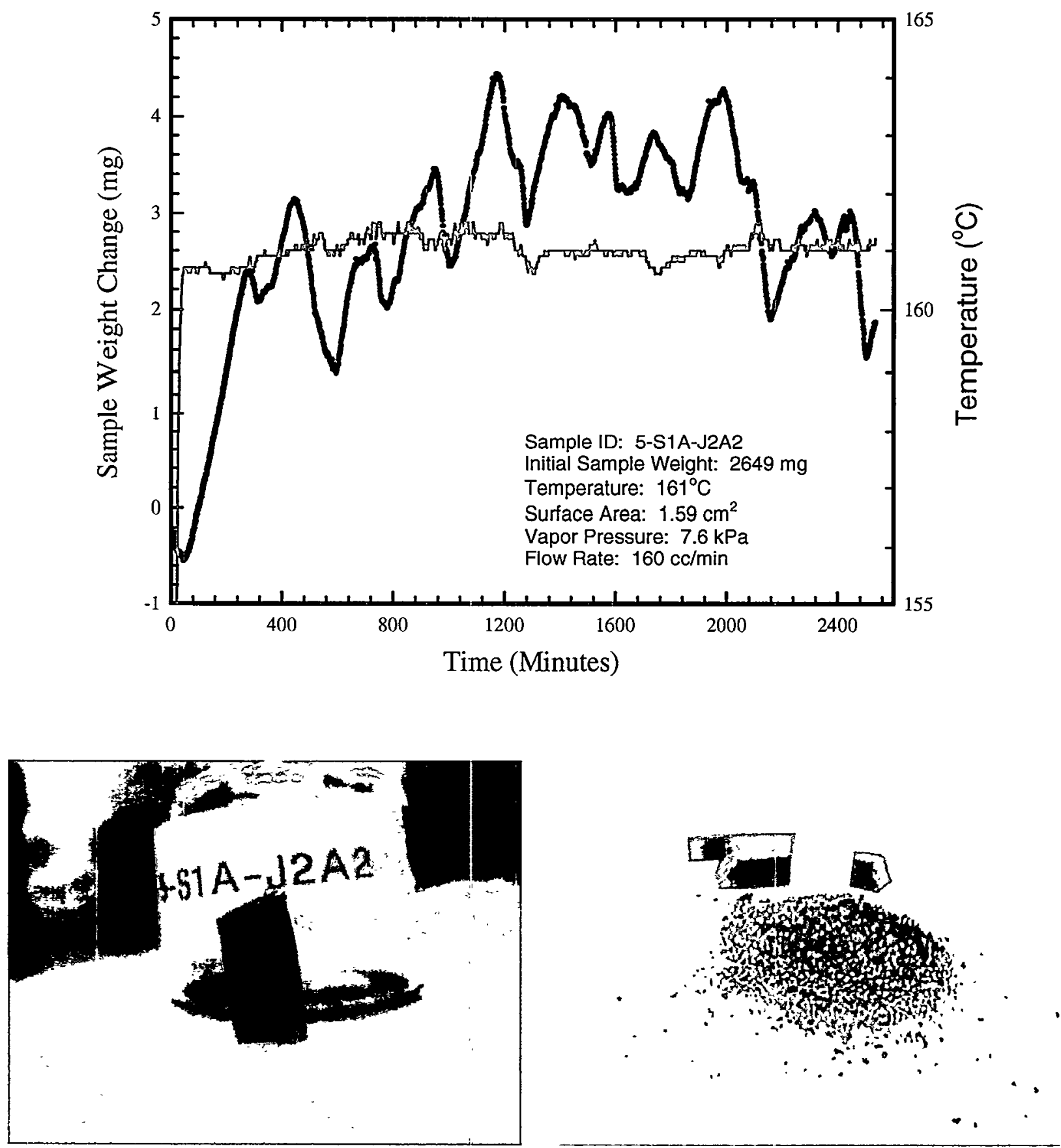

Figure 3.5. Results of TGA Run 81 Showing Photograph of Disintegrated SNF Sample 5-S1 A-J2A2 after Oxidation in Moist Helium 

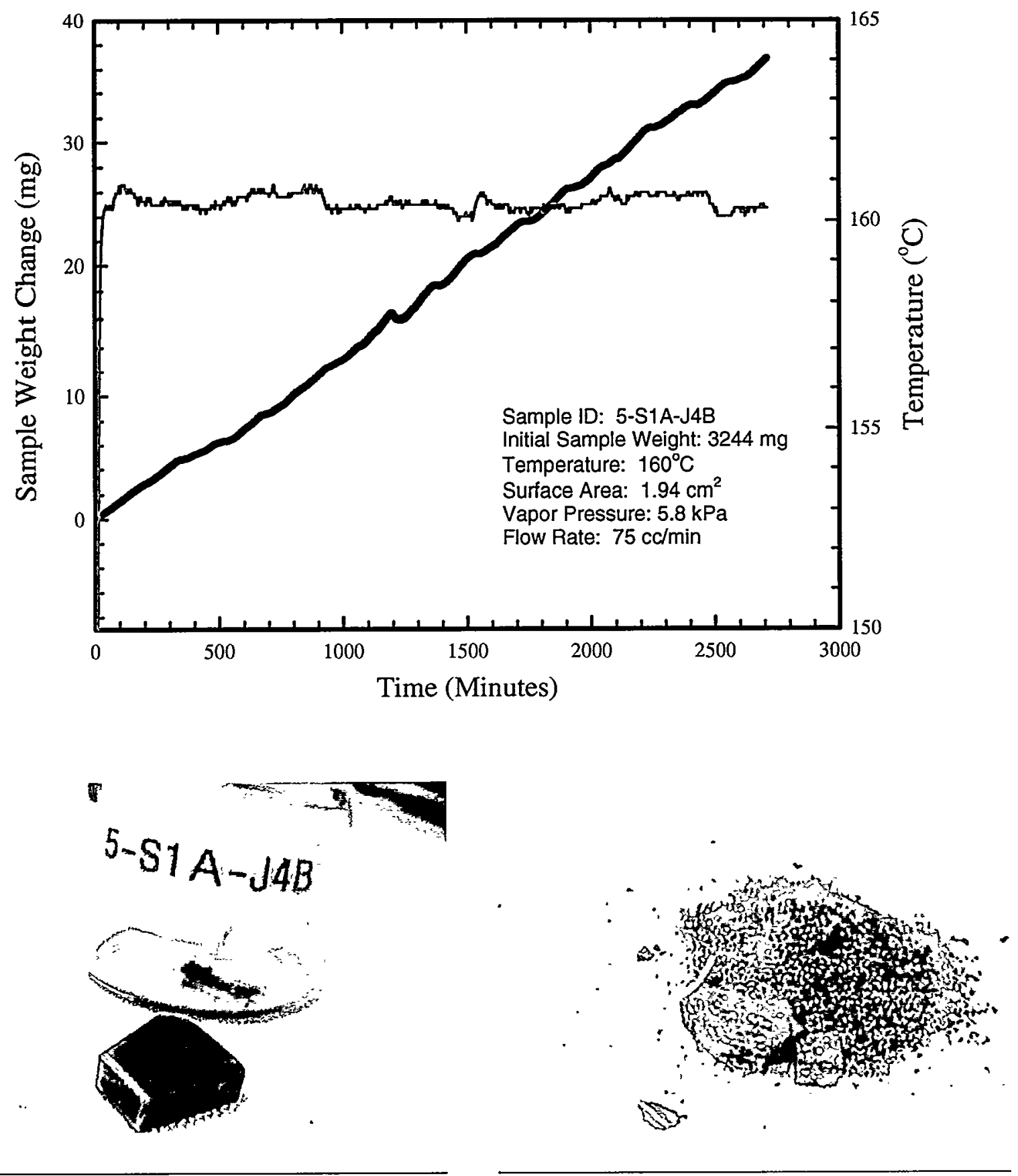

Figure 3.6. Results of TGA Run 82 Showing Photograph of Disintegrated SNF Sample 5-S1A-J4B after Oxidation in Moist Helium 


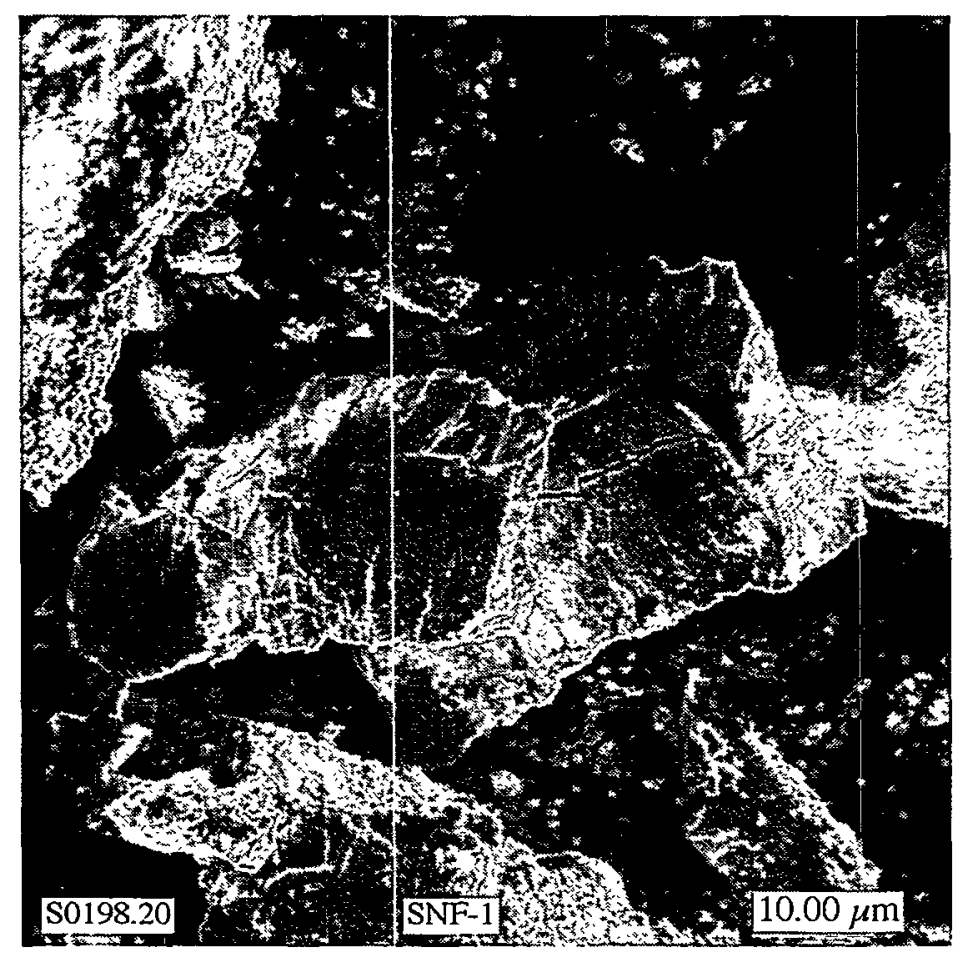

Figure 3.7. Photomicrograph of SNF Oxidation Product Showing Ranges of Particle Sizes from Submicron to about 50 Microns

\subsection{Oxidation of Unirradiated N-Reactor Fuel}

The results for the five unirradiated $\mathrm{N}$-Reactor fuel samples oxidized in the moist helium atmosphere are shown in Figures A.18 through A.22. Three of these tests were performed at a temperature of about $160^{\circ} \mathrm{C}$ (TGA Runs 75,87 , and 90 ). The differences between these runs were flow rates and sample loading configuration. TGA Run 75 was the first test conducted after the system was configured and calibrated for the moist-helium oxidation studies and was run at $169^{\circ} \mathrm{C}$ with a flow rate of $200 \mathrm{cc} / \mathrm{min}$. TGA Run 87 was performed to determine the effect of mass transfer on the reactivity of the test samples after introducing a single platinum mesh cover for the sample and reducing the gas flow rate to about $75 \mathrm{cc} / \mathrm{min}$. TGA Run 90 was performed to ascertain the potential effect of mass transfer on the reaction rate when the test samples were covered with the four-layered platinum mesh. All three of these tests for unirradiated $\mathrm{N}$-Reactor fuel material gave continuous weight gain without any indication of a mass loss as seen with the KW SNF. Visual examination of the fuel sample and the TGA system heat shields did not show distribution of oxidation products on the TGA system heat shields. The two lower temperature runs (TGA 77 and 79), however, gave a weight trace (Figures A.19 and A.20) with some ripples. This could be due to regular system noise and/or a small mass loss effect on a very small weight change. 
The morphology of the spalled oxide scales was examined using the SEM. The photomicrograph of the oxide is shown in Figure 3.8 and it shows the sheet-like scale similar to what was described in Colmenares' (1984) report. Generally, the very fine particulates seen in the oxide for the KW SNF were not generated in the unirradiated samples.

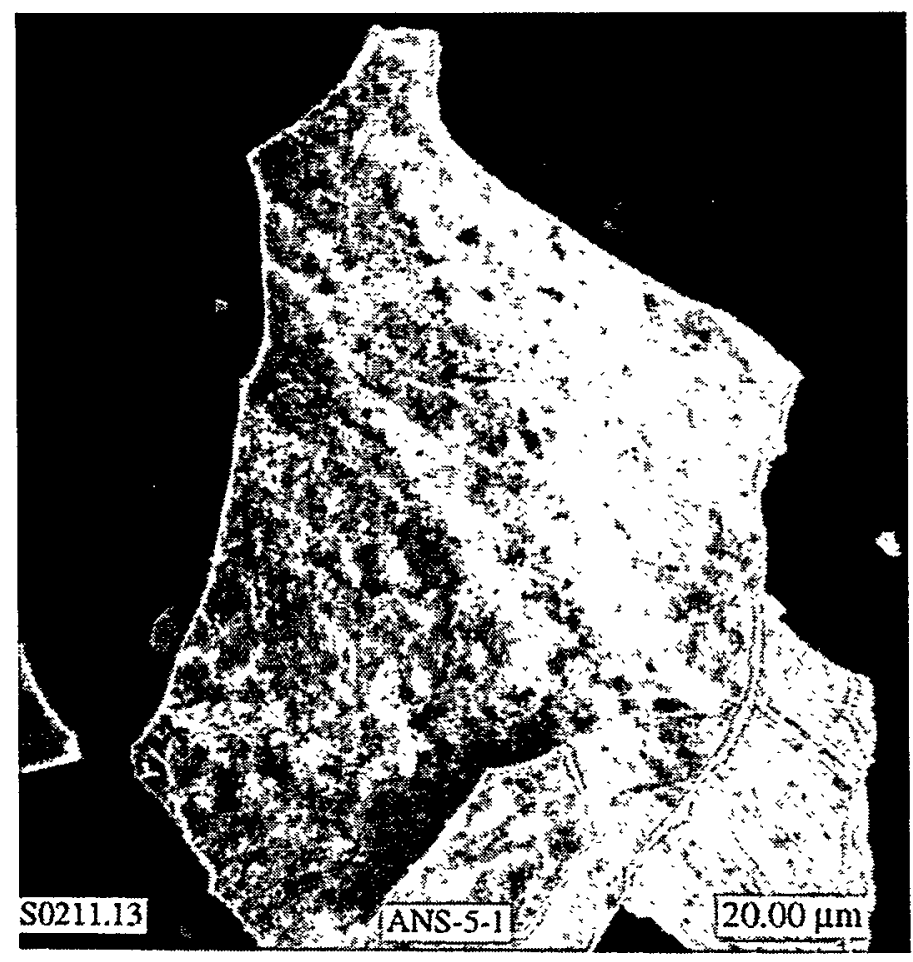

Figure 3.8. Photomicrograph of Unirradiated N-Reactor Fuel Oxidation Product 


\subsection{Oxidation Kinetics}

\subsection{KW SNF Oxidation Rate}

The oxidation behavior of the KW Basin SNF in the moist helium atmosphere for the temperature range tested (Figures A.1 through A.17) was analyzed assuming a linear oxidation mechanism, which is consistent with experimental observations and with a data summary for uranium oxidation given by Pearce and Kay (1987). The rate of weight change for each SNF run was analyzed by a linear regression fit to a set of weight change data using an equation of the form

$$
\Delta W=a+r t
$$

where $\Delta \mathrm{W}$ is the weight change, $a$ is the intercept on the weight change axis for cases where that axis did not start at zero point, and $r$, the slope of the fit, is the rate of weight gain in $\mathrm{mg} / \mathrm{min}$. The SNF sample weight change versus time plots in Figures A.1 through A.17 were grouped into two categories for the regression analyses. The first group comprised the SNF samples that experienced significant mass loss, Figure 4.1, and gave a weight change trace that was erratic. The second group comprised the remaining runs in which the SNF sampled showed either small (Figure 4.2) or unmeasurable (Figure 4.3) mass loss.

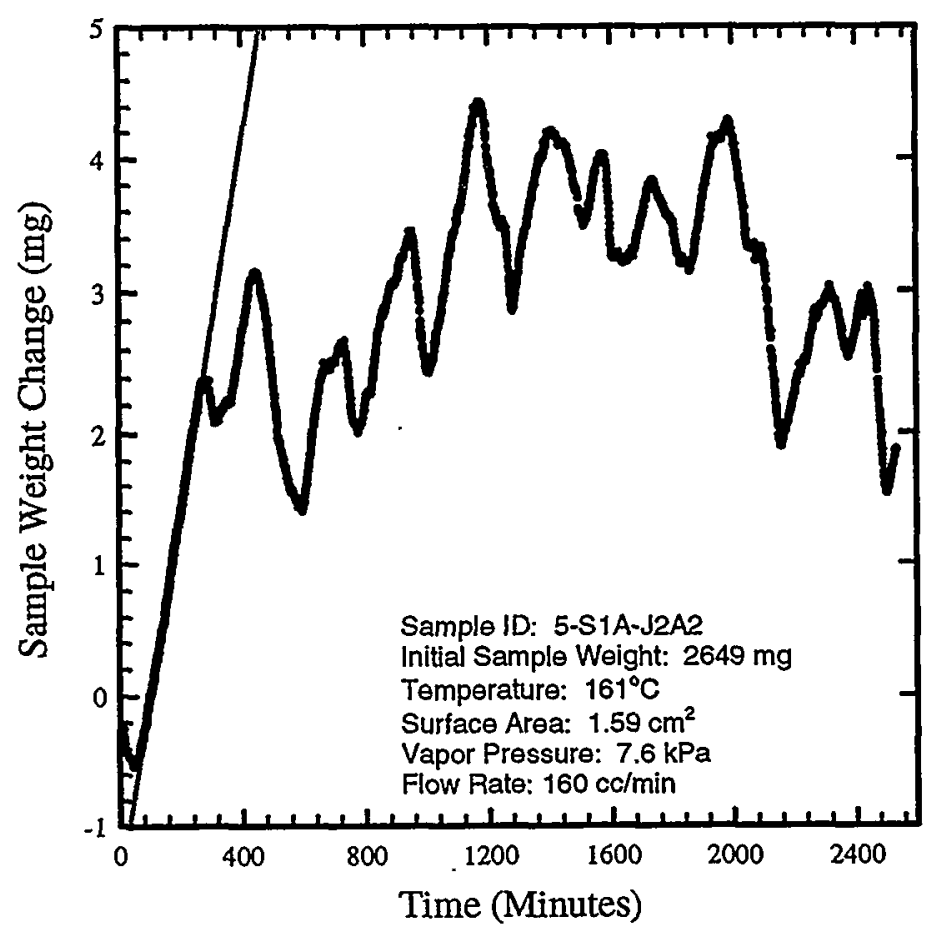

Figure 4.1. Regression Analysis of the Initial Segment of SNF Weight Change versus Time Data, TGA 81 Unirradiated N-Reactor Fuel Oxidation Rate 


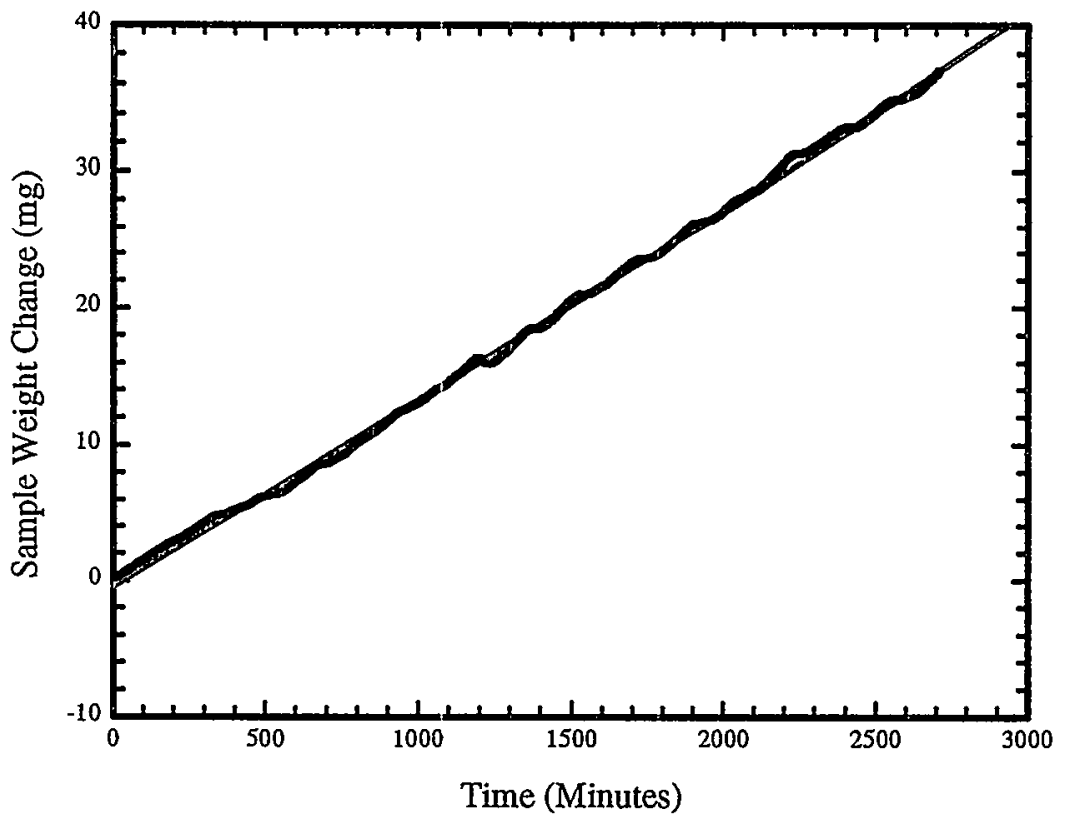

Figure 4.2. Regression Analysis of KW Basin SNF Complete Weight Change Versus Time Data, TGA 82

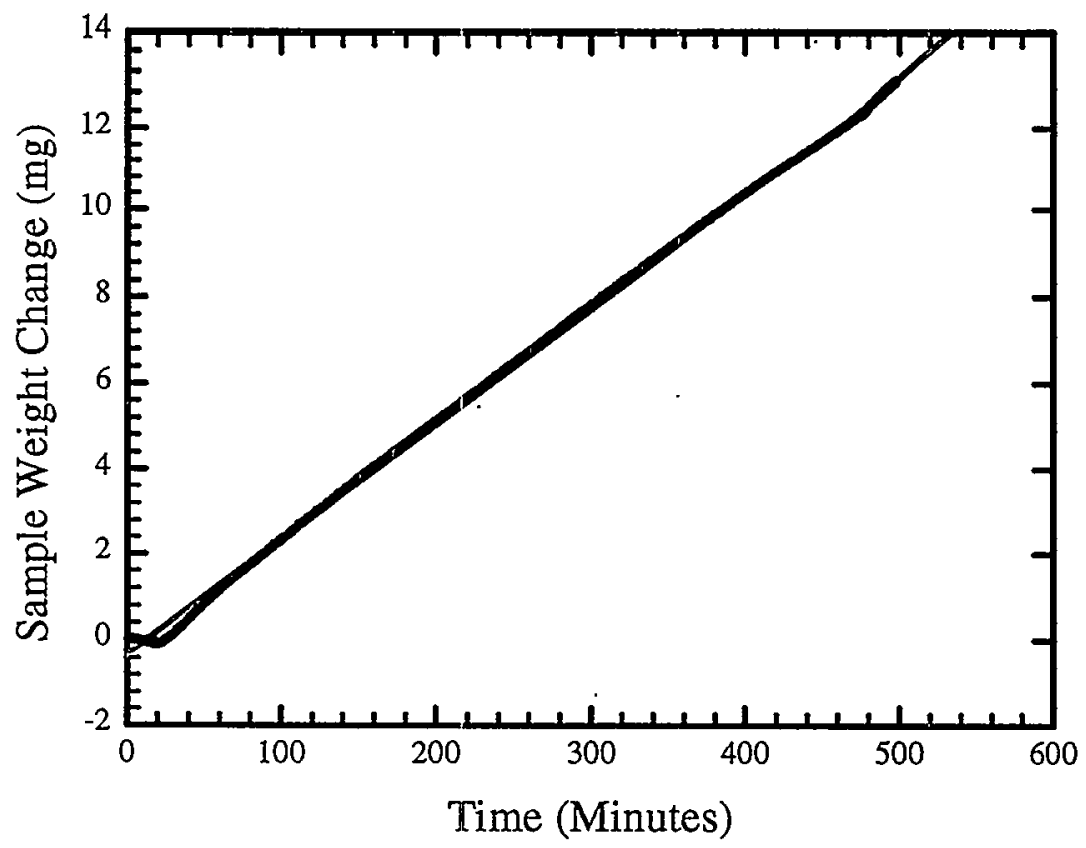

Figure 4.3. Regression Analysis of KW Basin SNF Complete Weight Change Versus Time Data, TGA 96 
For the group of runs where the SNF sample lost a significant fraction of the oxidation product, Figure 4.1 (TGA Run 81), the weight change versus time plot shows an increasing and decreasing weight change. The linear oxidation rate for such weight change data was determined by analyzing the initial segment of the weight trace where the sample showed a continuous weight gain. The analysis assumed negligible mass loss during the beginning of the test because there was a minimal amount of oxidation products formed. This exercise was used to extract oxidation rates from these tests to compare with the literature data and the other SNF experiments with relatively no mass loss problem. TGA Runs 83, 84, 86 , and 88 were analyzed in a similar way. The results of these analyses were differentiated from the rest of the SNF tests results in the Arrhenius plot, Figure 4.4, where they are compared to the unirradiated $\mathrm{N}$-Reactor fuel data and in Figure 4.5 where all the TGA runs are compared to the literature data. The literature data came from a group of publications that are summarized in a report by Trimble (1998). The estimated oxidation rates for these tests are represented as open circles and labeled as 'partial SNF data' in the legend.

The second group of SNF test results which showed continuous weight increases with time, Figures 4.2 (TGA Run 82) and 4.3 (TGA Run 96), were analyzed using all the weight trace data. Other SNF results that were analyzed this way were TGA Runs $80,85,89,91,92,97$, and 98 . The oxidation rates for these SNF tests are represented as filled squares in Figures 4.4 and 4.5, and labeled as 'complete SNF data' in the legend.

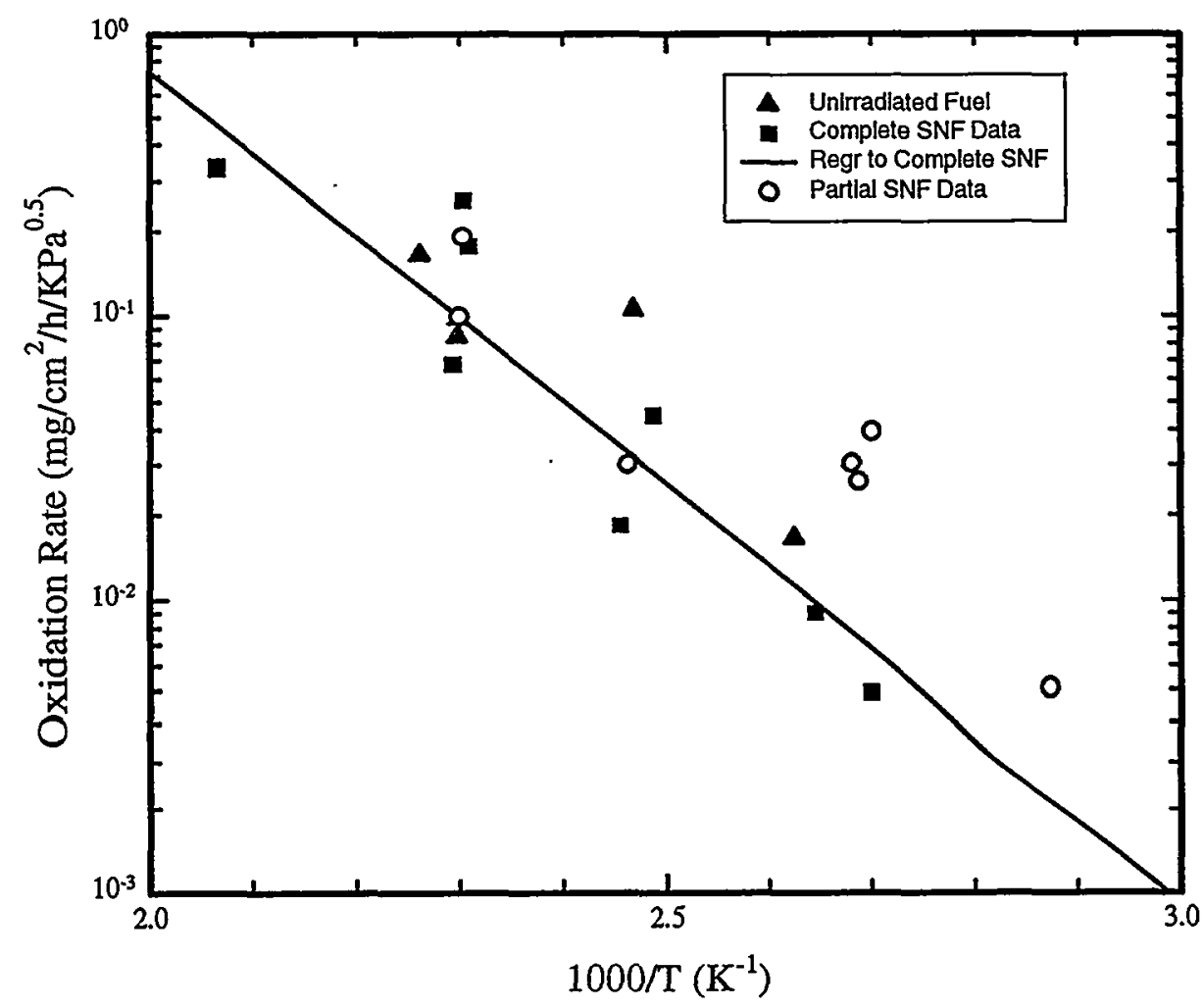

Figure 4.4. Oxidation Rate of KW SNF and Unirradiated N-Reactor Fuel in Moist Helium 


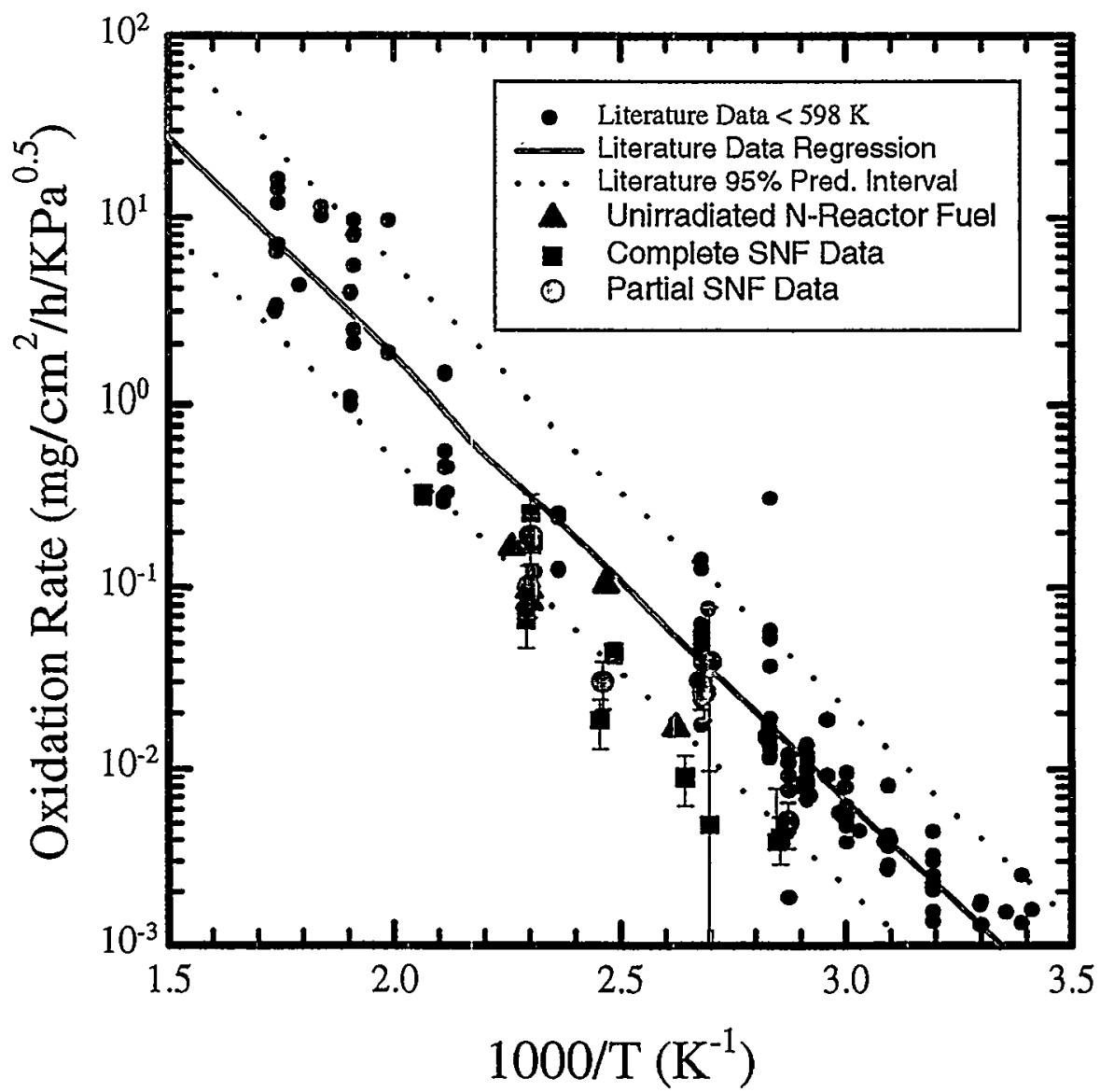

Figure 4.5. Comparison of KW SNF and Unirradiated N-Reactor Fuel Oxidation Rates with Literature Data for Uranium in "Oxygen Free" Water Vapor

The summary results of the linear regression analyses of all the KW SNF data are given in the last five columns of Table 3.1. The generated SNF oxidation rates were normalized to the water vapor pressure by dividing the rates by the square root of vapor pressure in $\mathrm{kPa}$ and the results are shown as an Arrhenius plot in Figure 4.4. The rate constant for KW SNF oxidation in moist helium was estimated for Figure 4.4 by a linear regression fit to the SNF complete oxidation rate data (filled squares) to an Arrhenius expression of the form

$$
\mathrm{k}=\mathrm{k}_{0} \exp \left(-\mathrm{E}_{\mathrm{a}} / \mathrm{RT}\right)
$$

where $\mathrm{k}_{0}$ is the pre-exponential factor, $\mathrm{E}_{\mathrm{a}}$ is the activation energy, $\mathrm{R}$ is the gas constant, and $\mathrm{T}$ is absolute temperature in Kelvin. The regression analysis gave a KW SNF rate constant

$$
k=4.53 \times 10^{5} \exp (-13.3 / R T) m g / \mathrm{cm}^{2} / \mathrm{hr} / \sqrt{k P a}
$$


where the activation energy is in $\mathrm{kcal} / \mathrm{mole}$. The literature data for the temperature range of interest from several experimenters listed in the references were subjected to the same normalization and plotted together in Figure 4.5 for comparison with the KW SNF oxidation rate.

The oxidation of unirradiated N-Reactor fuel material in a moist helium environment also showed linear kinetics. The effect of sample mass loss on the weight trace for the unirradiated samples was in most cases negligible. The regression analyses, therefore, utilized the complete test data and were fitted with Equation 4.1. The rate constants obtained for the unirradiated N-Reactor fuel samples are shown in Figures 4.4 and 4.5 as filled triangles for comparison. 


\subsection{Discussion}

\subsection{KW SNF Oxidation}

The limited oxidation experiments using samples sectioned from the corroded/damaged KW SNF element 4378 in moist helium atmosphere gave different experimental difficulties. The difficulties were caused by two main observations.

1. The makeup of the spalled oxide contains a fraction that was fine and dispersible, such that the low reactant gas flow (75 to $200 \mathrm{cc} / \mathrm{min}$ ) was adequate to agitate the powder and suspend it in the gas stream. This resulted in mass loss from the sample and made the small weight gain measurement very difficult.

2. Three of the SNF samples tested disintegrated during the oxidation process. SNF sample disintegration strongly depends on the initial state of corrosion damage to the fuel and not so much on the treatment.

The first observation also made it necessary to reduce the reactant gas flow rate to a level that had increased potential for air in-leakage. Even low concentrations of oxygen in the gas stream can poison the moisture reaction with uranium as reported in Colmenares (1984). Consequently, lower oxidation rates could be measured.

Steps were taken to minimize any of these effects on the KW SNF oxidation and generate an oxidation rate that can be compared to the literature database. The general observation from the limited data (Section 4.1) suggests that the KW SNF oxidation rate in moist helium falls at the lower boundary of $95 \%$ prediction interval (Figure 4.5 ) of the literature data. A discussion for the comparison of the SNF results with the literature data for unirradiated uranium will be in Section 5.1.3.

\subsubsection{SNF Sample Mass Loss}

The SNF samples showed significant weight loss even though the sample crucible had enough volume to contain the oxidation product. As shown in Figure 3.2, the mass loss was strongly dependent on the reactant gas flow rate. This observation suggests that the particulates were carried by the flowing gas stream out of the crucible onto the heat shields below (direction of the gas flow was from the top to bottom, Figure 2.1). The approximate dimension of the sample chamber tube is one inch $(2.54 \mathrm{~cm})$ in diameter which gives a cross sectional area of about $5 \mathrm{~cm}^{2}$. The range of gas flow rate for the tests was $75 \mathrm{cc} / \mathrm{min}$ to $200 \mathrm{cc} / \mathrm{min}$ resulting in gas velocity range of about $15 \mathrm{~cm} / \mathrm{min}$ to $40 \mathrm{~cm} / \mathrm{min}$. The only probable way for such low velocity gas flow to blow out the particulates from the sample crucible is that very small particles were generated by the oxidation process. Submicron particles have been observed for corrosion products resulting from the water corrosion of the SNF at the K-Basin (Abrefah et al.1998b). 
Other data that support the generation of dispersible particles by the oxidation process were the significant mass loss during TGA Run 88 (Figure A.8). Even though a 52-mesh size platinum was added to the sample crucible as a cover to minimize the mass loss, the sample still lost a significant fraction of its oxidation product.

The oxidation products for the unirradiated N-Reactor fuel samples differed from the dispersible oxidation product of the SNF. The unirradiated samples generated sheets of oxidation products that were not easily dispersed by the gas flow and therefore, showed negligible mass loss even for runs that had no platinum gauze cover.

\subsubsection{SNF Sample Disintegration}

The observed behavior of sample disintegration of the KW SNF sample after oxidation may be explained by the results of the metallographic examination (Marschman et al. 1997) of samples taken from the same damaged region of the SNF element. Two examples of the photomicrographs in the Marschman et al. (1997) report are shown in Figure 5.1. Microcrack networks were observed in these samples from the damaged region, and the heat tinting technique (described in Marschman et al.1997) gave an indication that some of these cracks were filled with uranium hydride. From these photomicrographs, it can be postulated that when a SNF sample similar to the one shown in Figure 5.1 is being oxidized, the microcracks and the hydrides act as easy pathways for the oxidation. This is in part due to (a) relatively easy diffusion path for the oxidant ( $\mathrm{O}$ for dry air and $\mathrm{OH}$ for the water vapor) and (b) the increased reactivity of high-surface area uranium hydride. The volume increase associated with the oxide
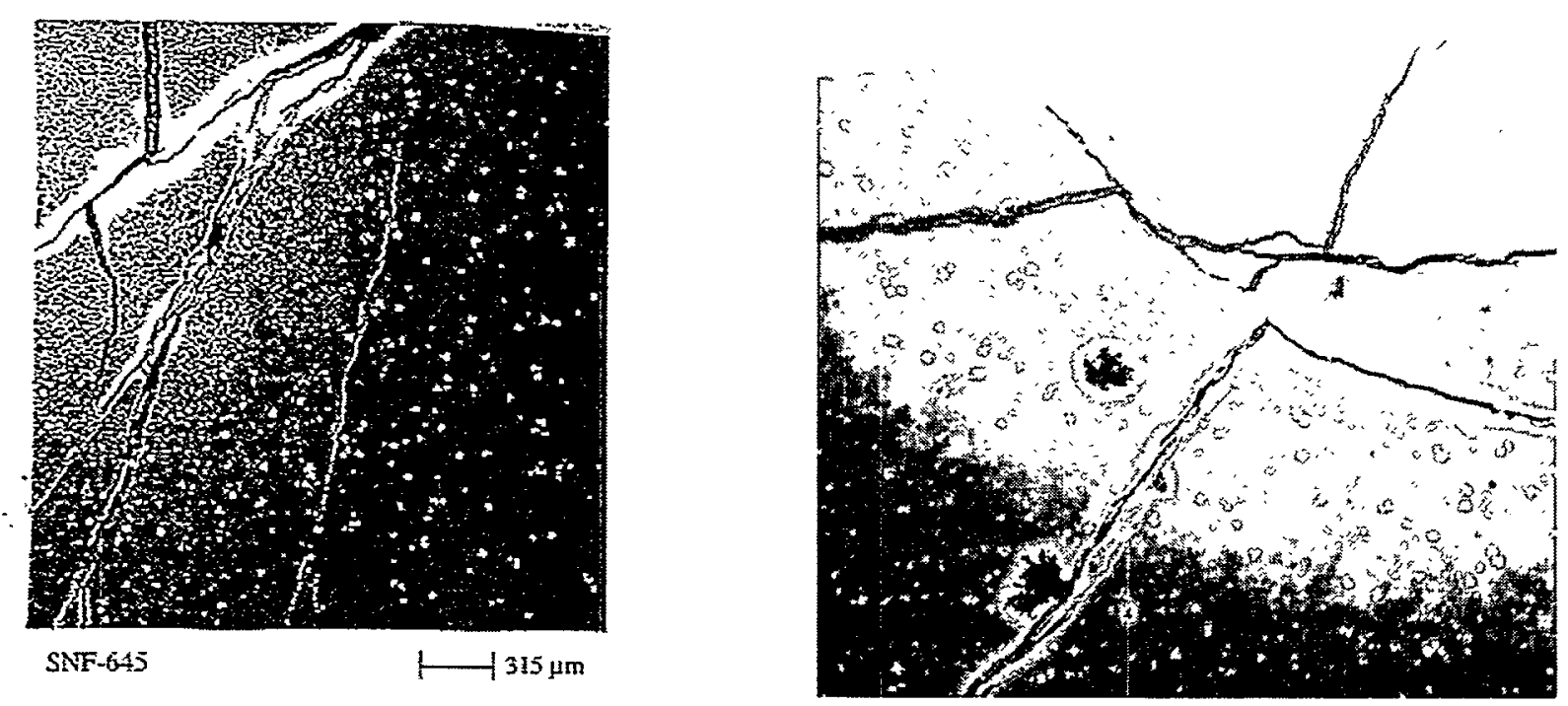

Figure 5.1. SNF Sample 5-S1A-A1A with Microcracks Filled with $\mathrm{UH}_{3}$ Precipitates (i.e., black regions with "Halo") 
formation causes the cracks to open up and consequently break the sample into smaller pieces. This hypothesis explains why only samples very close to the damage/corrosion region (i.e., 5-S1A-J2B1, 5-S1A-J2A2 and 5-S1A-J4B) of the KW SNF element are susceptible to disintegration.

The three samples that disintegrated during oxidation in moist helium were (a) a first corroded end piece, 5-S1A-J2B1, and (b) two second pieces, 5-S1A-J2A2 and 5-S1A-J4B. For case (b), the first piece was either a highly corroded sample with irregular geometry (5-S1A-J4A) or broke up into pieces during storage and handling (5-S1A-J2Al), and for these reasons could not be used for the TGA testing.

The disintegration process showed some temperature dependency (i.e., only samples tested at temperatures above $150^{\circ} \mathrm{C}$ disintegrated) in the moist helium oxidation studies. However, the key feature for the influence of temperature may be the extent of oxidation, which increases with increasing temperature. The dominant parameter for disintegration of the SNF samples is the initial microstructural state, that is, the presence of microcracks. The presence of uranium hydride in the microcracks will enhance the process for disintegration but is not a necessary property. The supporting data for the initial microcracks concept is the observation that SNF samples distant from the corrosion front did not disintegrate even though they were oxidized at either the same temperature (TGA Runs 88 and 89 ) or at higher temperatures (TGA Runs 96 and 97).

\subsubsection{SNF Oxidation Rate}

The oxidation rate of KW. SNF in moist helium for the temperature range tested follows linear oxidation kinetics. This observation is the same as the oxidation behavior reported in the literature for other metallic uranium in "oxygen free" moisture. The linear oxidation mechanism for the SNF is supported by a non-protective oxide layer that is also non-adherent and spalls off the uranium substrate at soon as it reaches a certain thickness. The linear oxidation behavior of the SNF and, for that matter other metallic uranium, suggests that the migration pathway for the $\mathrm{H}_{2} \mathrm{O}$ molecule and its dissociation radicals $(\mathrm{H}$ and $\mathrm{OH})$ may be through cracks and fissures in the oxide layer to the oxide/metal interface where they can react with the uranium substrate. There may be a very thin oxide layer at the interface as witnessed by Condon et al. (1983) which has a limited effect on the transport of the $\mathrm{OH}$ radical to the oxide/metal interface.

The experimental oxidation rates for the KW SNF compares reasonably with the literature reviewed data (Figure 4.5) for unirradiated metallic uranium but generally falls below the mean of the literature data. The lowering of measured oxidation rates for the KW SNF may be due to an oxygen poisoning effect that was difficult to control and measure accurately for this study. An experiment performed after the SNF oxidation run with an oxygen probe downstream from the sample reaction chamber indicated oxygen concentrations as high as $80 \mathrm{vppm}$ (volume parts per million) in the reactant gas stream. The input UHP helium gas supply was confirmed by the same oxygen analyzer to have oxygen concentrations in the range of about $1.5 \mathrm{vppm}$ for high flow rate and $8.6 \mathrm{vppm}$ for a low flow rate of about $30 \mathrm{cc} / \mathrm{min}$. This observation is an indication that the source of high oxygen concentration in the gas stream during the test was in-leakage from various connections including the balance box that is not perfectly sealed for these low oxygen concentrations. The oxygen concentrations measured using the same run configuration are within the ranges where the literature report of Colmenares (1984) indicates a potential lowering of 
the oxidation rate. Additional tests using the KW SNF sample in oxygen concentrations below the threshold limit of about $10 \mathrm{vppm}$ were not investigated for this campaign to assess what is the exact reduction factor for the SNF. However, if it is assumed to be the same as the literature value, then the experimental SNF oxidation rates can be multiplied by the maximum factor estimated from a figure in Colmenares' (1984) report (Figure 32 of page 309). A rough factor of about 7 for the averaged vapor pressure of all the SNF experimental runs was estimated. Multiplying individual KW SNF oxidation rate by this factor will move them up to be in very close agreement with the literature data.

A linear regression fit to the selected oxidation rates of the KW SNF, which had continuous weight gain data with limited effect of experimental uncertainties due to effects such as mass loss or balance drift (TGA Runs at about $75^{\circ} \mathrm{C}$ ), yielded an activation energy for the rate constant of $13.3 \mathrm{kcal} / \mathrm{mole}$. This value agrees very well with the activation energy for the literature data, estimated to be about $11.1 \mathrm{kcal} /$ mole. The agreement in the activation energies is another indication that the KW SNF material reactivity in moist helium is not significantly different from reaction of other metallic uranium in "oxygen free" water vapor.

\subsection{Oxidation of Unirradiated N--Reactor Fuel}

The main objective for running oxidation experiments using the unirradiated uranium sectioned from an N-Reactor fuel element was to establish the baseline oxidation rate for the alloy 601 uranium material and to assess how the data compares with oxidation rates for similar literature material. In other cases, these tests were performed when we changed the system configuration to determine any significant effect on the oxidation rate. Because of the limited scope, only a few experiments were carried out using the unirradiated material.

\subsubsection{Unirradiated N-Reactor Fuel Oxidation Rate}

The oxidation behavior of the unirradiated $\mathrm{N}$-Reactor fuel samples also follows the linear oxidation mechanism for the temperature range tested. The oxide scale produced by the reaction was non-adherent and spalled off as scales. Generally the oxide generated by reacting unirradiated samples with moisture was much less dispersible than the KW SNF oxidation products. The polishing of the unirradiated samples did not significantly influence the reactivity of these samples compared to the diamond-sawed KW SNF. This observation is supported by the linearity of the weight gain because oxide film on the surface of the uranium sample proved to be unprotective.

The oxidation rate of the unirradited N-Reactor fuel samples agree reasonably with the KW SNF and in comparison, falls below the mean for the literature data. The low rates may be ascribed to the same oxygen poisoning effect. 


\subsection{Conclusions}

The oxidation behavior of the KW Basin SNF in the moist helium atmosphere and the temperature range of $100^{\circ} \mathrm{C}$ to $211^{\circ} \mathrm{C}$ follows the linear oxidation kinetics. The oxidation product was non-adherent and spalls off generating an oxide powder with other observed properties. The XRD analysis of some of the oxide powder identified hyperstoichiometric uranium oxide as the main chemical phase.

The calculated oxidation rate of the KW SNF compares reasonably with the reviewed literature data for unirradiated metallic uranium but generally falls on the boundary of the $95 \%$ prediction interval for the literature data. The lower oxidation rates measured could be due to oxygen poisoning effect. The SNF oxidation rates agree reasonably with the rates for the unirradiated N-Reactor fuel samples.

A fraction of the spalled oxidation products for the SNF samples consisted of very small particles that were resuspended in the gas stream and carried away to other parts of the system with most of it settling on the heat shield below the sample crucible. SEM analysis of part of the oxidation product shows particle sizes ranging from submicron to chunks larger than hundreds of microns. The unirradiated $\mathrm{N}$-Reactor fuel samples generated a very small quantity of these fine particulates. The blown out oxidation product resulted in the sample mass loss that was resolved by using four-layered platinum gauze made from a combination of 52-mesh and 100-mesh sizes of platinum.

Three of the SNF samples studied disintegrated into small particulates after or during the oxidation tests. The disintegration occurred for samples that may have matrix damage (i.e., microcracks) resulting from in-storage corrosion and tested above $150^{\circ} \mathrm{C}$. The other samples tested above this temperature that did not show the same disintegration behavior may have minimum matrix damage. XRD analyses of particulates from the disintegration process identified metallic particles. 


\subsection{Future Work}

The oxygen concentrations observed in the gas stream were above the threshold that was reported in the literature to affect metallic uranium reaction with water vapor. It will be prudent to run a few experiments using both the unirradiated N-Reactor fuel and the KW Basin SNF samples to determine what the lowering factor is for the TGA system and the test configuration used. Such a test matrix is recommended for an extended investigation so that the SNF data could be accurately compared to the literature. The lower temperature tests on the TGA system were always a challenge. However, we learned enough during these tests that given longer times such experiments could be performed to generate reliable oxidation rates at and below $75^{\circ} \mathrm{C}$ using a different system or by changing the configuration of the TGA system used in this study. Additionally, experiments should be performed using samples taken from other K-Basin SNF elements to strengthen the inference that the observed oxidation behavior applies to the whole K-Basin SNF inventory. 


\subsection{References}

Abrefah, J., H.C. Buchanan, W.M. Gerry, W.J. Gray, and S.C. Marschman. 1998a. Dry Air Oxidation Kinetics of K-Basin Spent Nuclear Fuel. PNNL-11786, Pacific Northwest National Laboratory, Richland, Washington.

Abrefah, J., S.C. Marschman, and E.D. Jenson. 1998b. Examination of the Surface Coatings Removed from K-East Basin Fuel Elements. PNNL-11806, Pacific Northwest National Laboratory, Richland, Washington.

Abrefah, J., T.A. Thornton, L.E. Thomas, F.B. Berting, and S.C. Marschman. 1994. Characterization Plan for Hanford Spent Nuclear Fuel. PNNL-10210, Pacific Northwest National Laboratory, Richland, Washington.

Colmenares, C.A. 1984. "Oxidation Mechanisms And Catalytic Properties of the Actinides." Prog. Solid State Chem. 15:257.

Baker, M. McD., L.N. Less, and S. Orman. 1966. "Uranium+Water Reaction, Part 1-Kinetics, Products, and Mechanism." Transactions of the Faraday Society, 62:2513.

Bennett, M.J., B.L. Myatt, D.R.V. Silvester, and J.E. Antill. 1975. "The Oxidation Behavior of Uranium in Air at $50-300^{\circ} \mathrm{C}$." J. of Nuclear Materials 57:221.

Condon, J.B., S.S. Cristy, and J.R. Kirkpatrick. 1983. "Uranium Reaction with Water Vapor." Final Progress Report, Y-12, Report Y/DU-274, Union Carbide Corporation, need city and state.

Gerber, E.W. 1996. Integrated Process Strategy for K Basin Spent Nuclear Fuel. WHC-SD-SNF-SP005, Westinghouse Hanford Company, Richland, Washington.

Marschman, S.C., T.D. Pyecha, and J. Abrefah. 1997. Metallographic Examination of Damaged NReactor Spent Nuclear Fuel Element SFEC5,4378. PNNL-11438, Pacific Northwest National Laboratory, Richland, Washington.

Pearce, R.J. 1989. A Review of the Rates of Reaction of Unirradiated Uranium in Gaseous Atmosphere. RD/B/6231/R86, Central Electric Generating Board, Berkeley Nuclear Laboratories, United Kingdom.

Pearce, R.J. and P. Kay. 1987. The Reaction of Uranium in the $\mathrm{U}-\mathrm{O}_{2}-\mathrm{H}_{2} \mathrm{O}$ and $\mathrm{U}-\mathrm{H}_{2} \mathrm{O}$ System. TPRD/B/0954/R87, Central Electric Generating Board, Berkeley Nuclear Laboratories, United Kingdom. 
Sellers, E.D. 1998. Letter to H. M. Hatch, "Contract No. DE-AC06-96RL13200 Action on Baseline Change Request SNF-BCR-98-04 Complete Thermogravimetric Analysis Measurements.” 98-SFD-094, Department of Energy Richland Operations Office, Richland, Washington.

Trimble, D.J. 1998. Reaction Rate Constant for Uranium in Water and Water Vapor. HNF-2853, Rev 0, Duke Engineering and Services Hanford, Inc., Richland, Washington. 
Appendix A

SNF and Unirradiated N-Reactor Fuel Oxidation Results in Helium/Water Vapor Atmosphere 

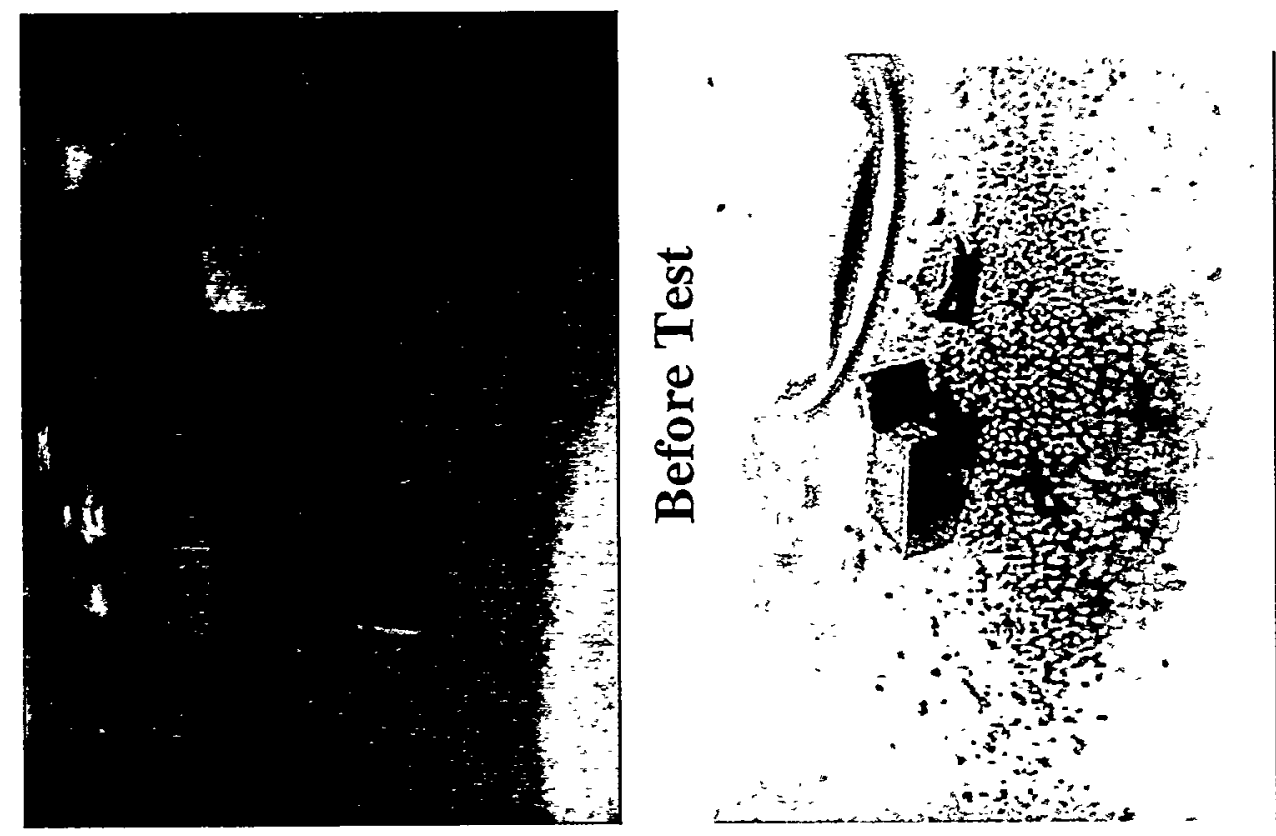

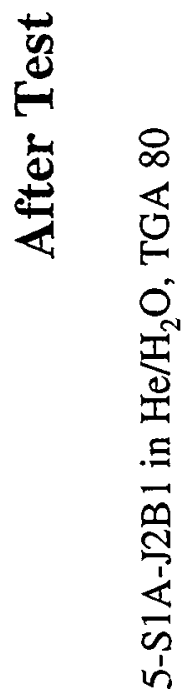

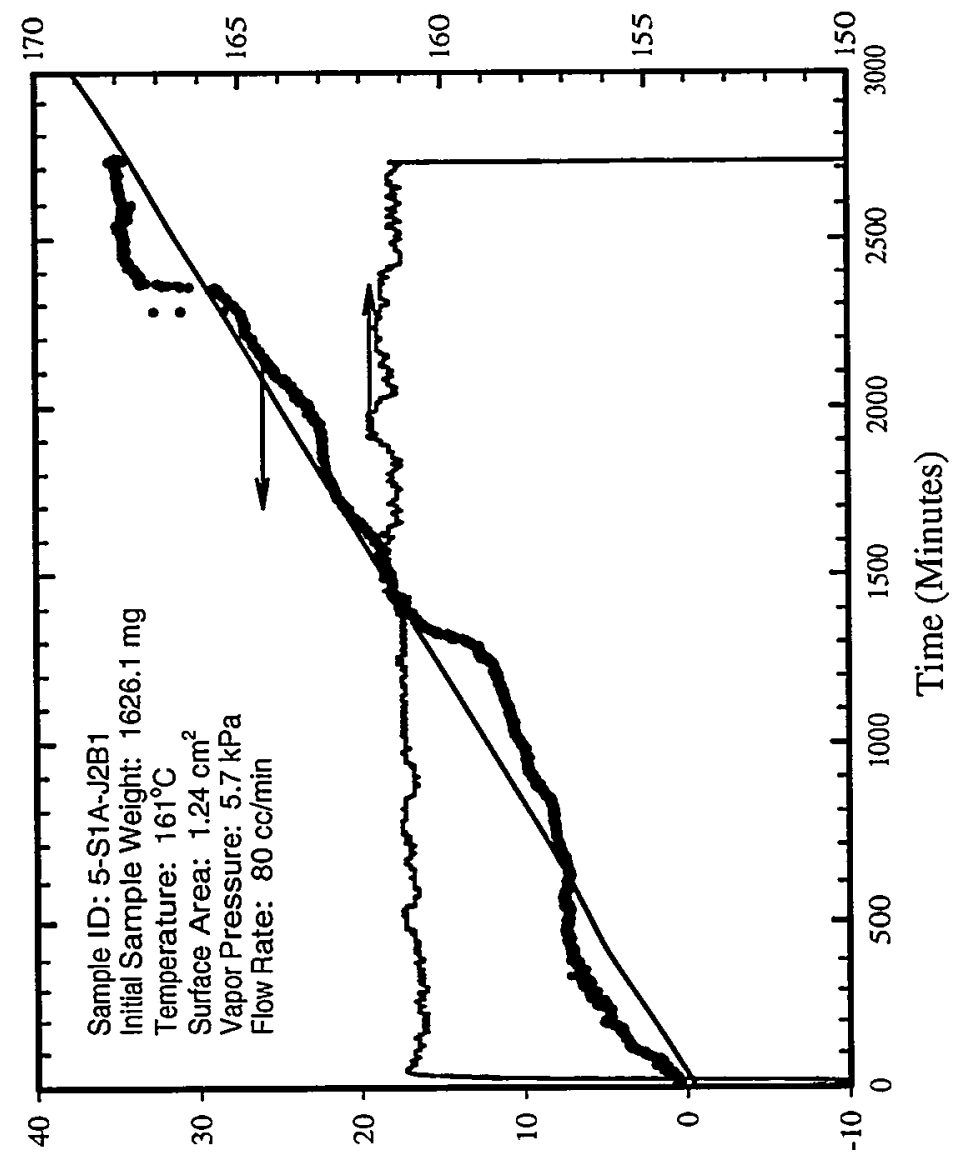

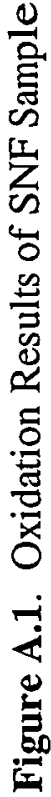

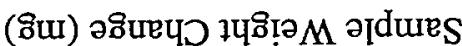



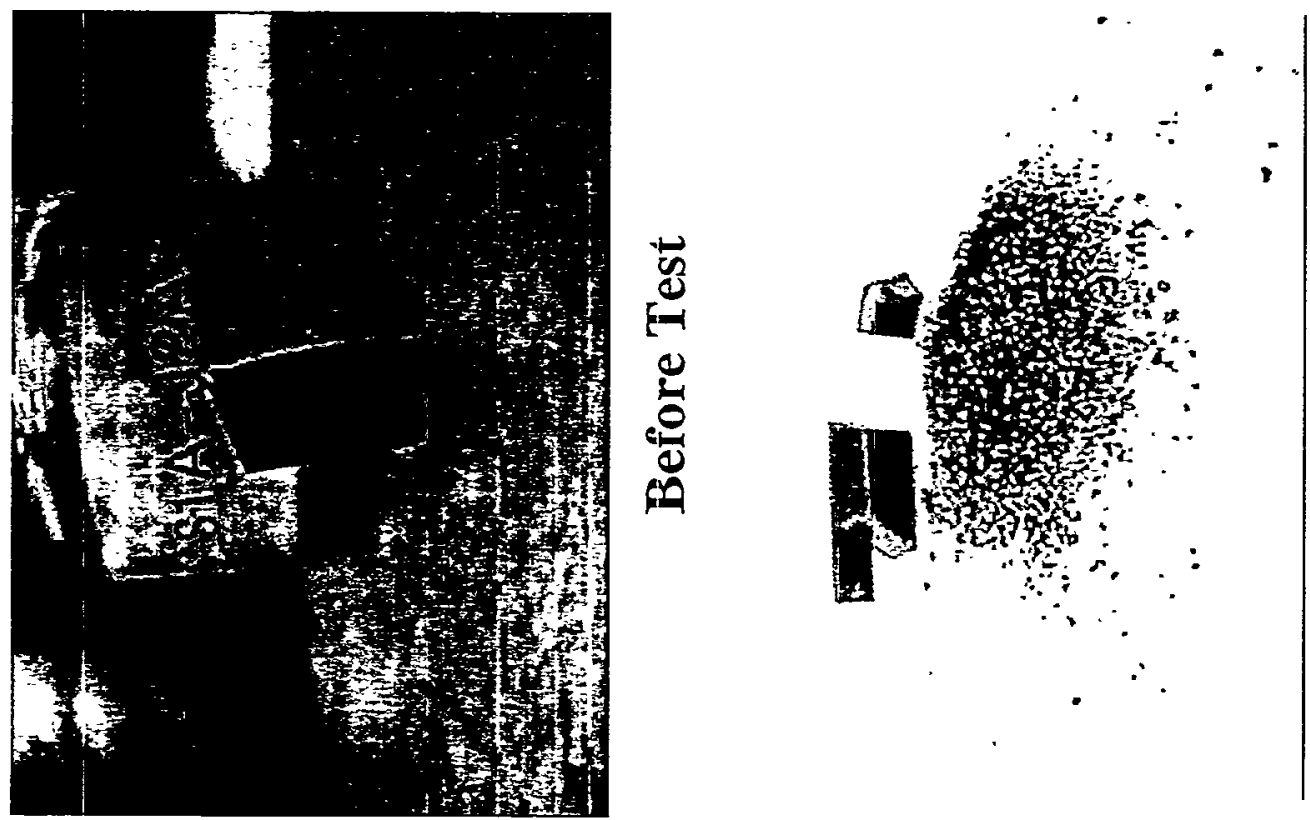

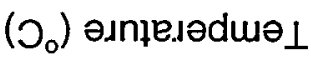

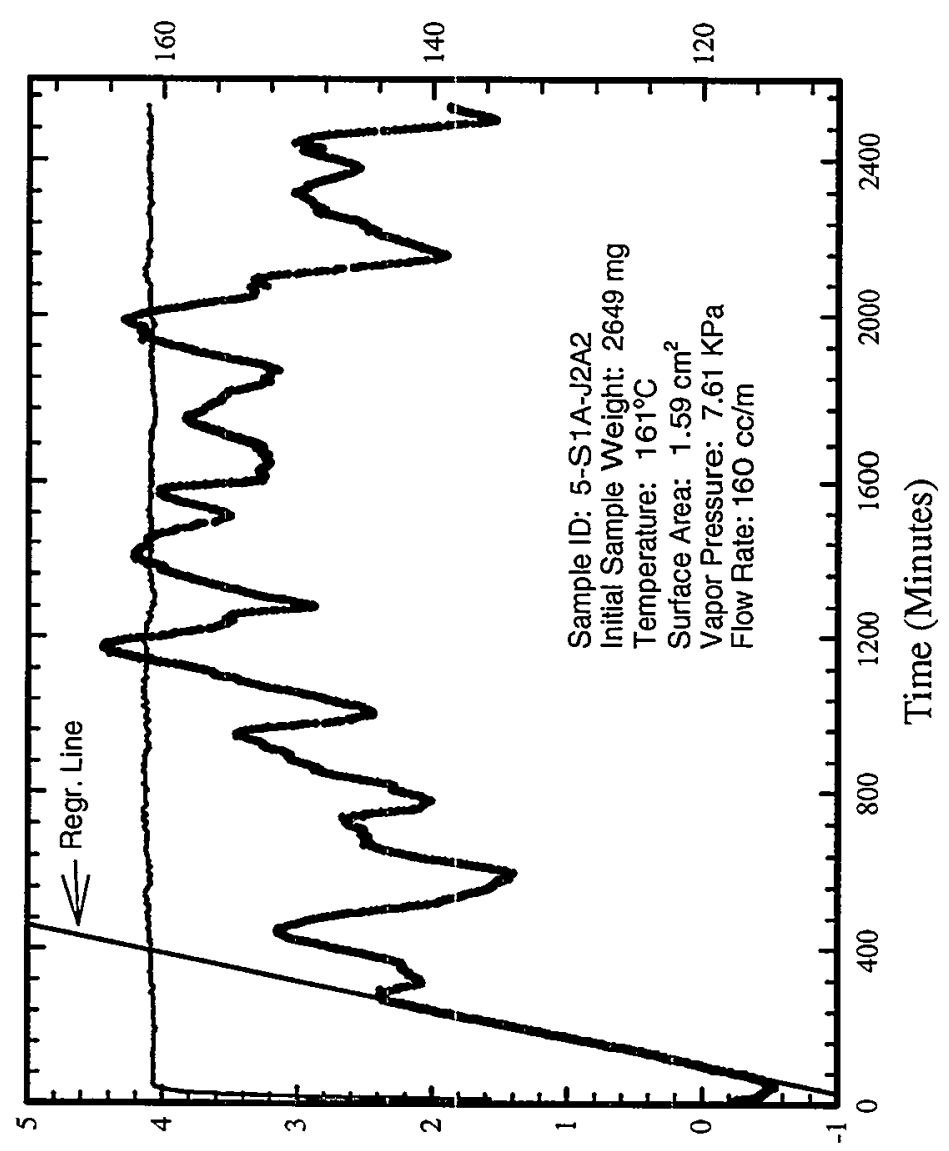

范

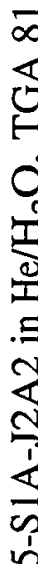

हี

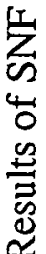

苞

ำ

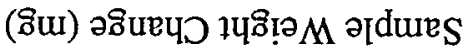



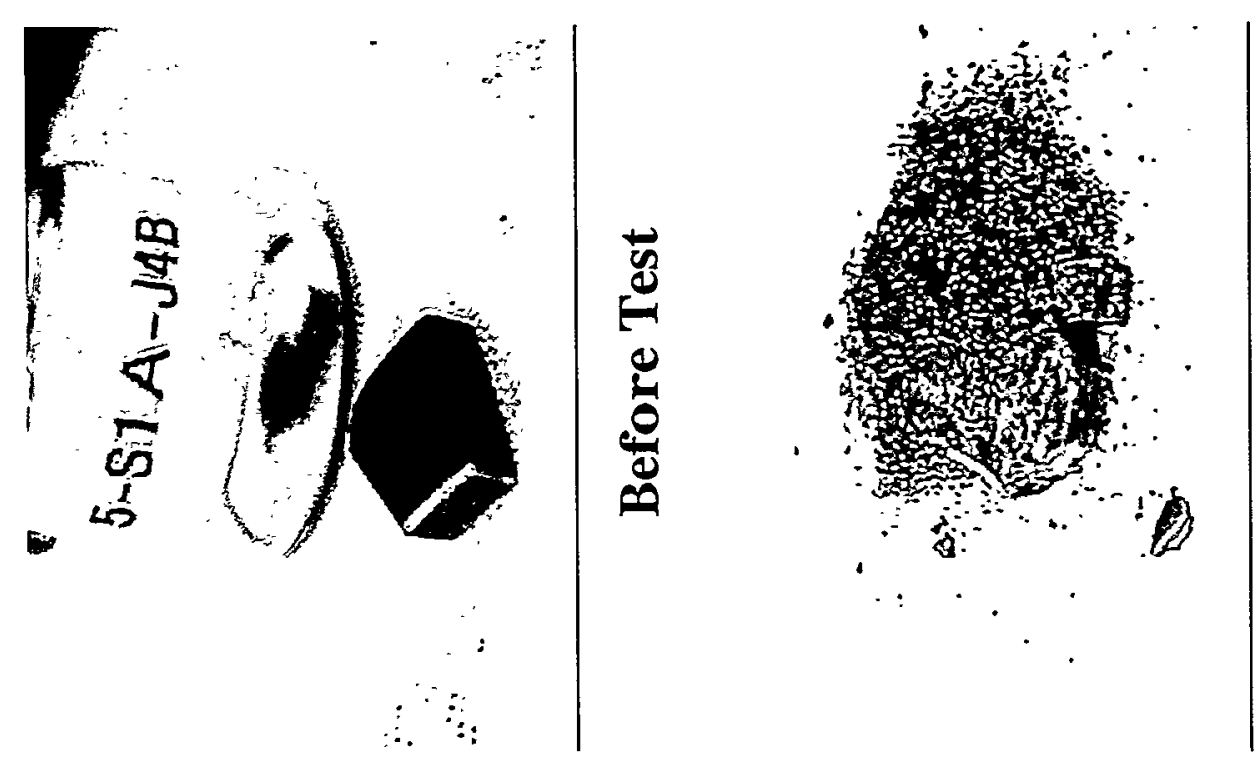

$\frac{\pi}{4}$

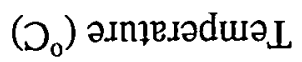

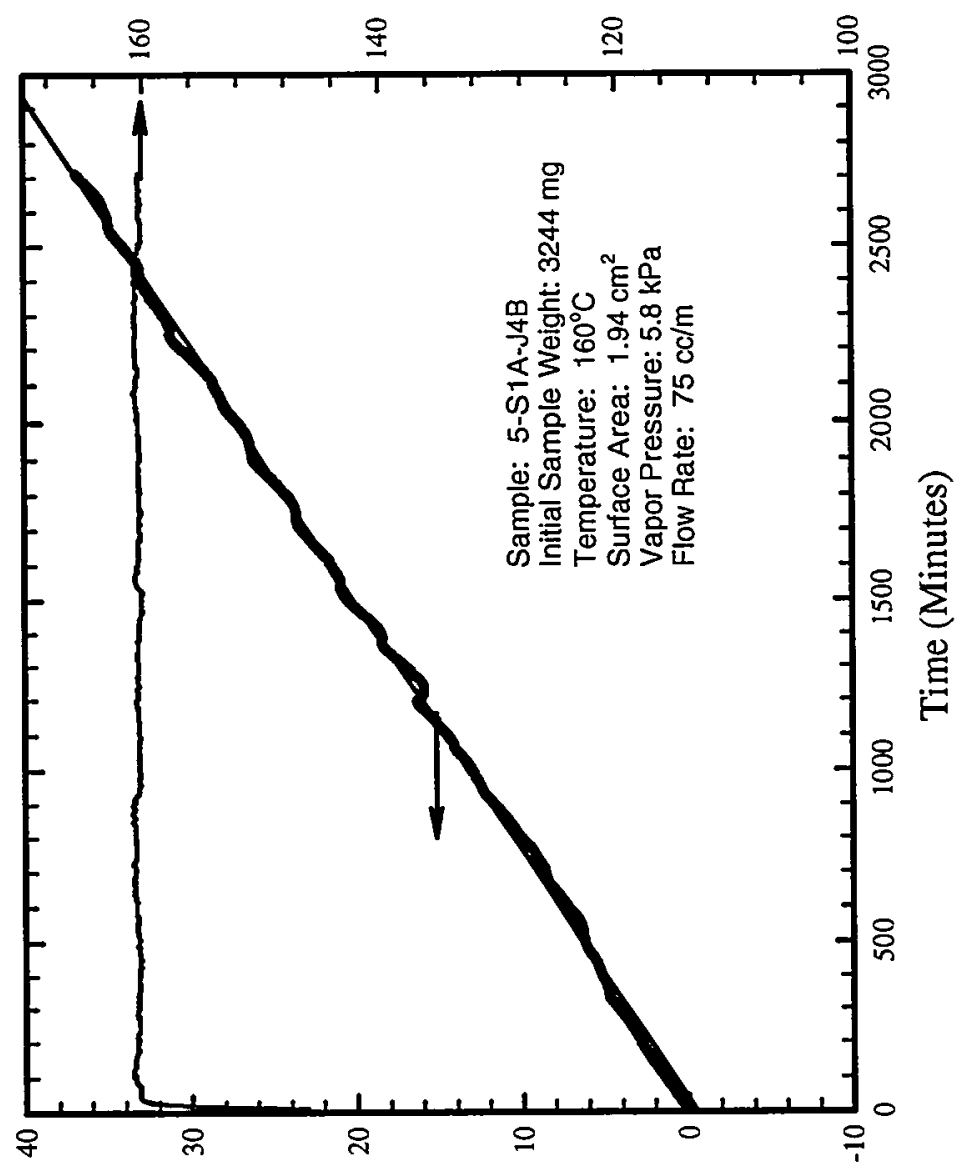

年

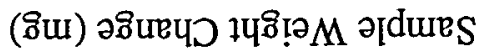



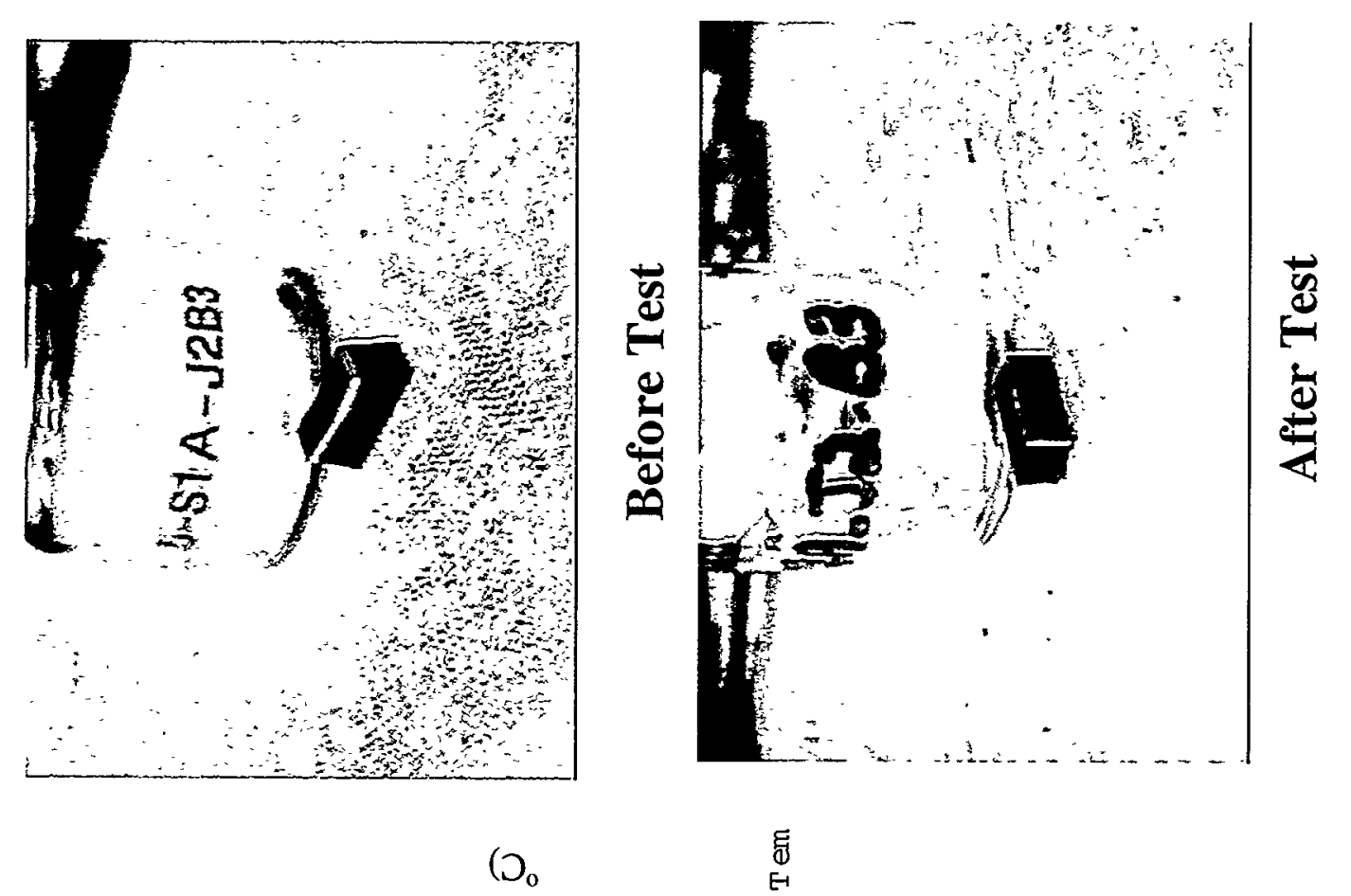

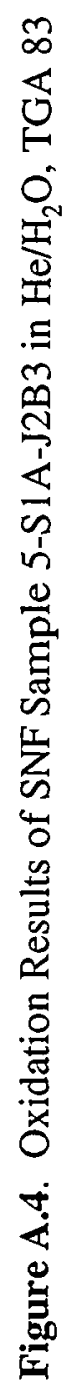

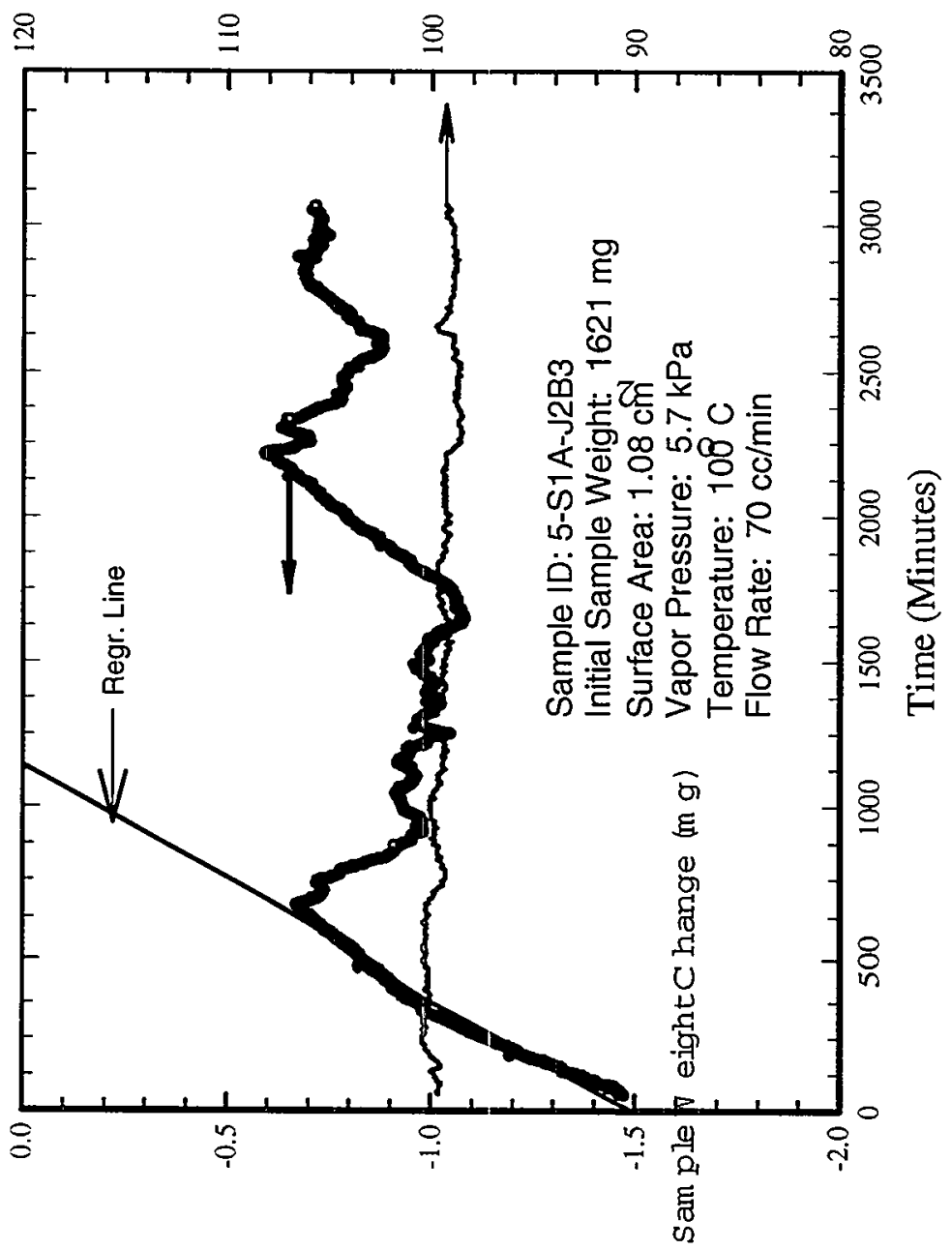



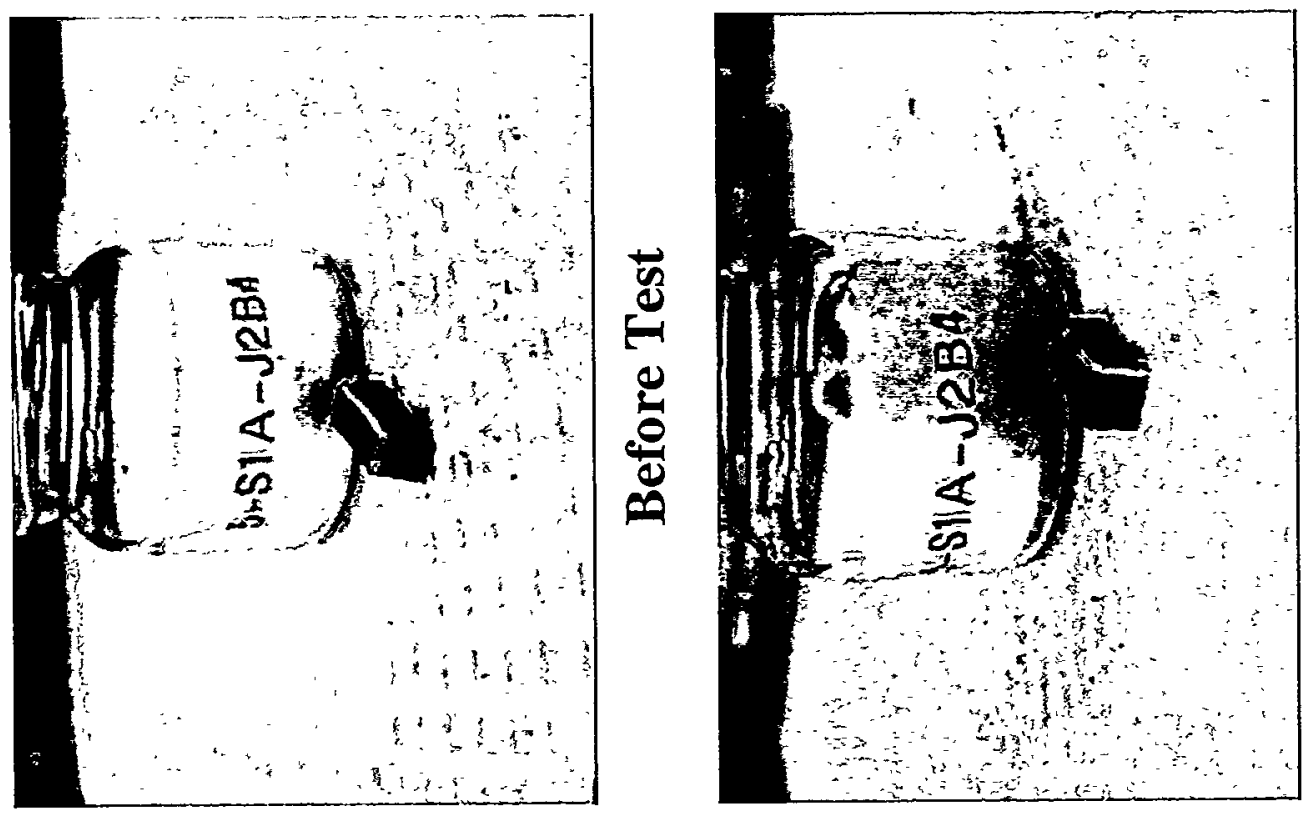

$\frac{\vec{y}}{2}$

$\left(\mathcal{O}_{\mathrm{o}}\right)$ əInฺอ.ədur $\mathrm{L}$

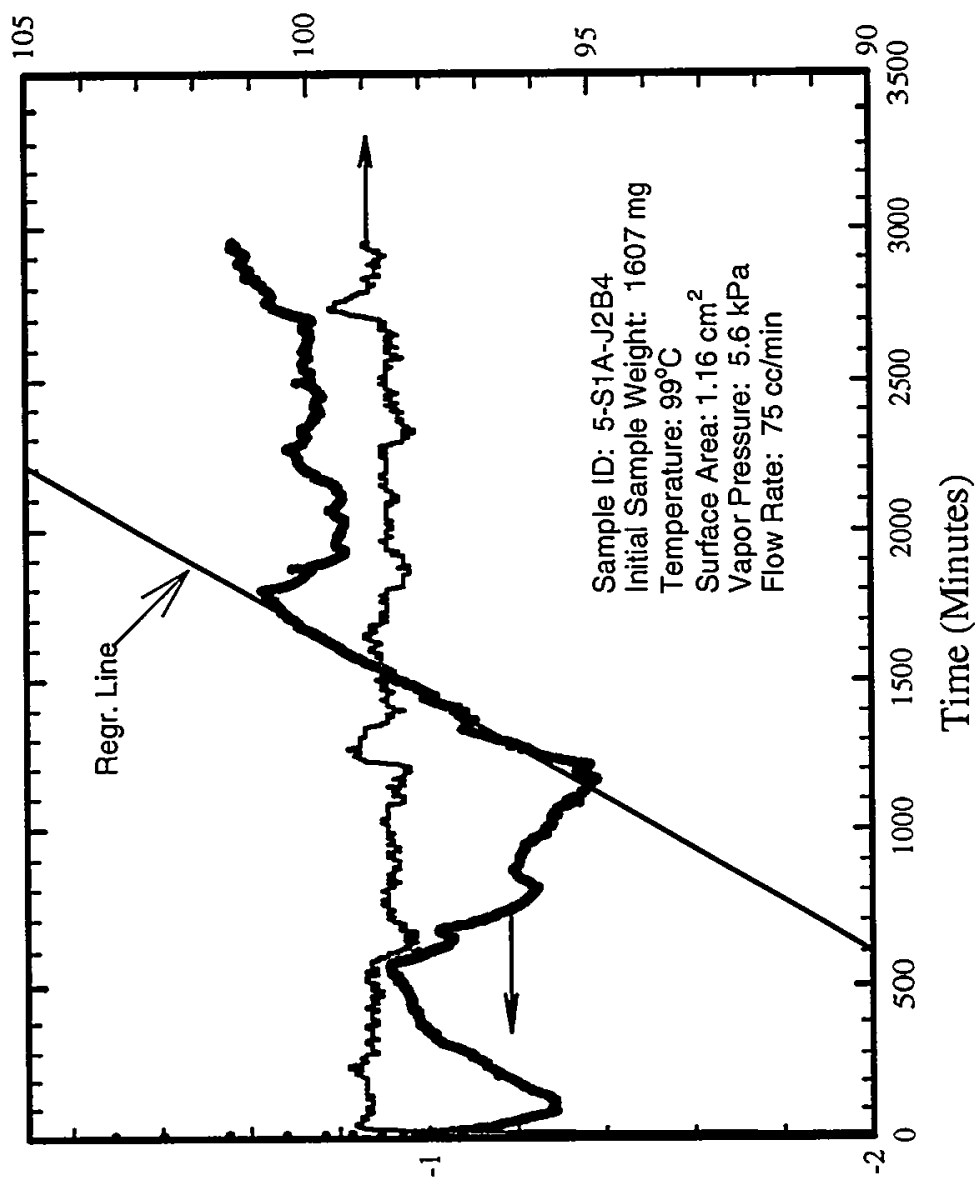

志

范

莺

崖

4

羿

总

帒

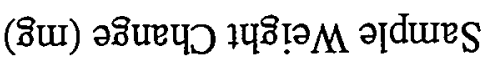



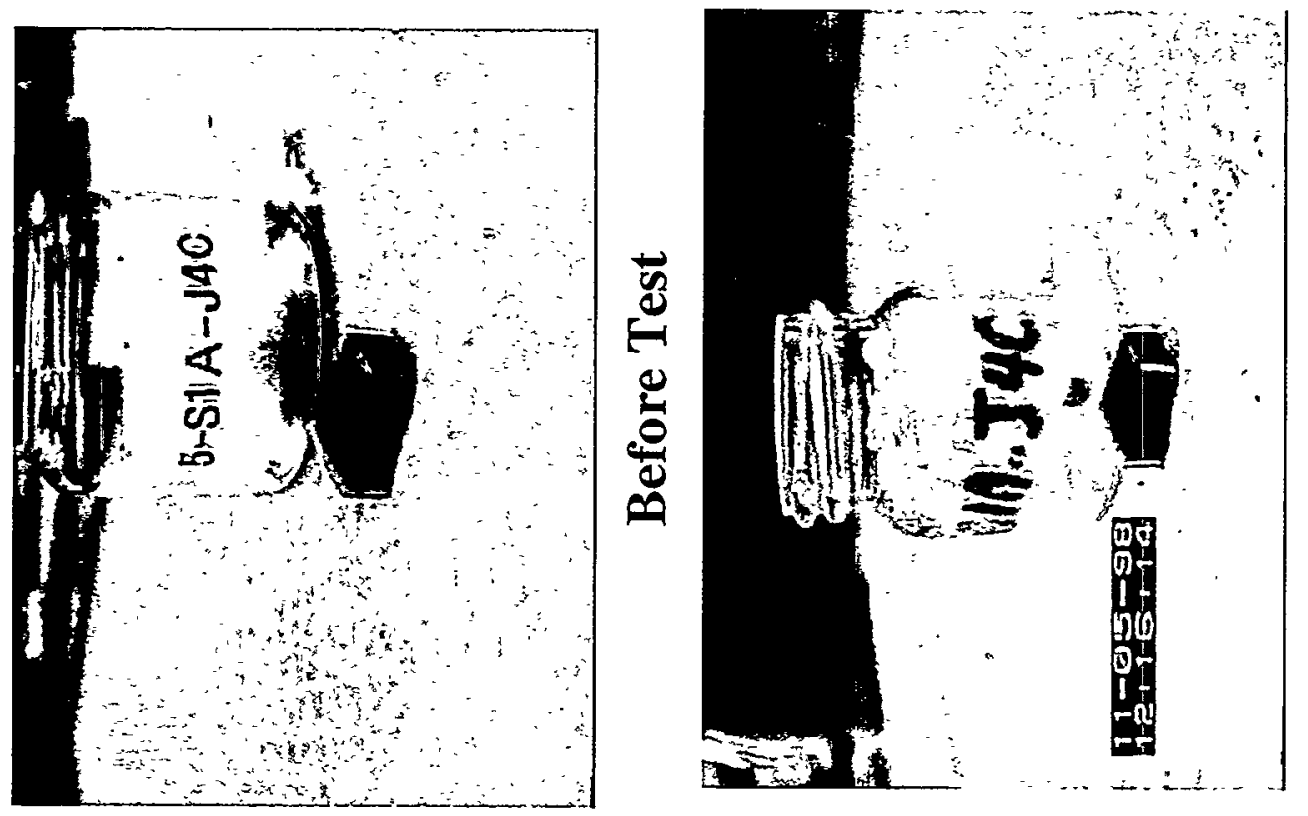

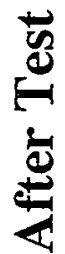

$\left(\supset_{\mathrm{o}}\right)$ əImฺ.Iəduə $\mathrm{L}$

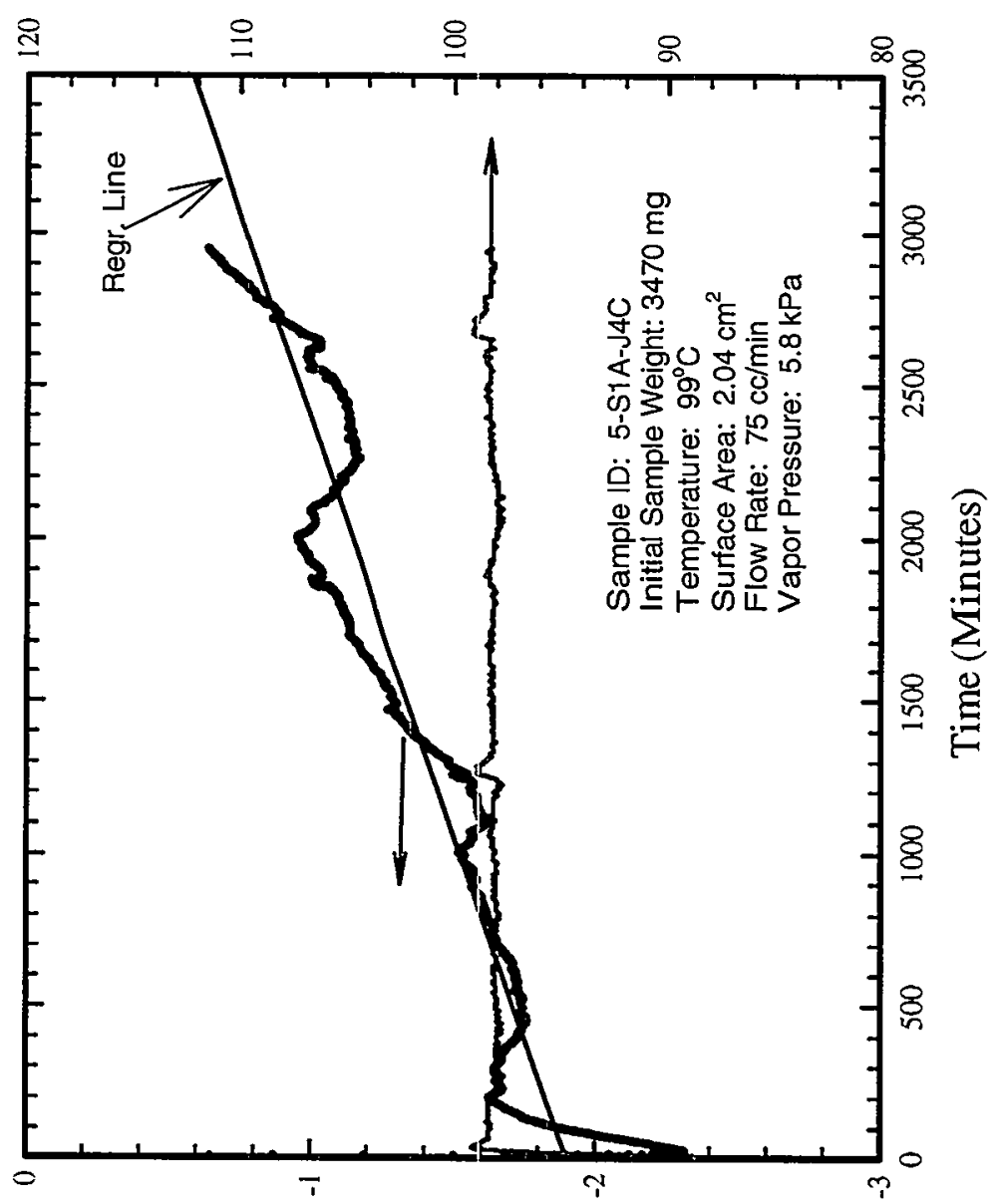

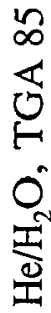

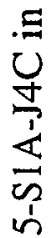

(ภิน) วชินеนว ¥บริเว 

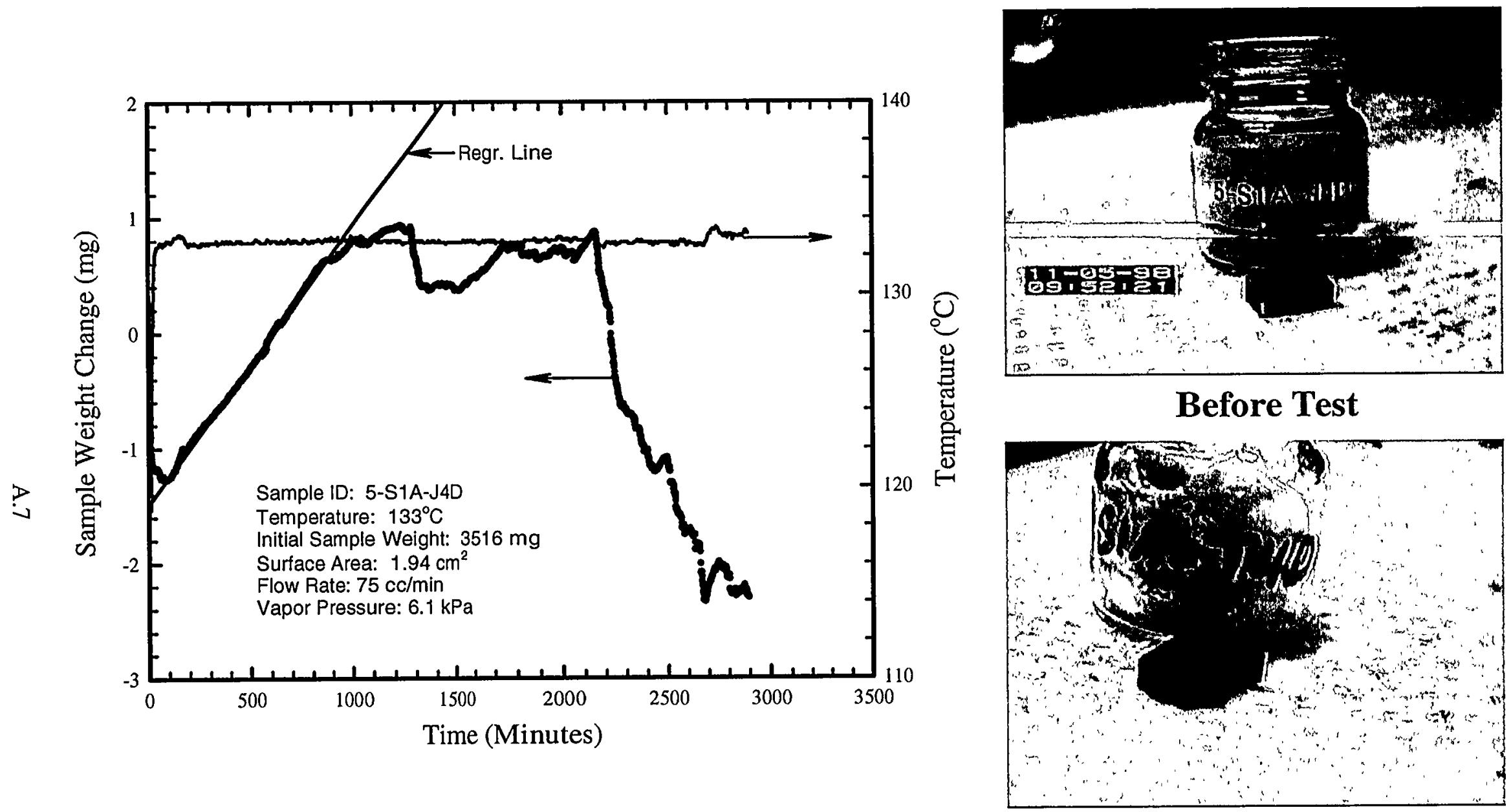

After Test

Figure A.7. Oxidation Results of SNF Sample 5-S1A-J4D in $\mathrm{He}_{2} / \mathrm{H}_{2} \mathrm{O}$, TGA 86 

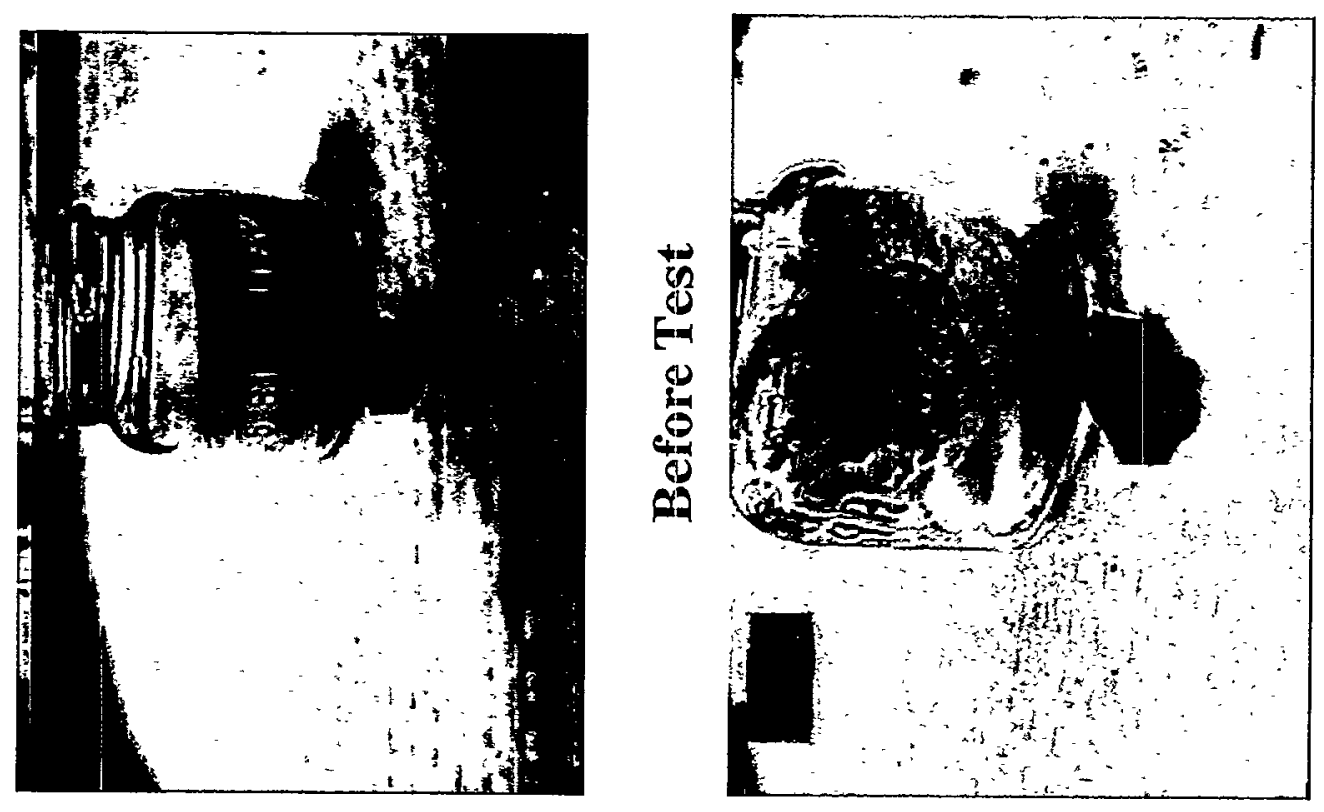

选

$\left(\mathrm{O}_{0}\right)$ ə.ณฺ..ІəduวL

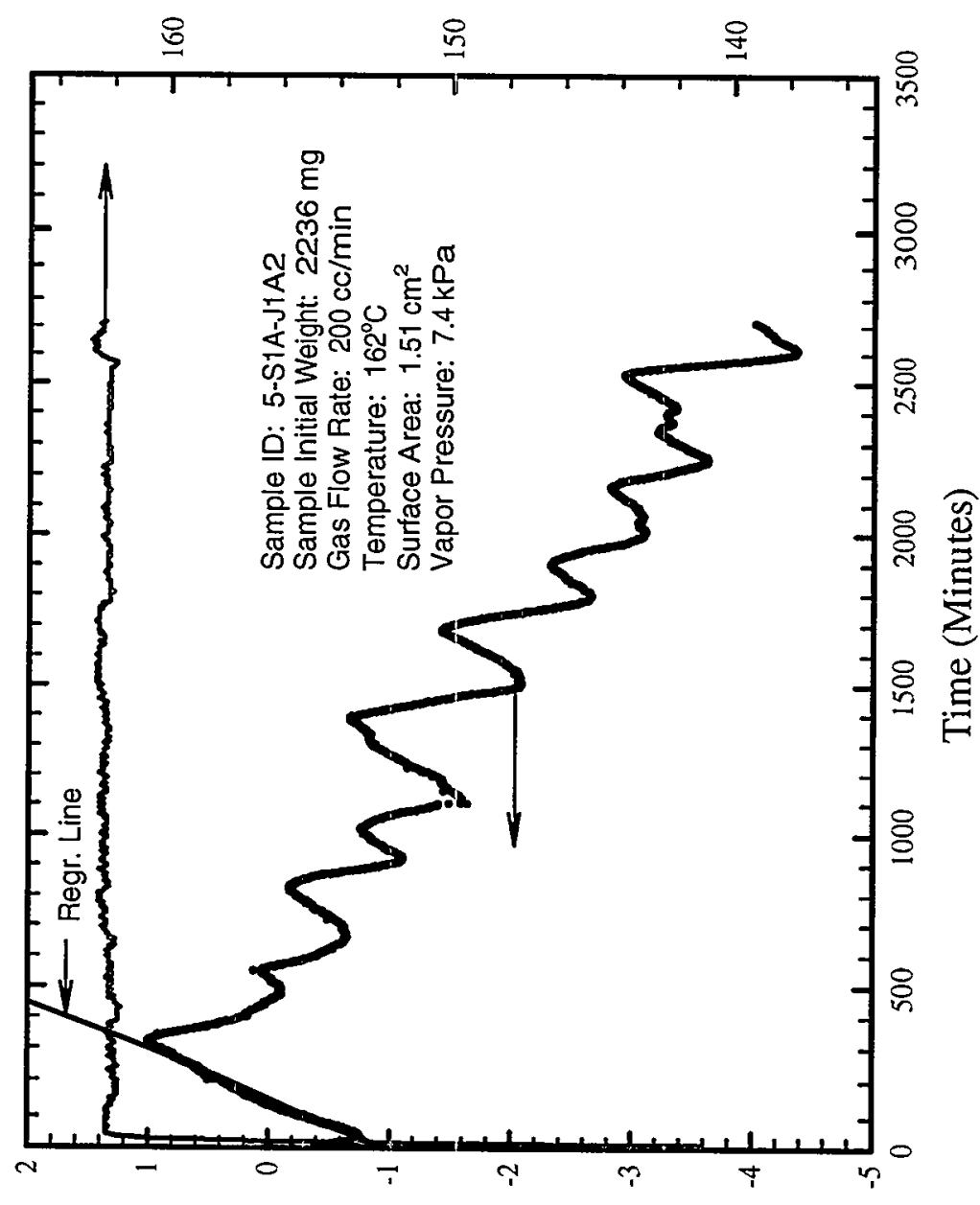

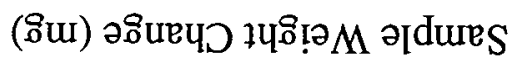



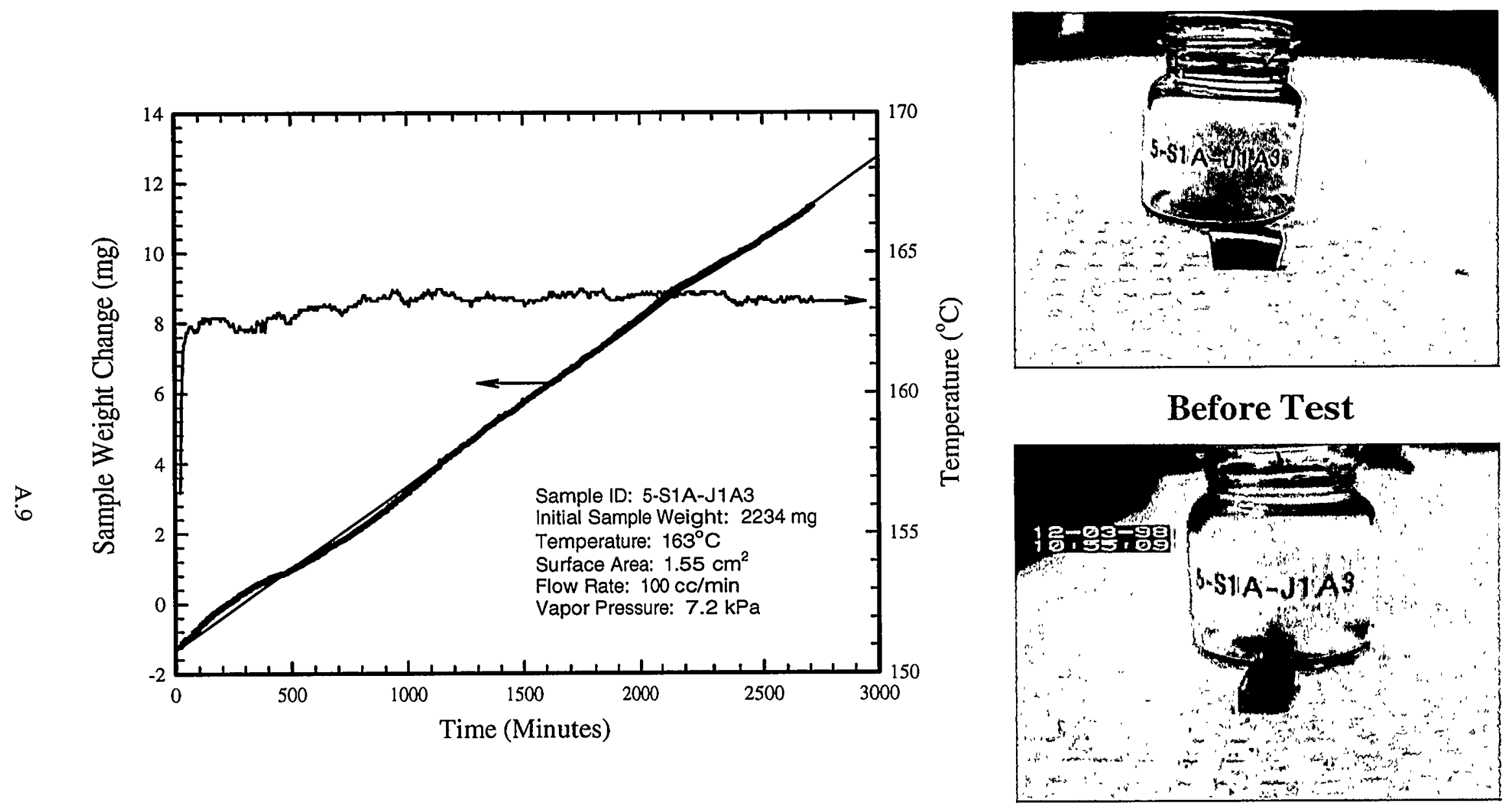

After Test

Figure A.9. Oxidation Results of SNF Sample 5-S1A-J1A3 in $\mathrm{He} / \mathrm{H}_{2} \mathrm{O}$, TGA 89 

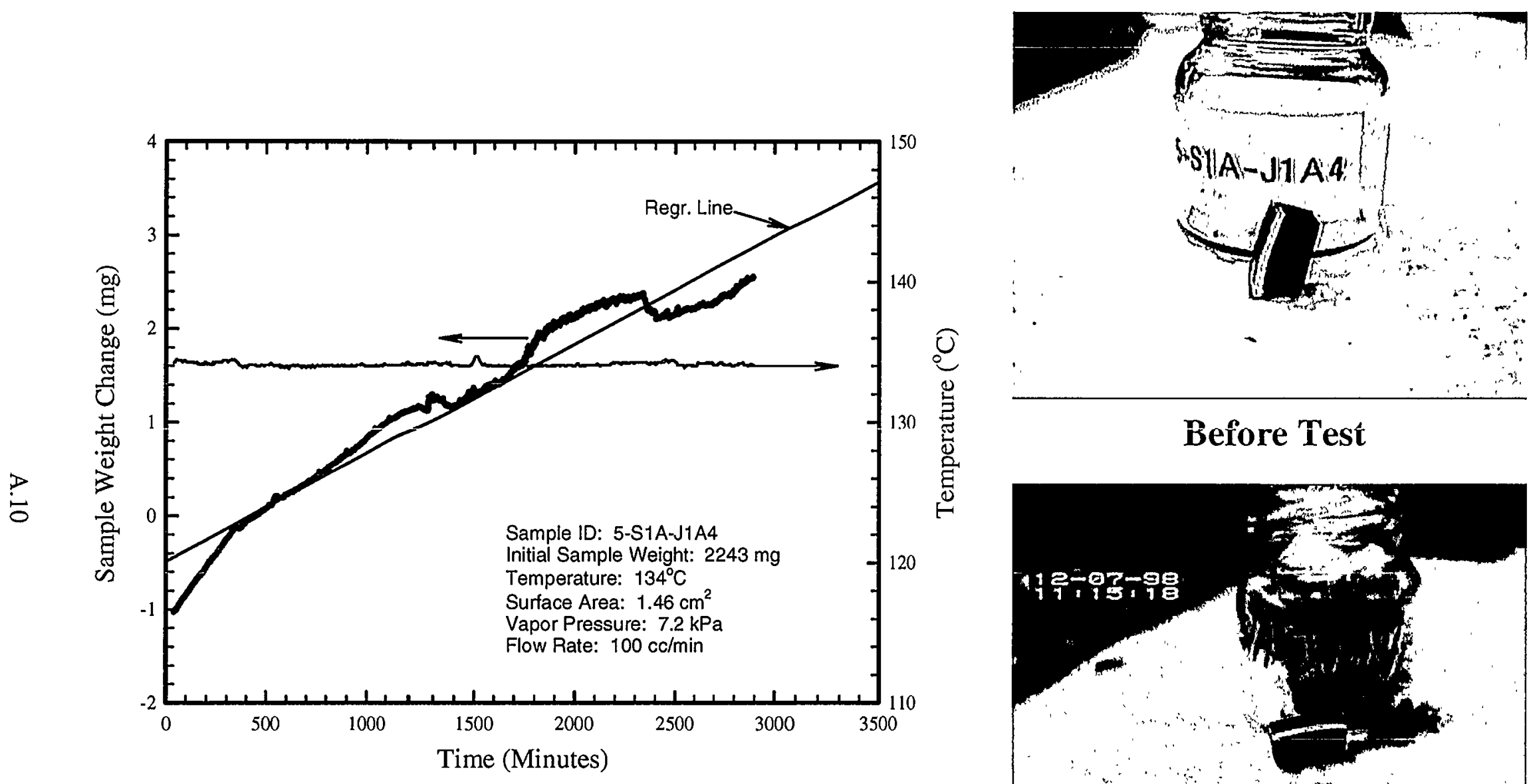

Before Test

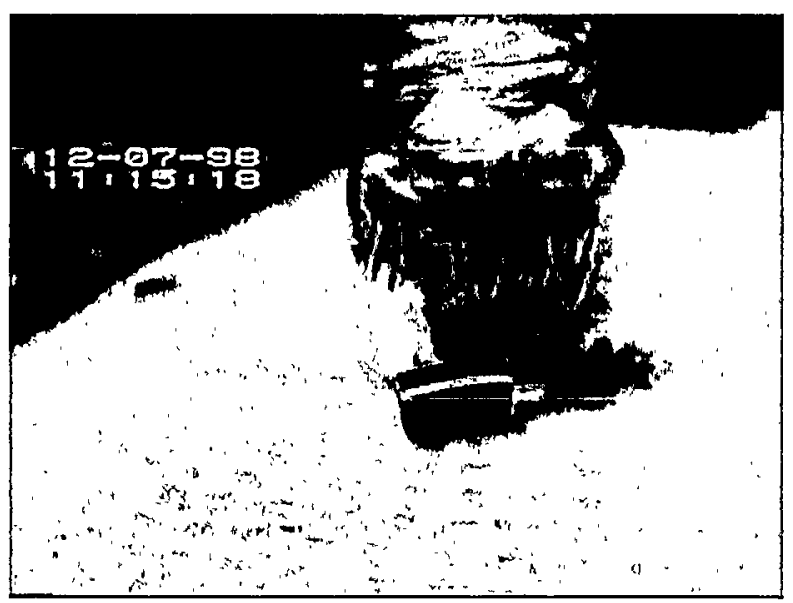

After Test

Figure A.10. Oxidation Results of SNF Sample 5-S1A-J1 A4 in $\mathrm{He} / \mathrm{H}_{2} \mathrm{O}$, TGA 91 

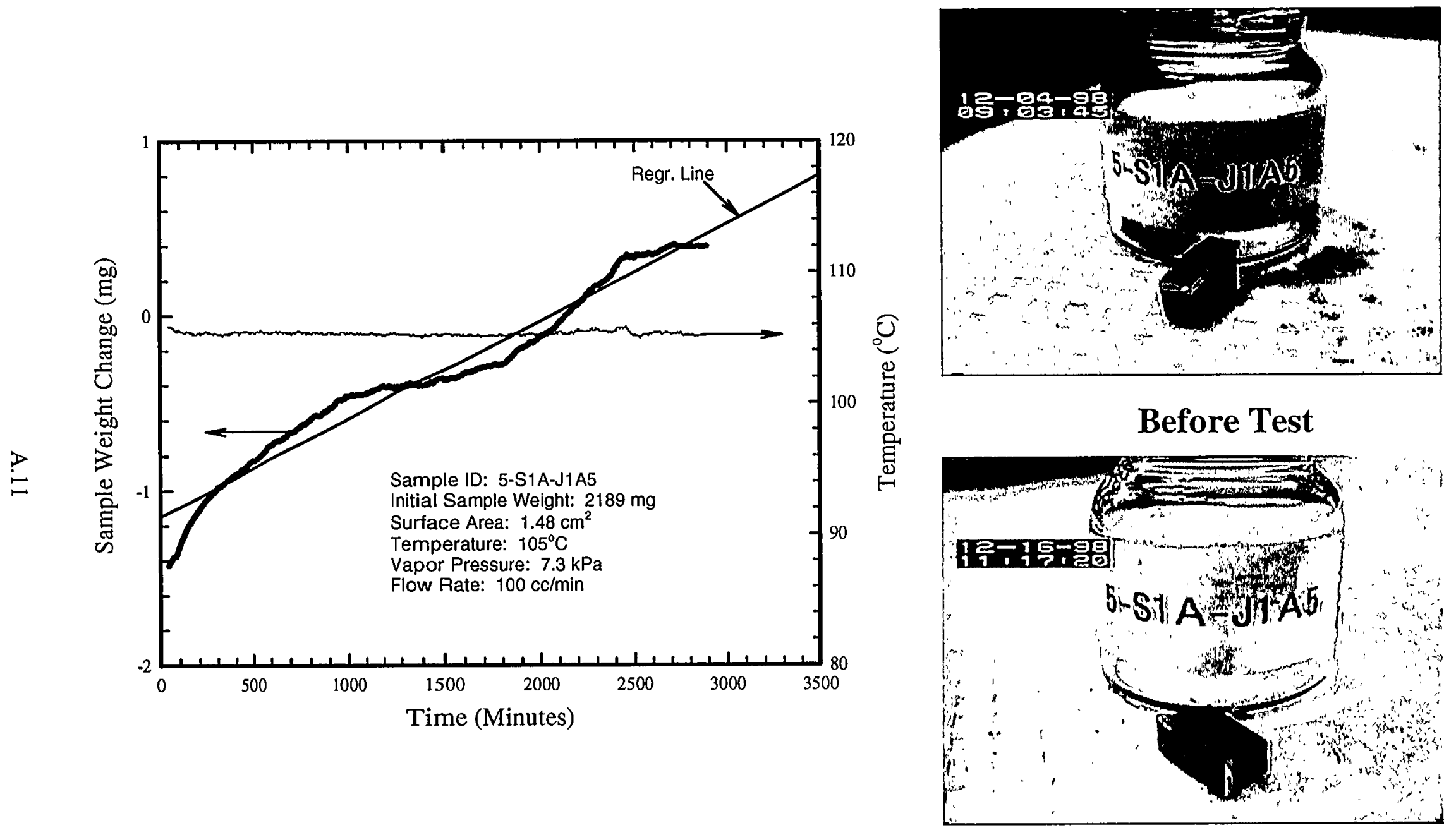

After Test

Figure A.11. Oxidation Results of SNF Sample 5-S1A-J1A5 in $\mathrm{He}_{2} \mathrm{H}_{2} \mathrm{O}$, TGA 92 

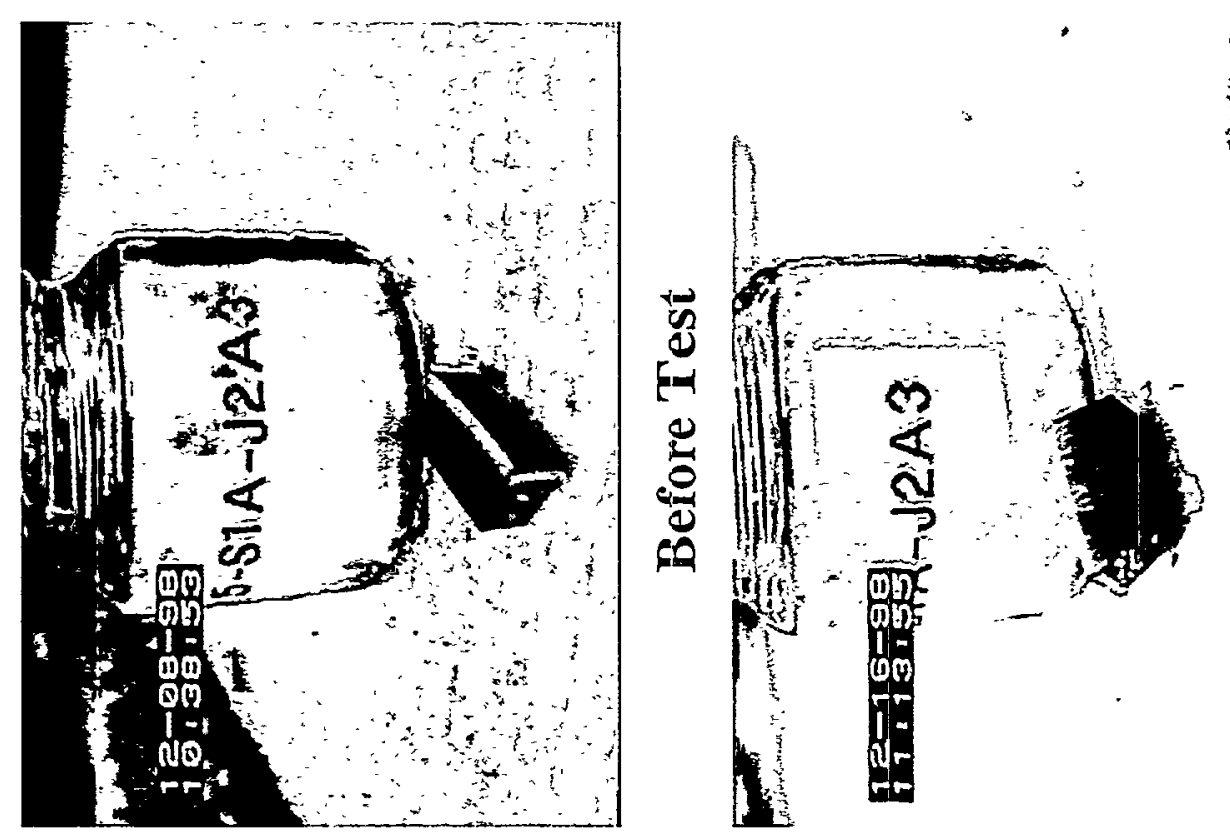

$\left(\supset_{0}\right)$ a.nฺॄ.əduว
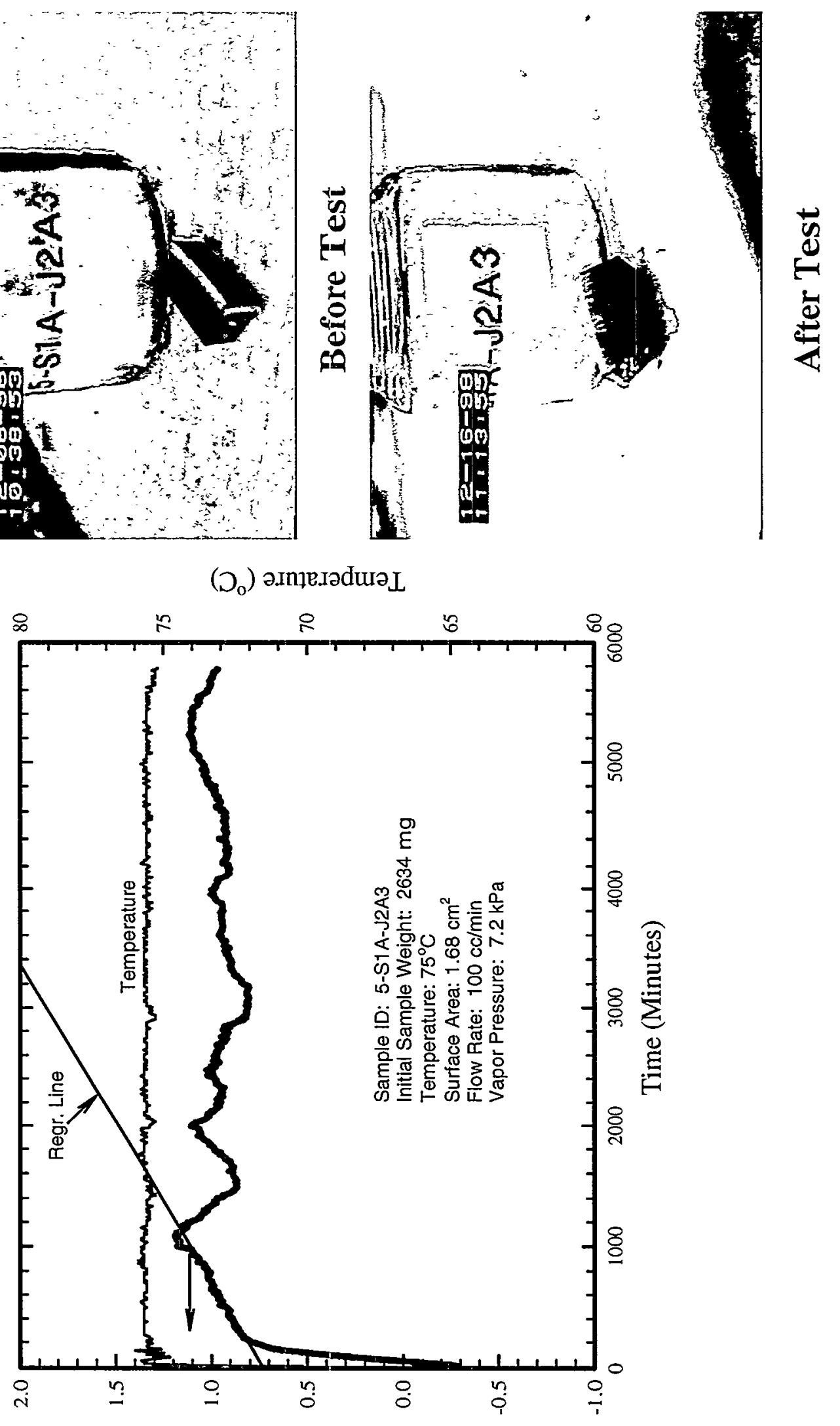

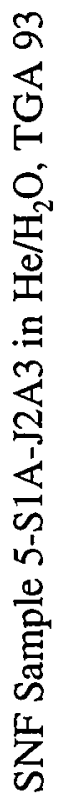

茨

蒙

.

光

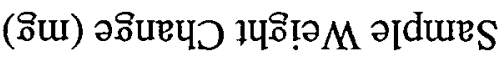



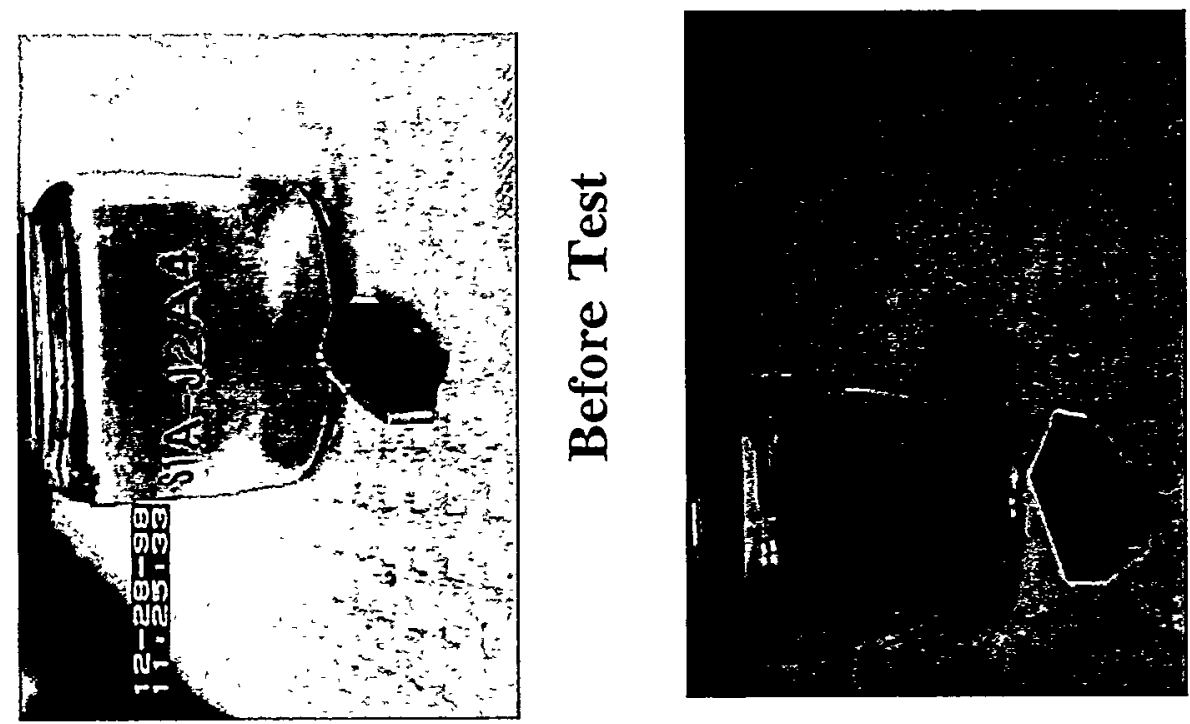

这

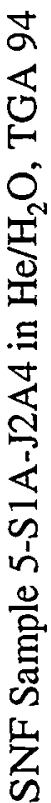

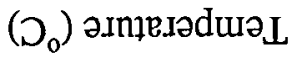

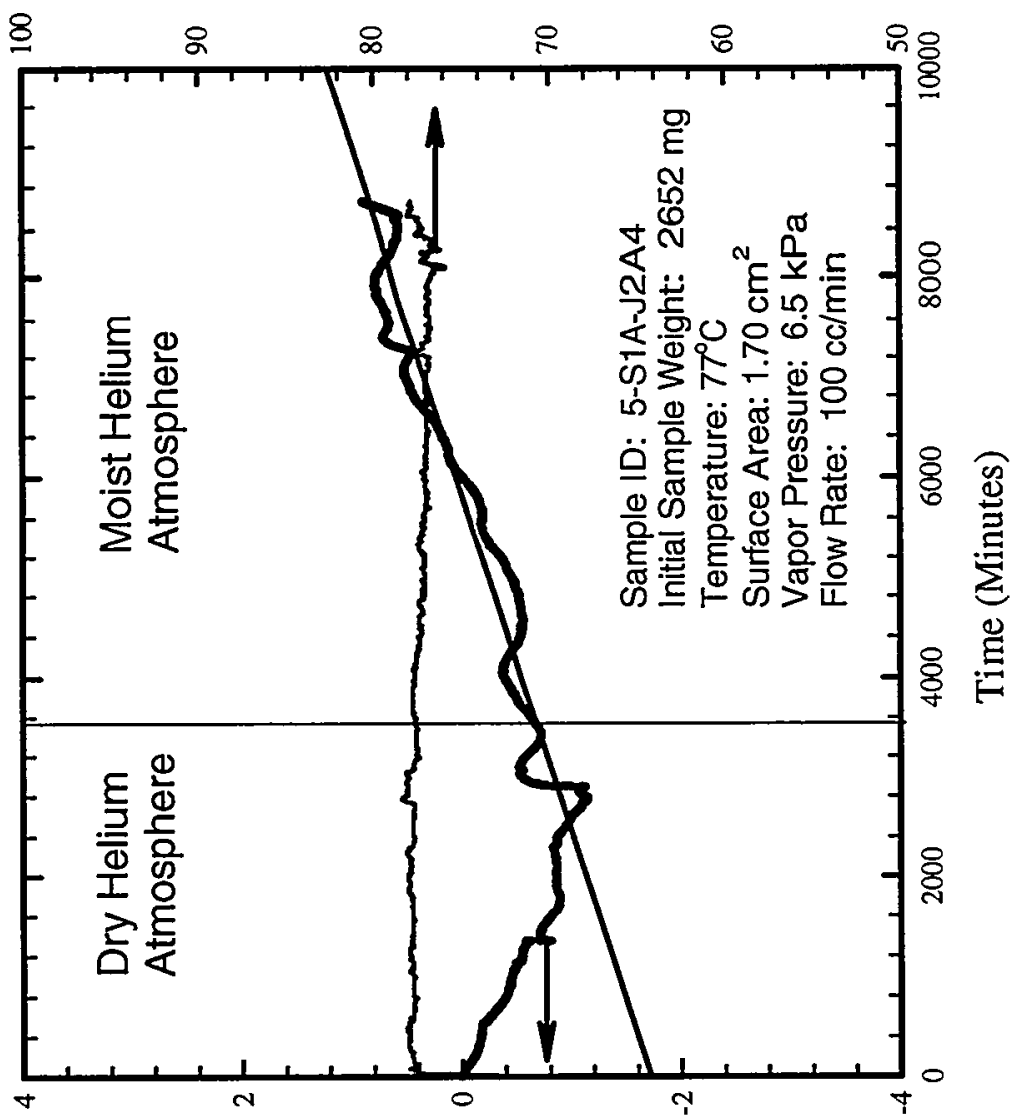

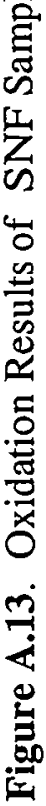

(รัน) วถ์นณบว 

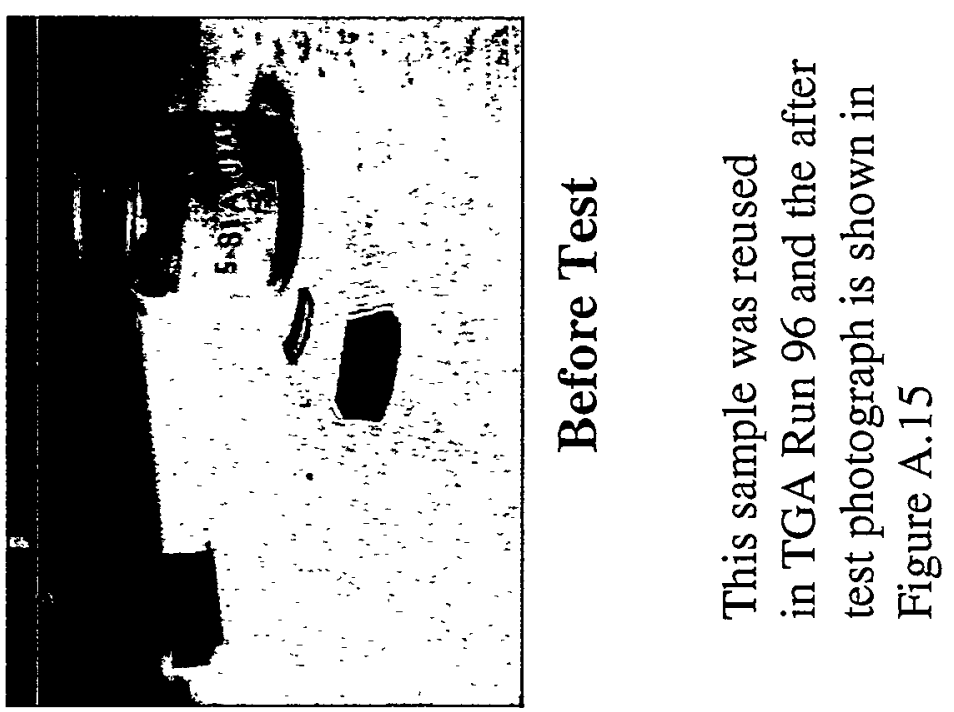

岁

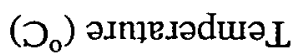

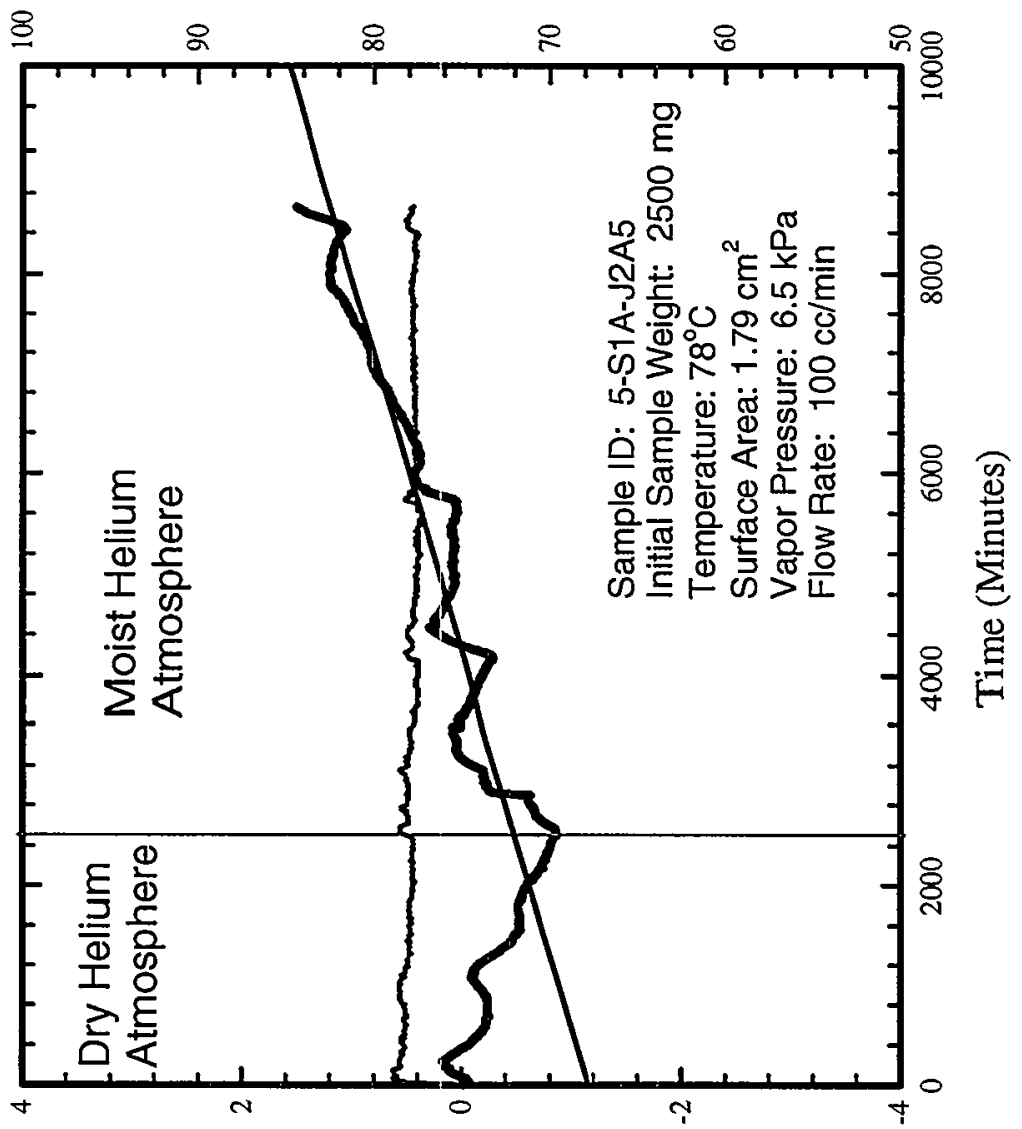

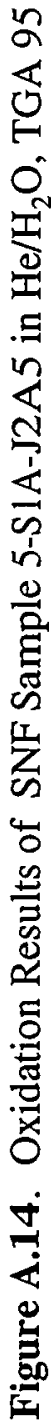

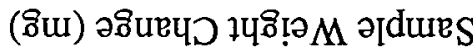



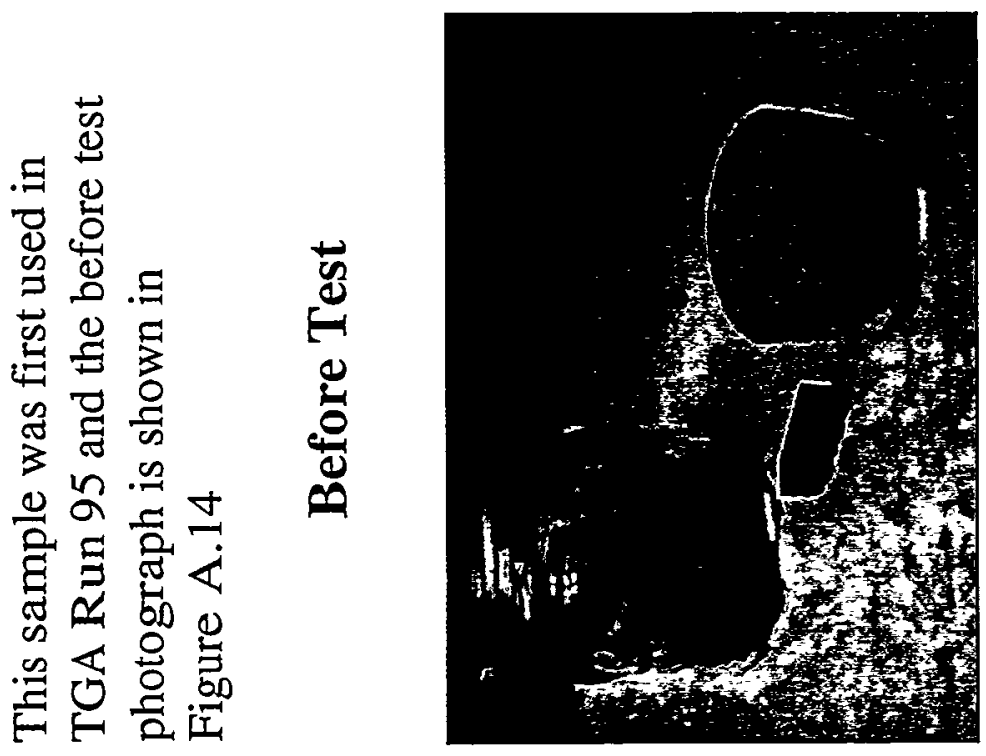

恋

$\left(\supset_{0}\right)$ วІпฺฺ.ıวduวL

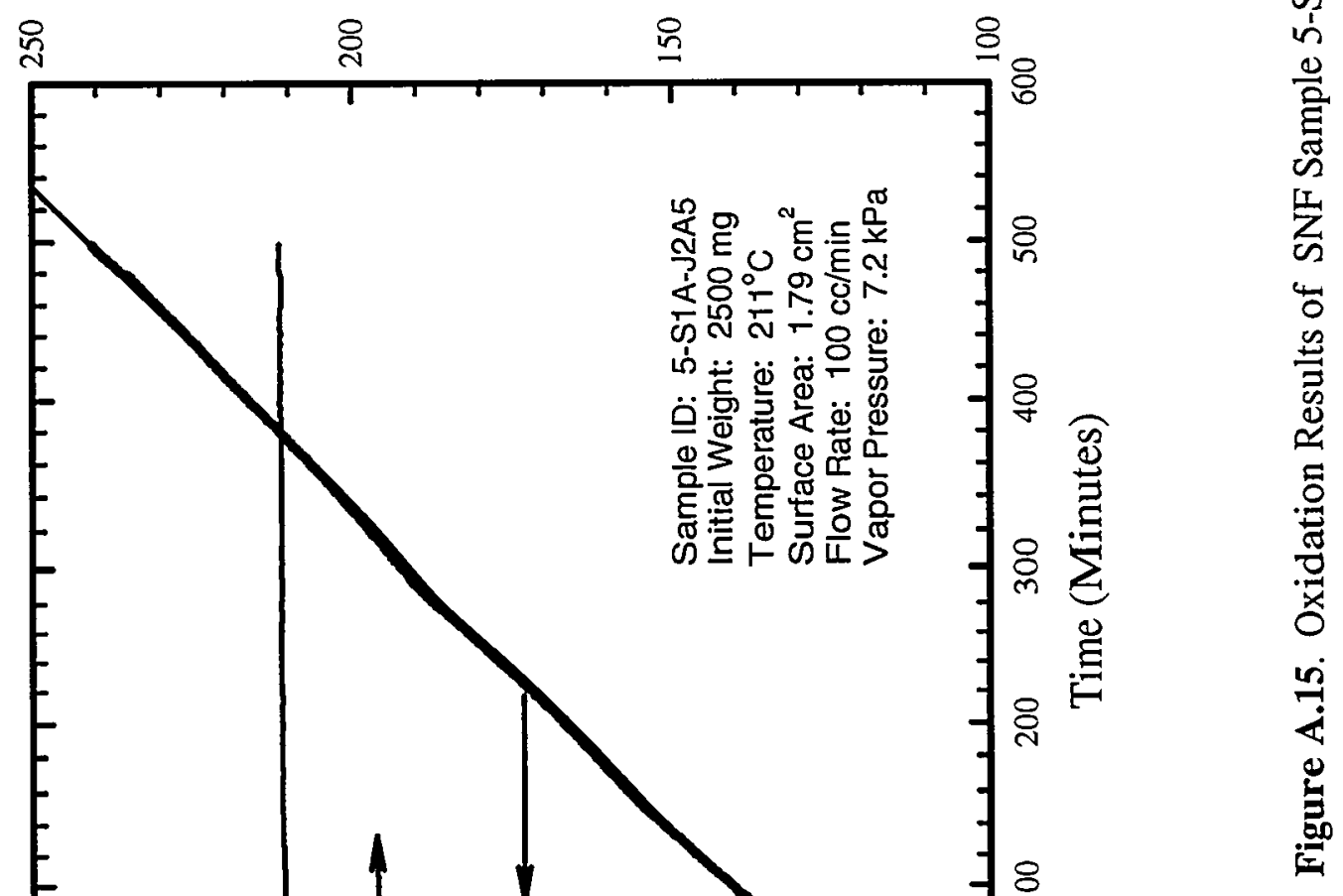



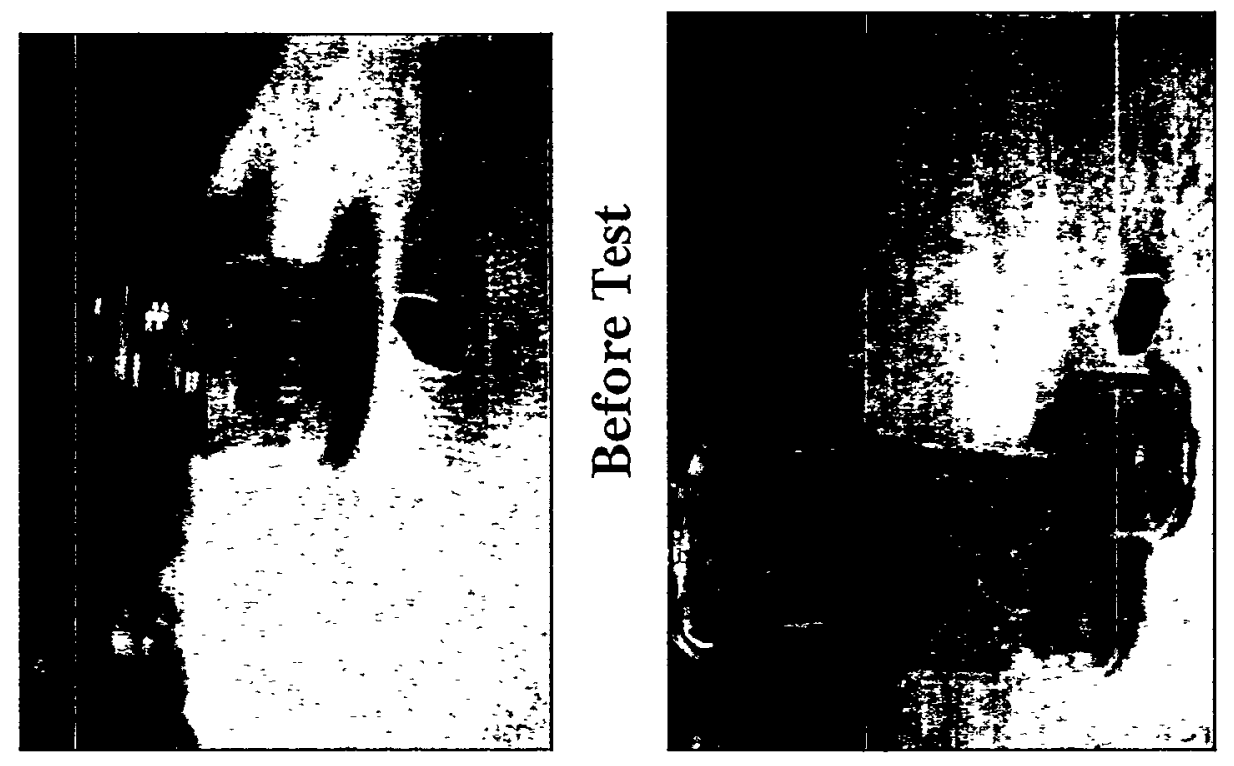

苞

å

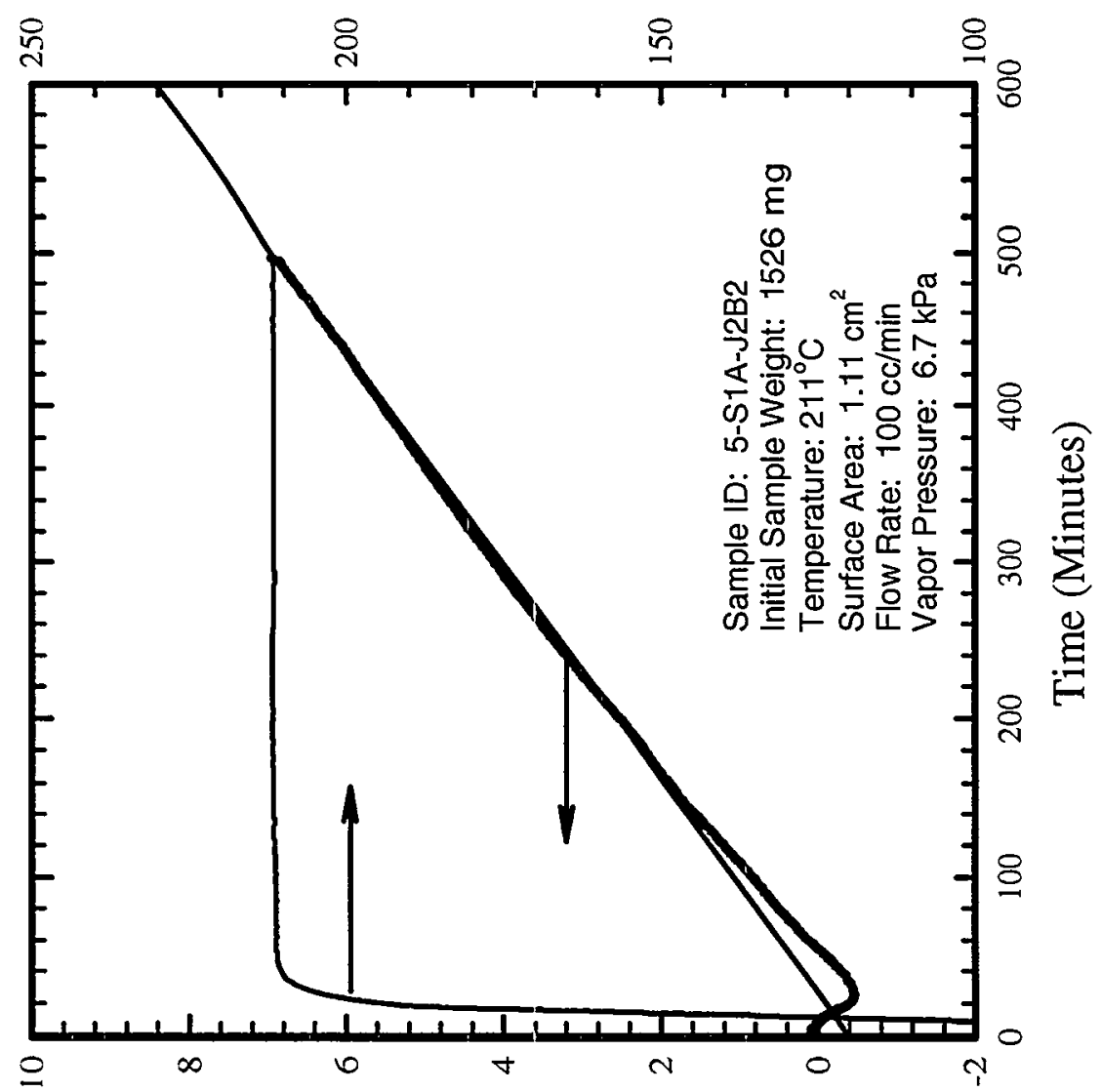

离

L

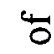

$\stackrel{0}{9}$

옳

$\stackrel{0}{3}$

旬

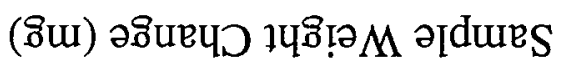



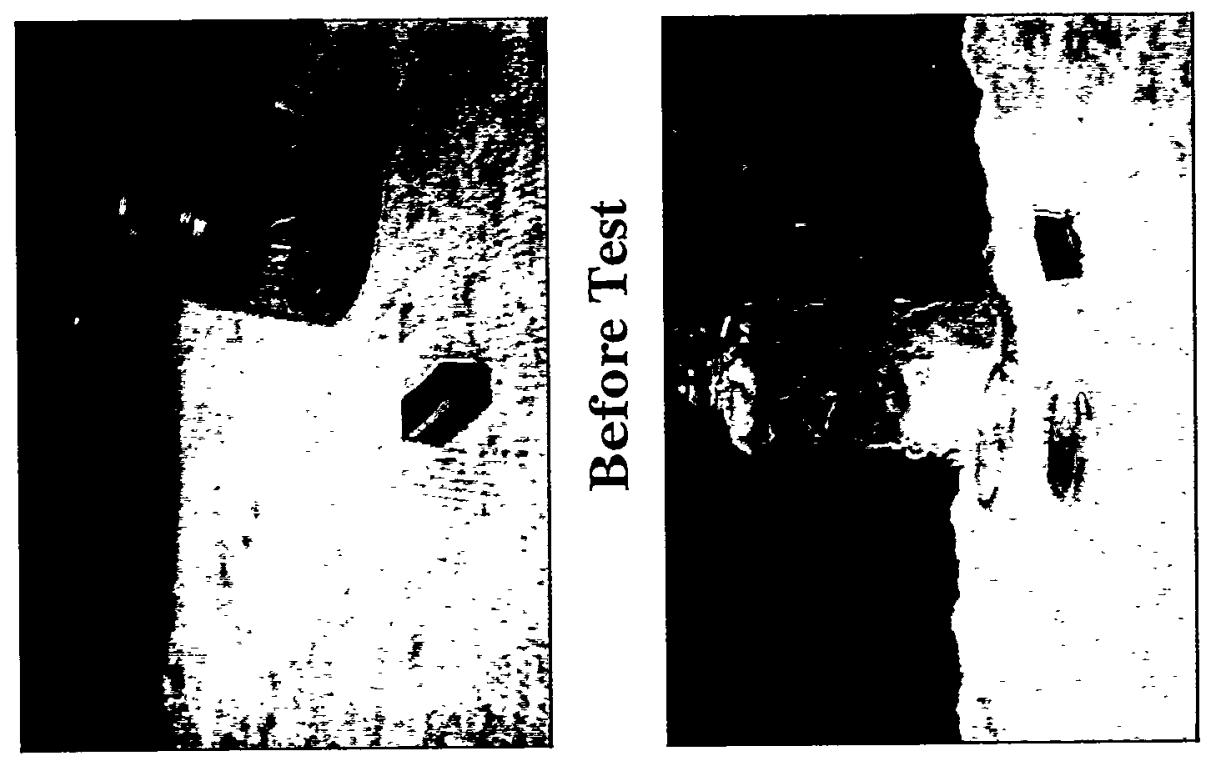

范

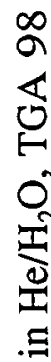

$\left(\supset_{0}\right)$ әлщщ.

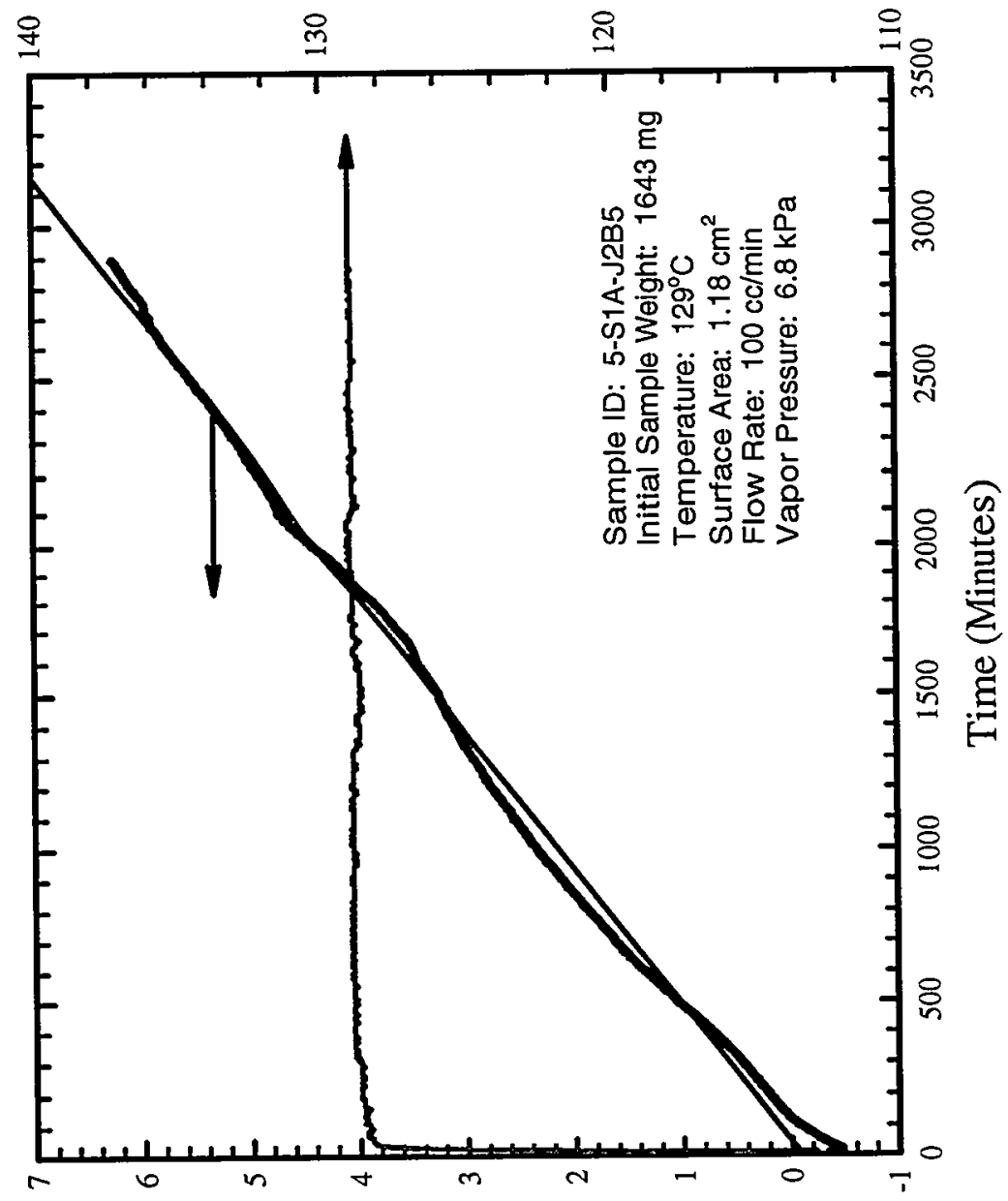

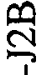

i

n่

疍

贡

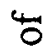

号

రิ

굴

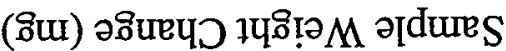




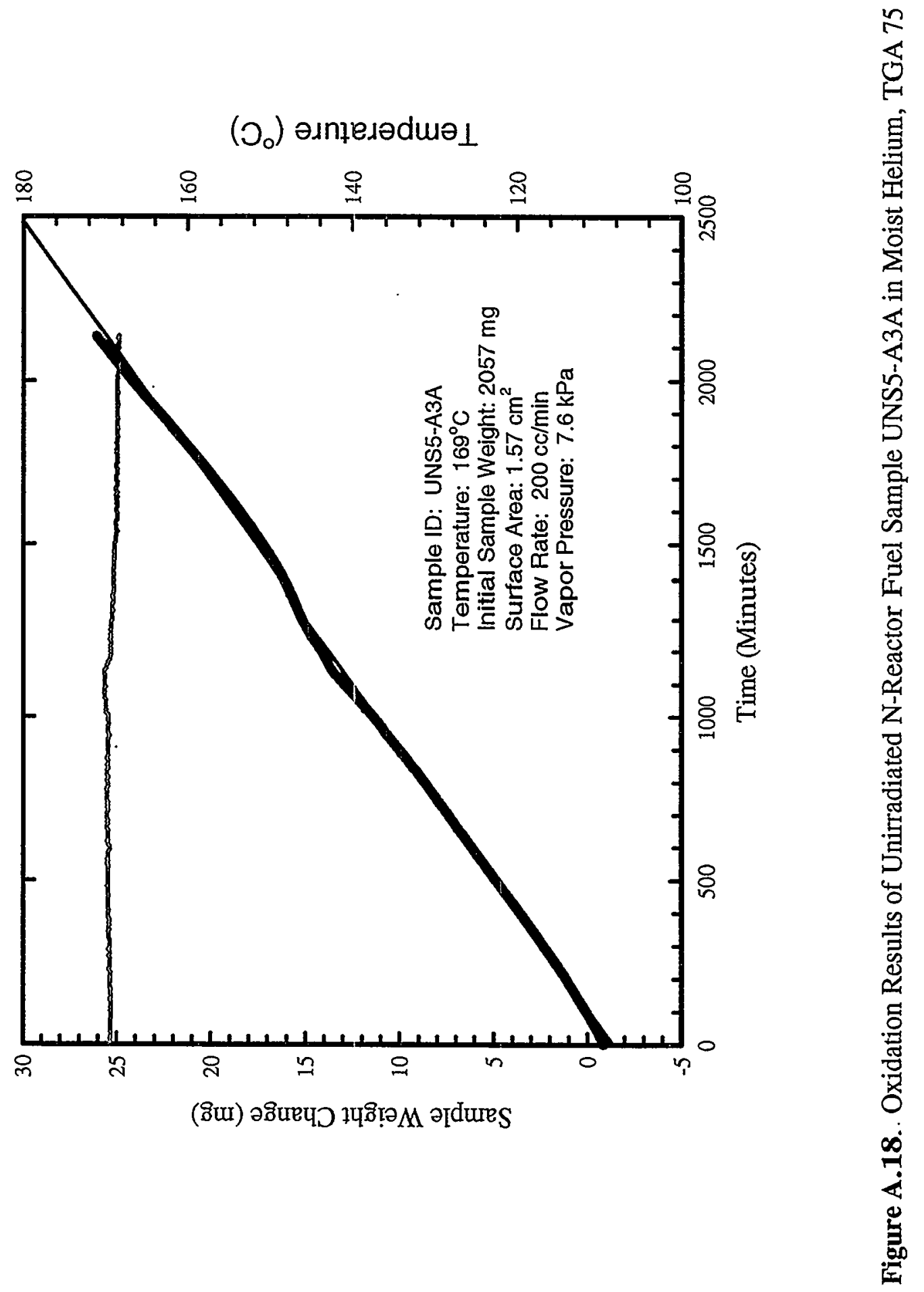




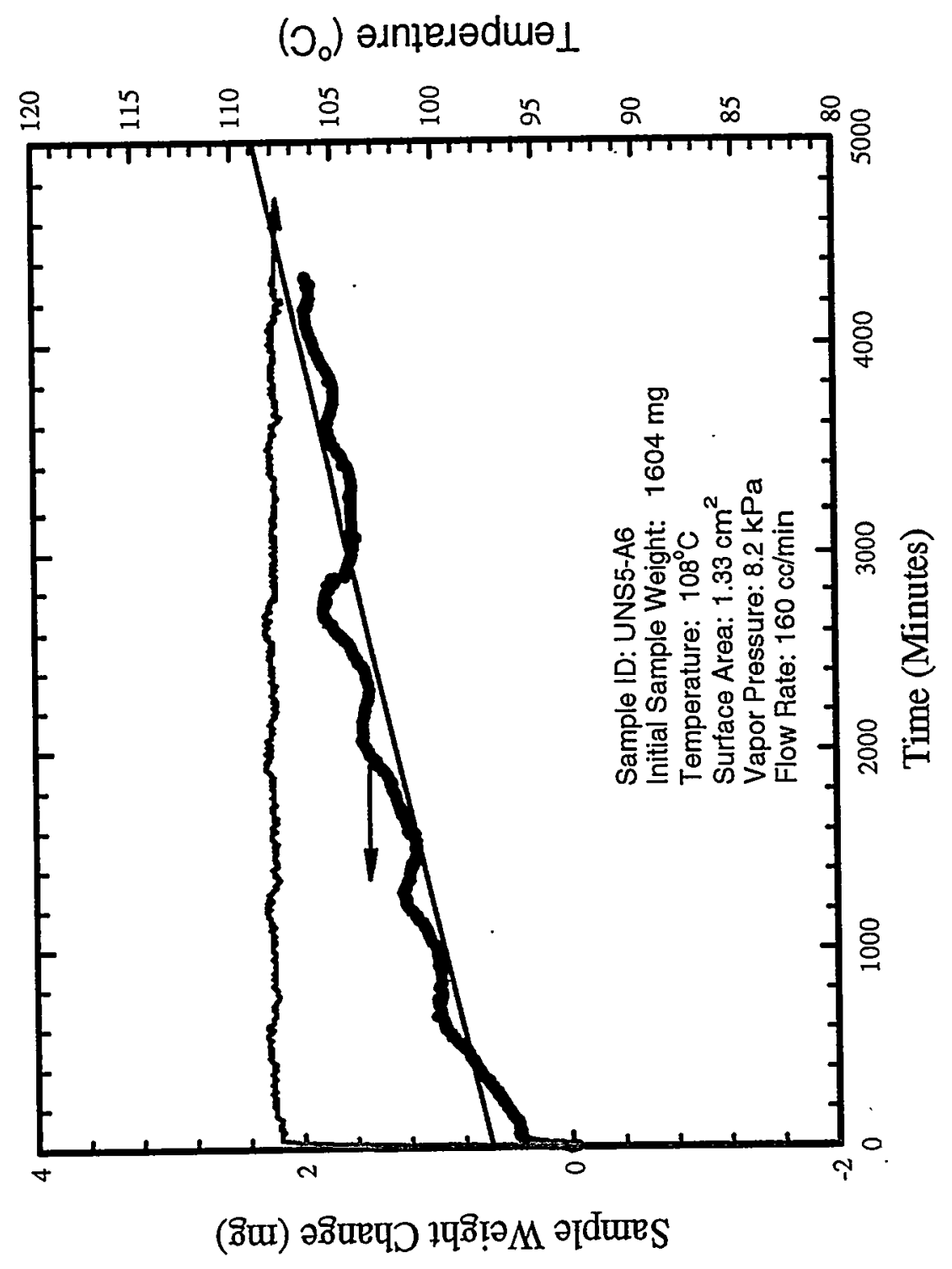

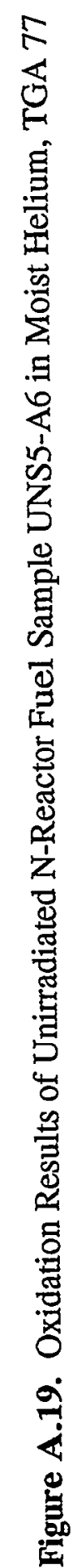




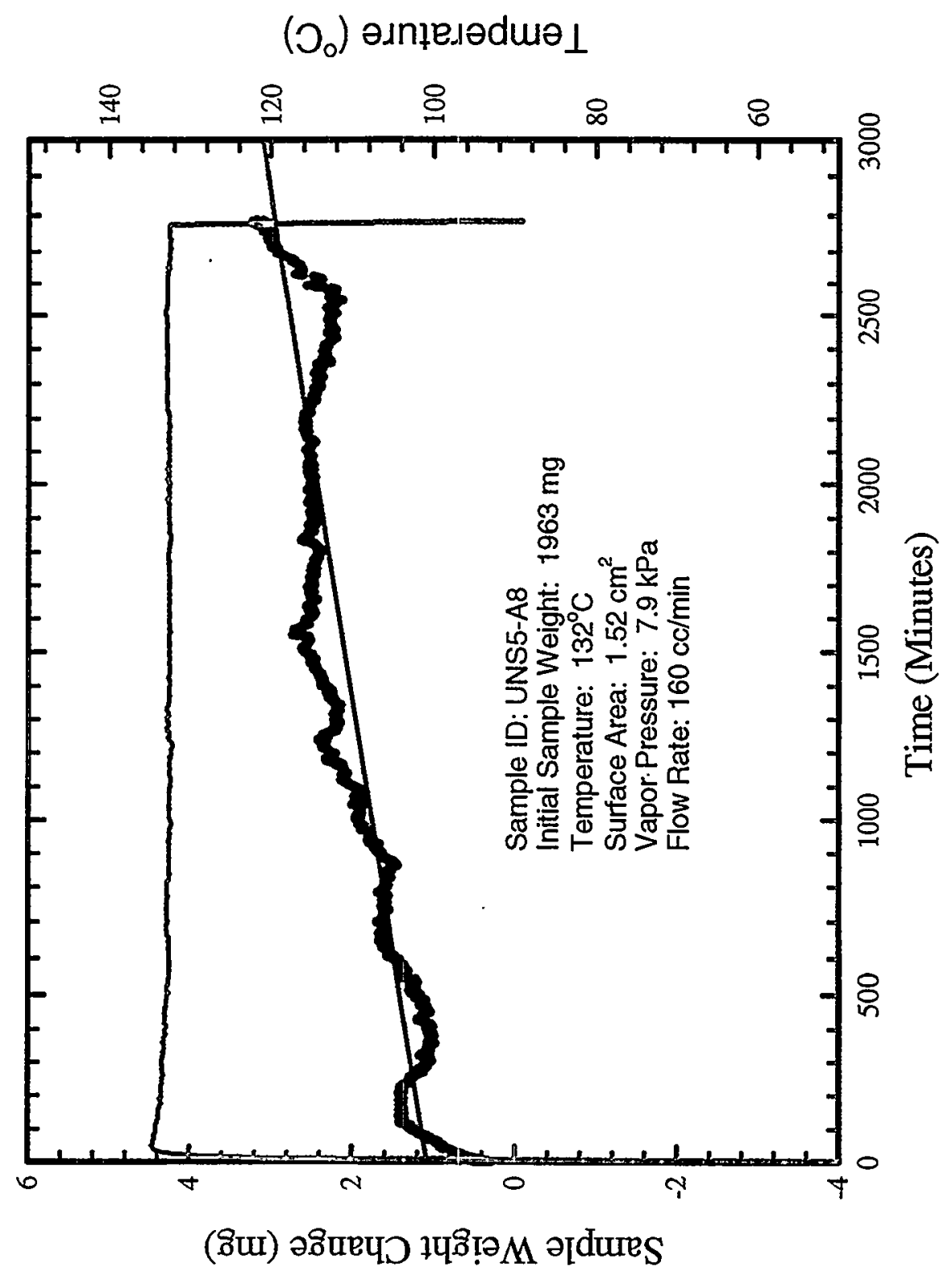

年 


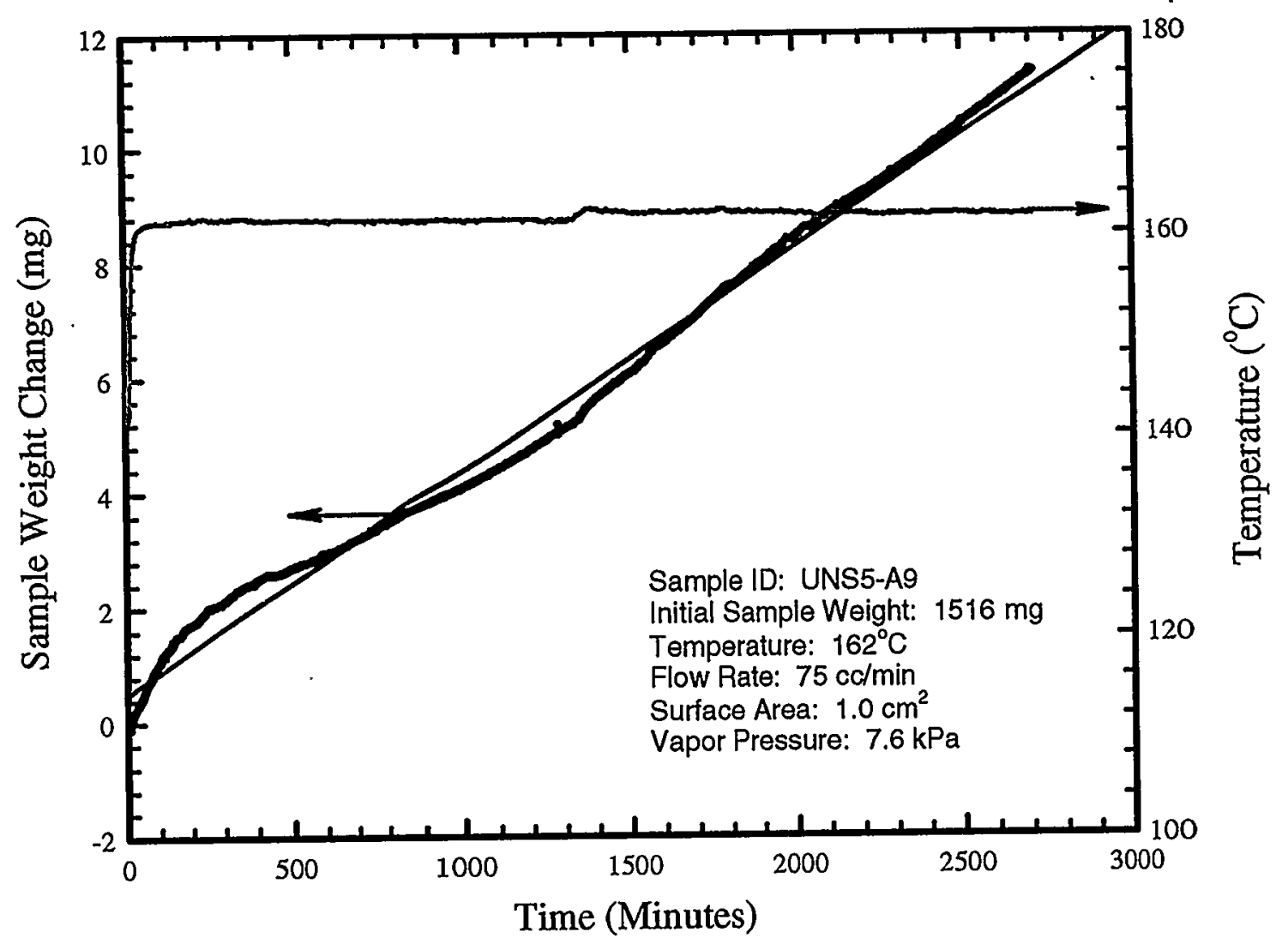

Figure A.21. Oxidation Results of Unirradiated N-Reactor Fuel Sample UNS5-A9 in Moist Helium, TGA 87 


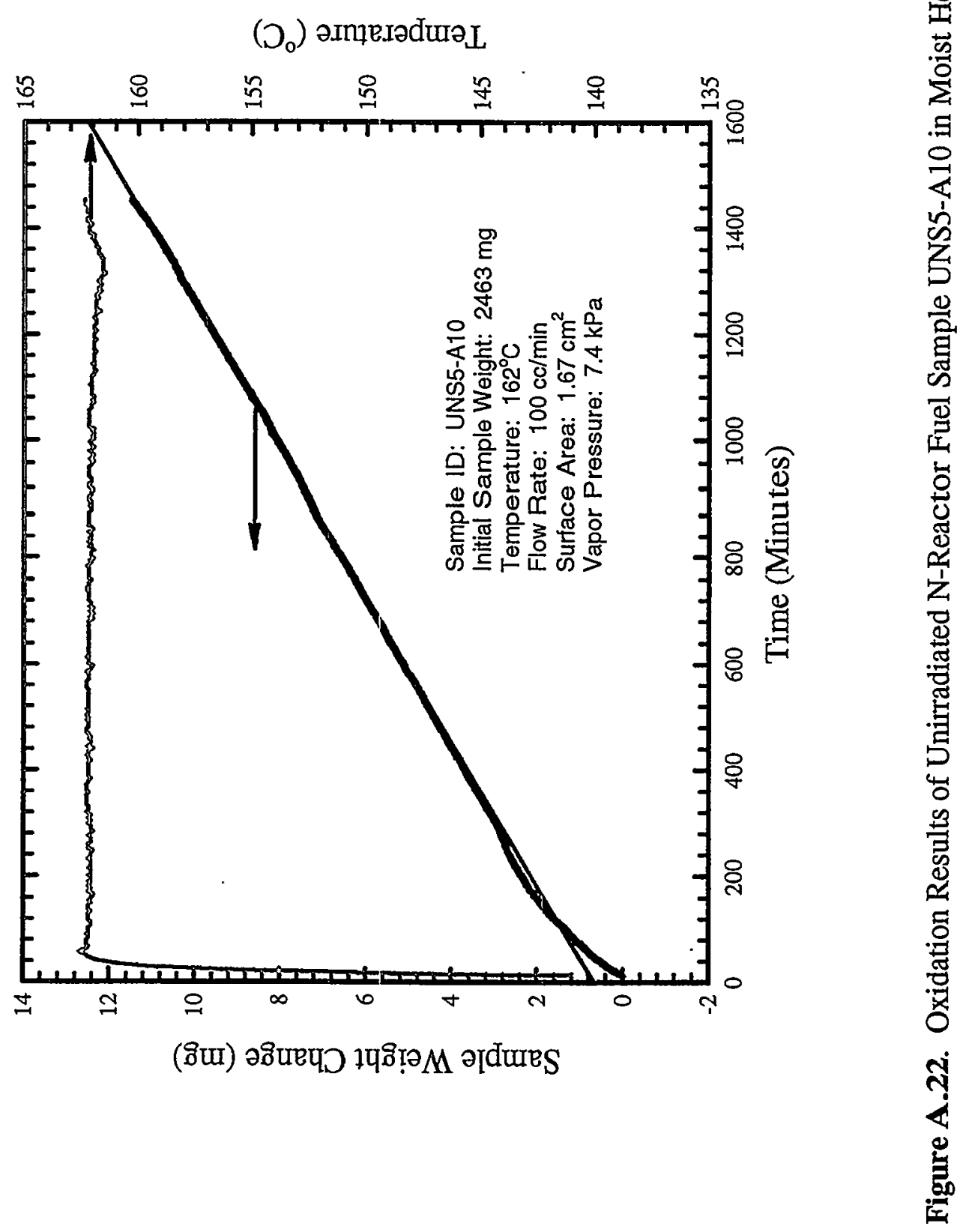




\section{Appendix B}

\section{SEM/XRD Photomicrographs of SNF Oxidation Products and Results of Drying Calcium Oxalate}




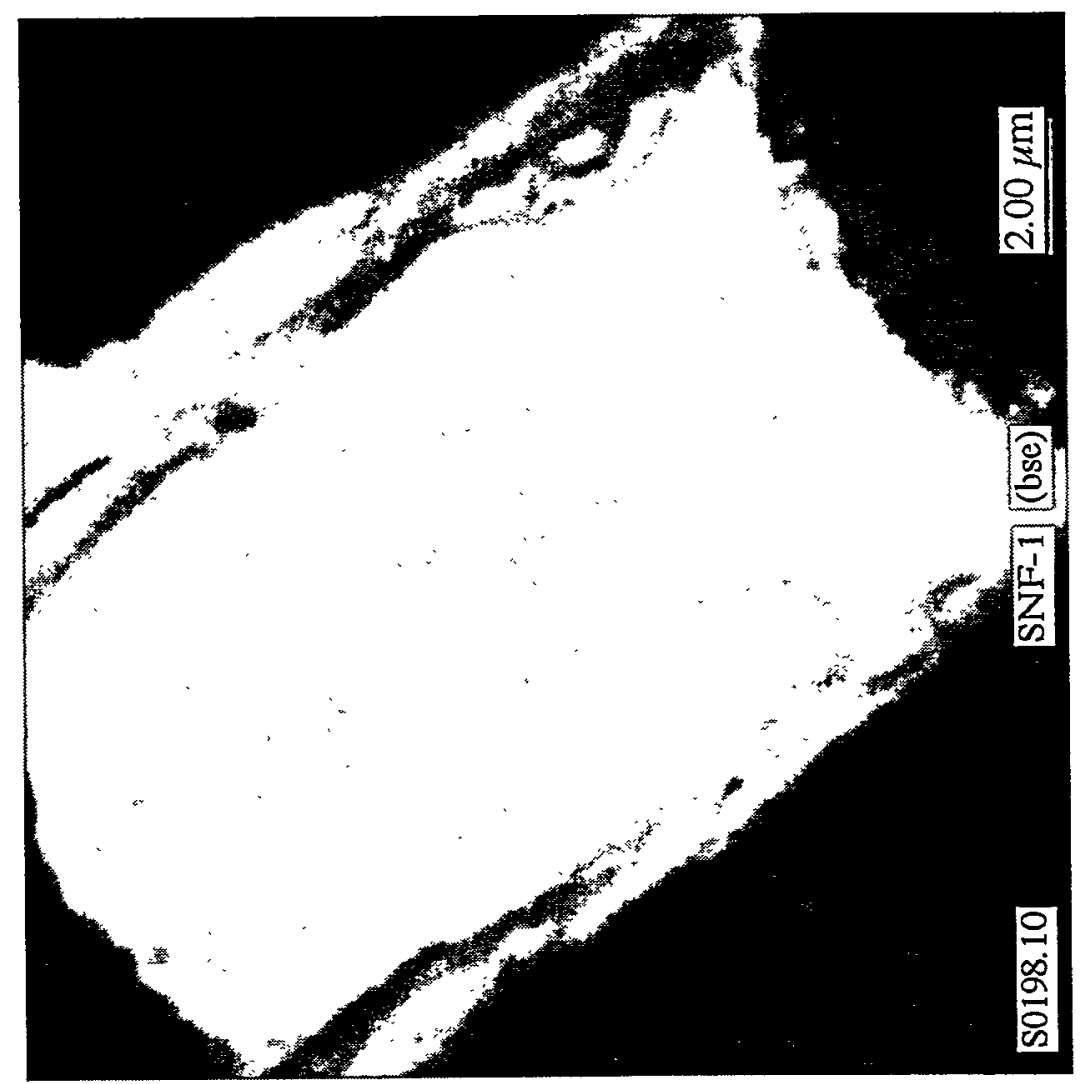

סृ

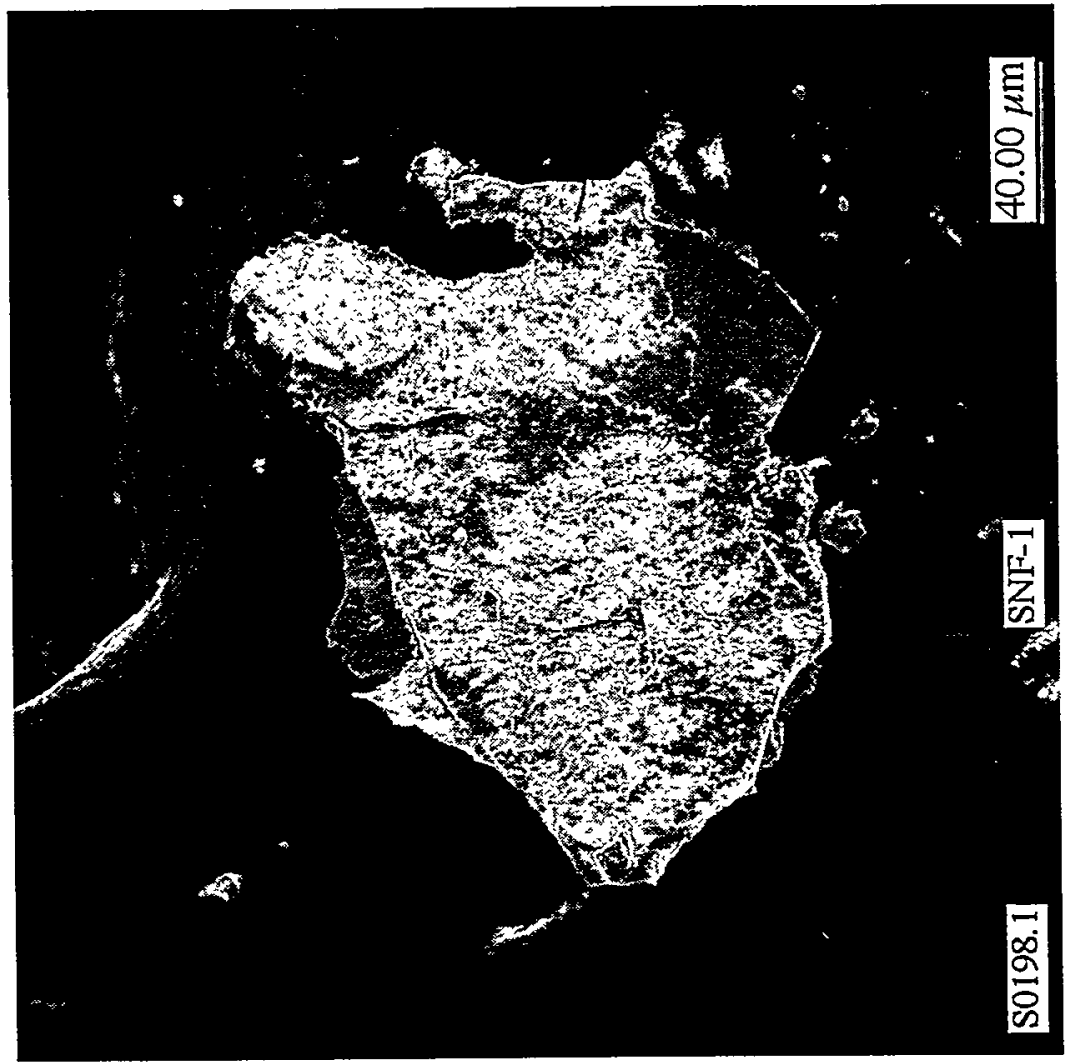

落

B. 1 

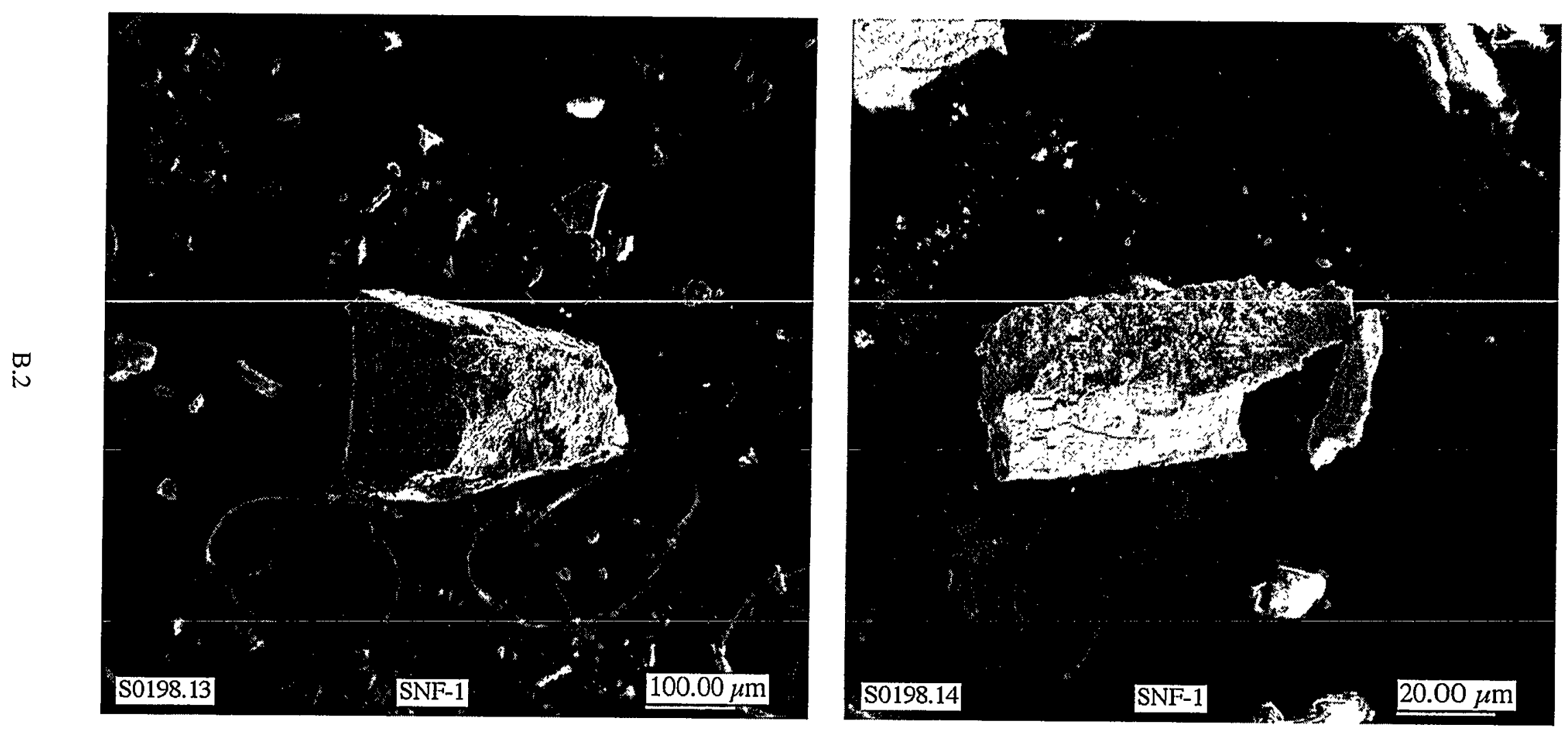

Figure B.2. Photomicrographs of SNF Oxidation Products Showing Chunks and Small Particulate Oxides 


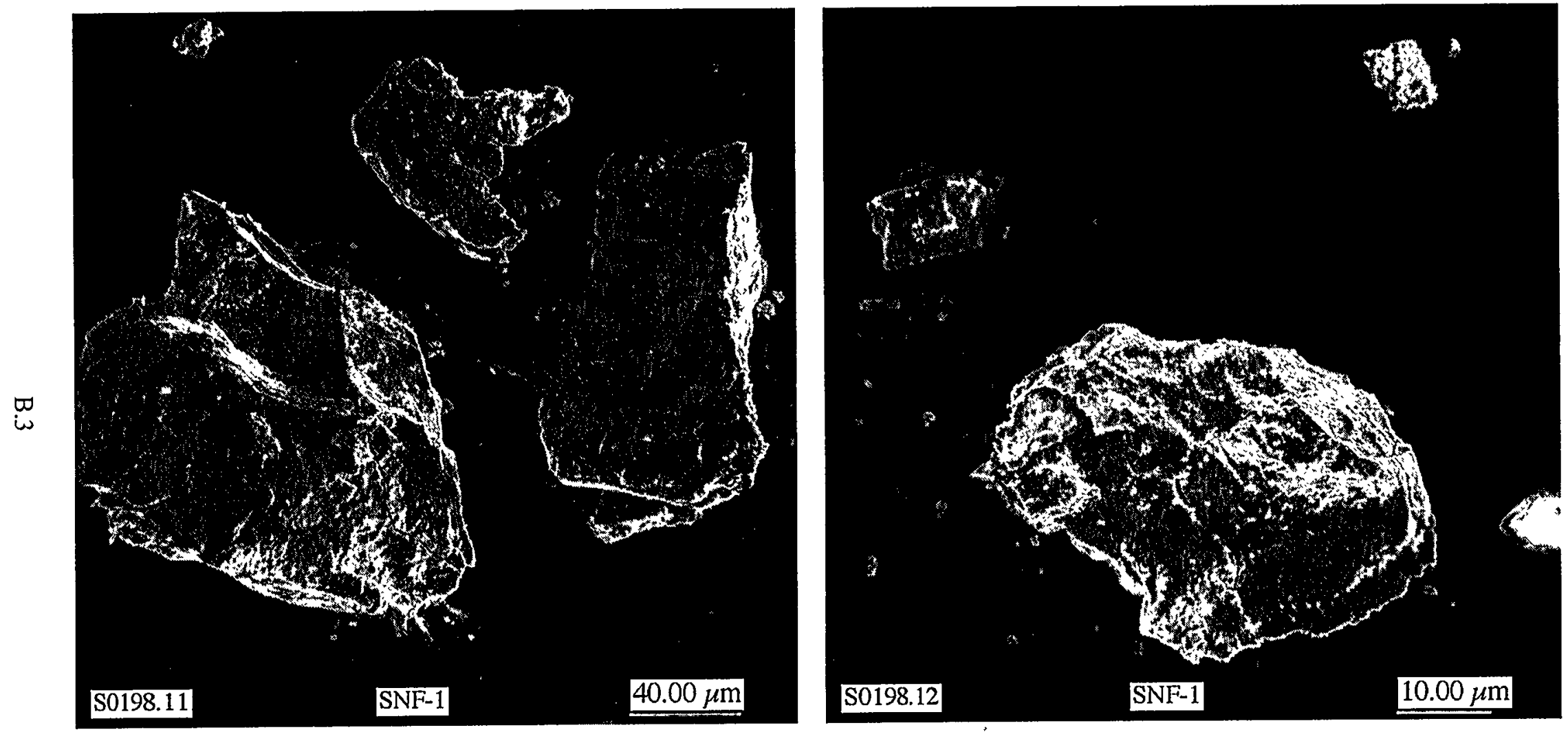

Figure B.3. Photomicrographs of SNF Oxidation Products Showing the Rock-type Oxide Particles 


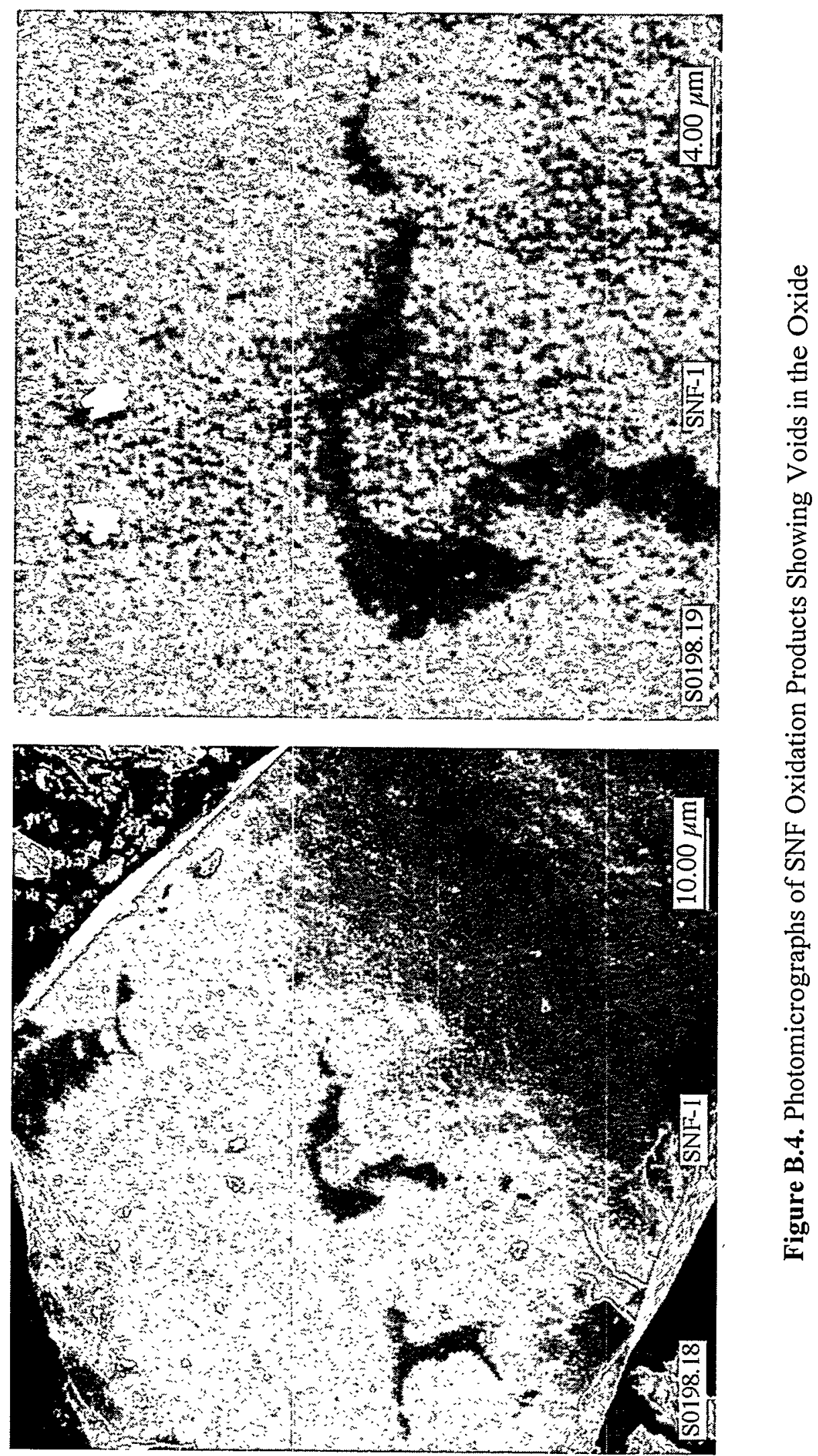

B. 4 


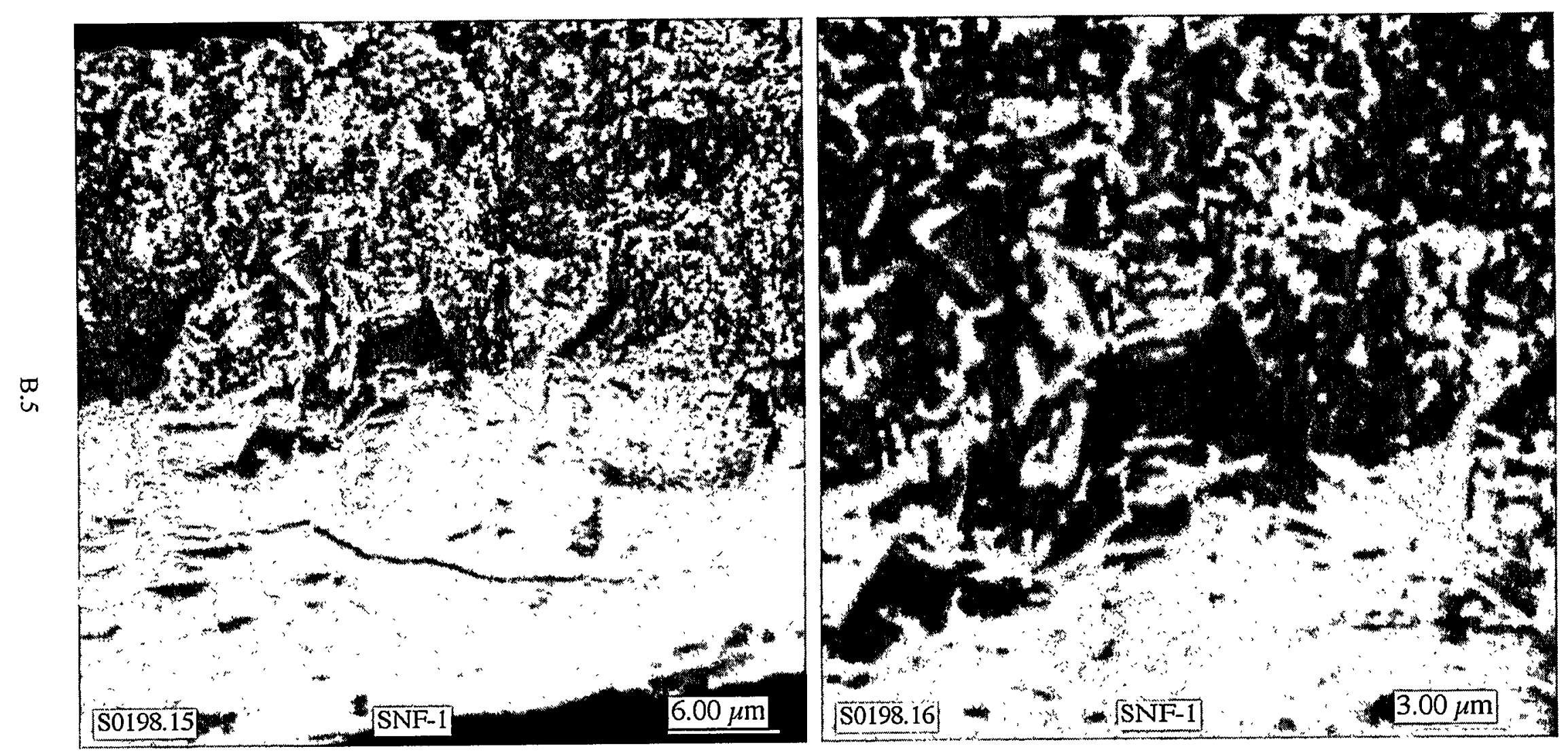

Figure B.5. Photomicrographs of SNF Oxidation Products Showing Carbide Inclusions 


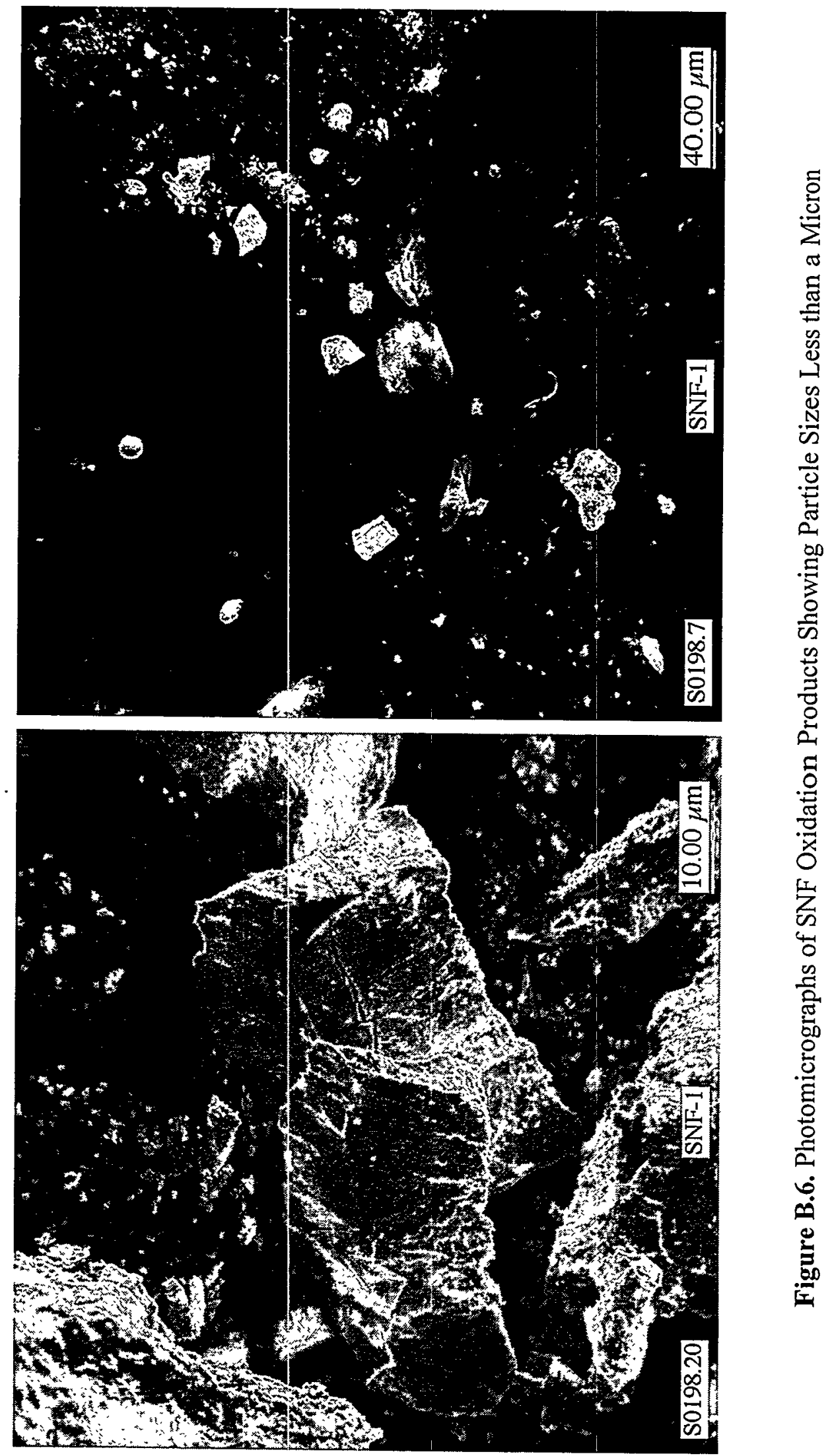




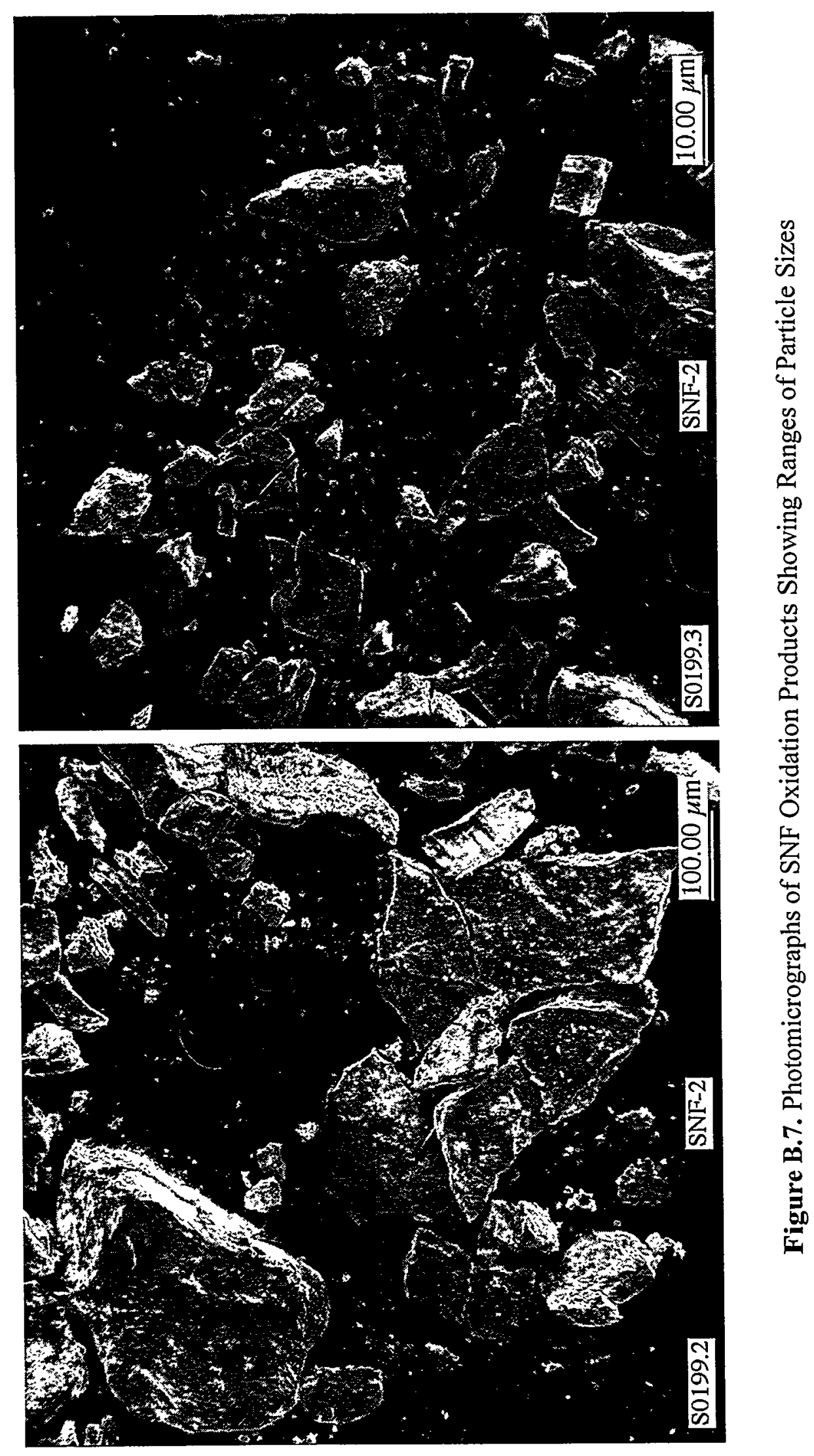

B. 7 

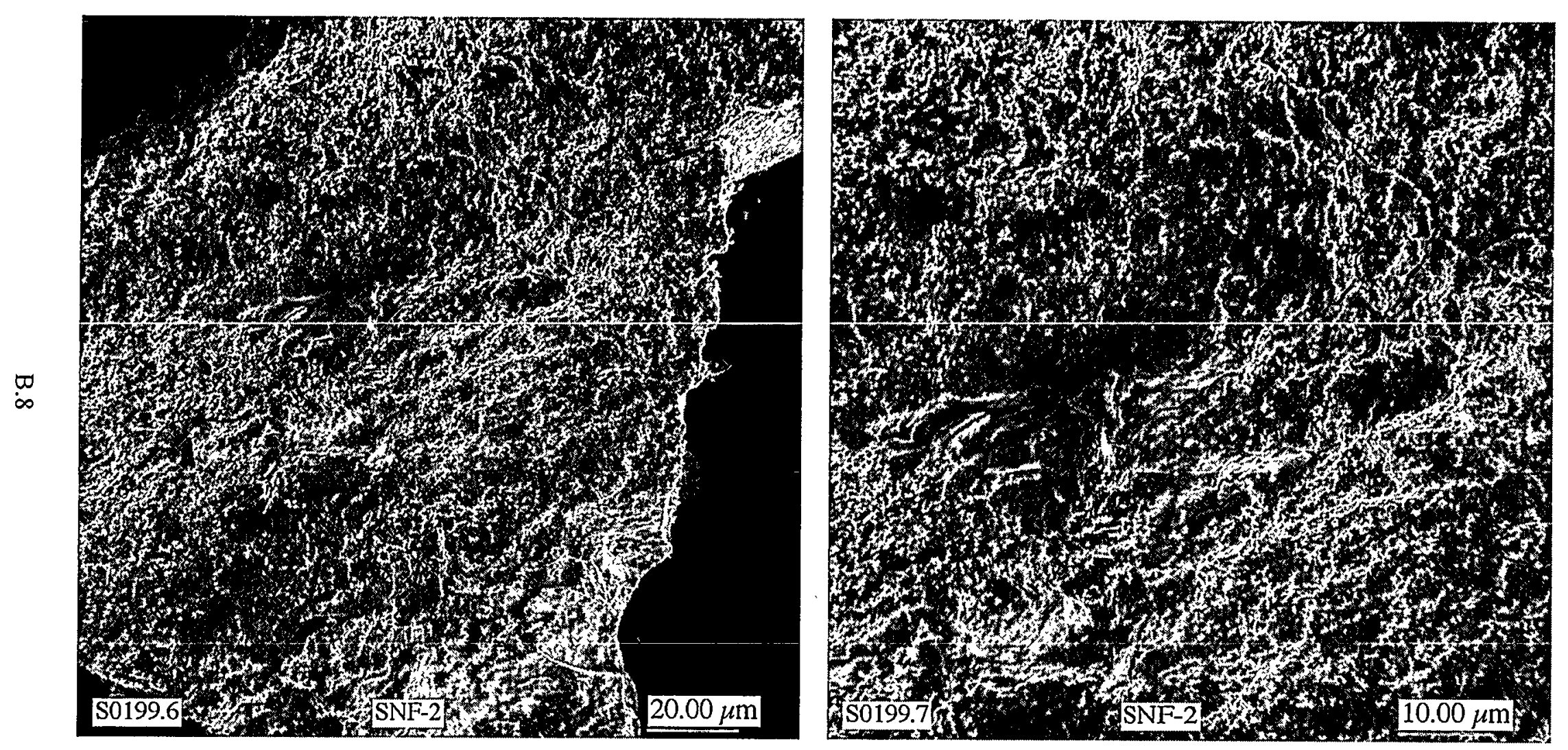

Figure B.8. Photomicrographs of SNF Oxidation Products Showing Some Morphological Features of the Oxide Particles 

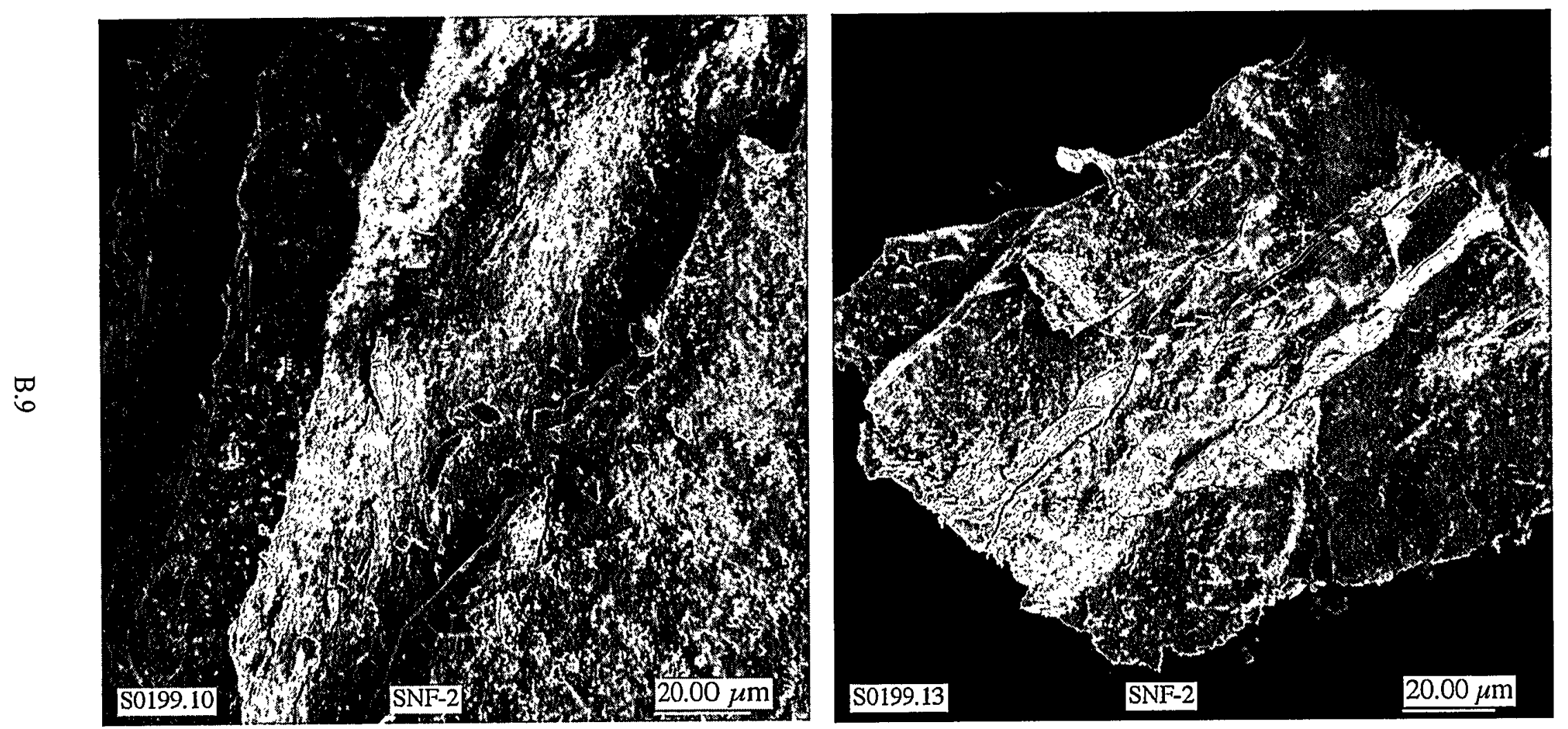

Figure B.9. Photomicrographs of SNF Oxidation Products Showing Transgranular Spallation of the Oxide Scale 


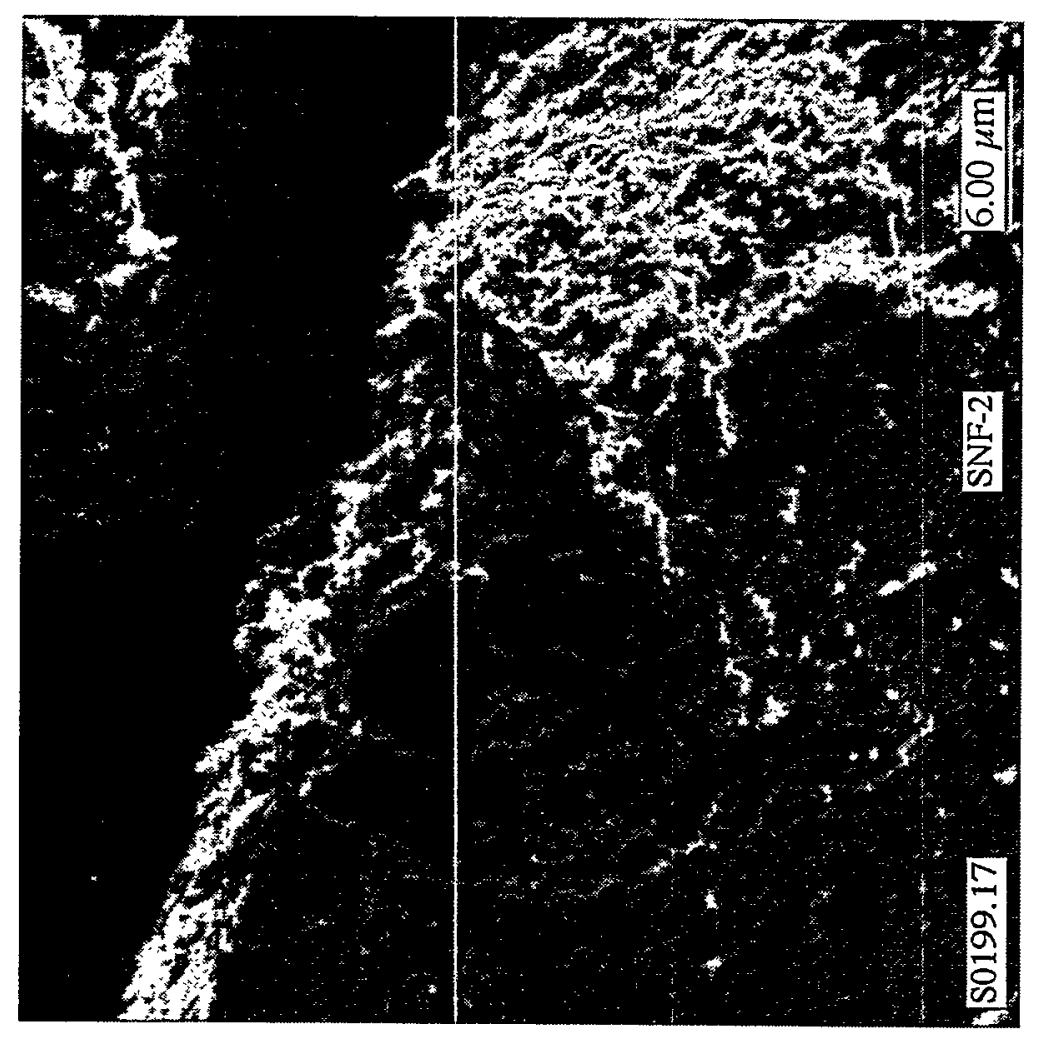

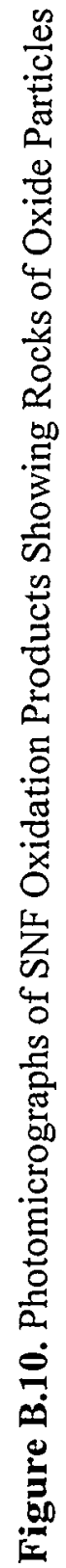

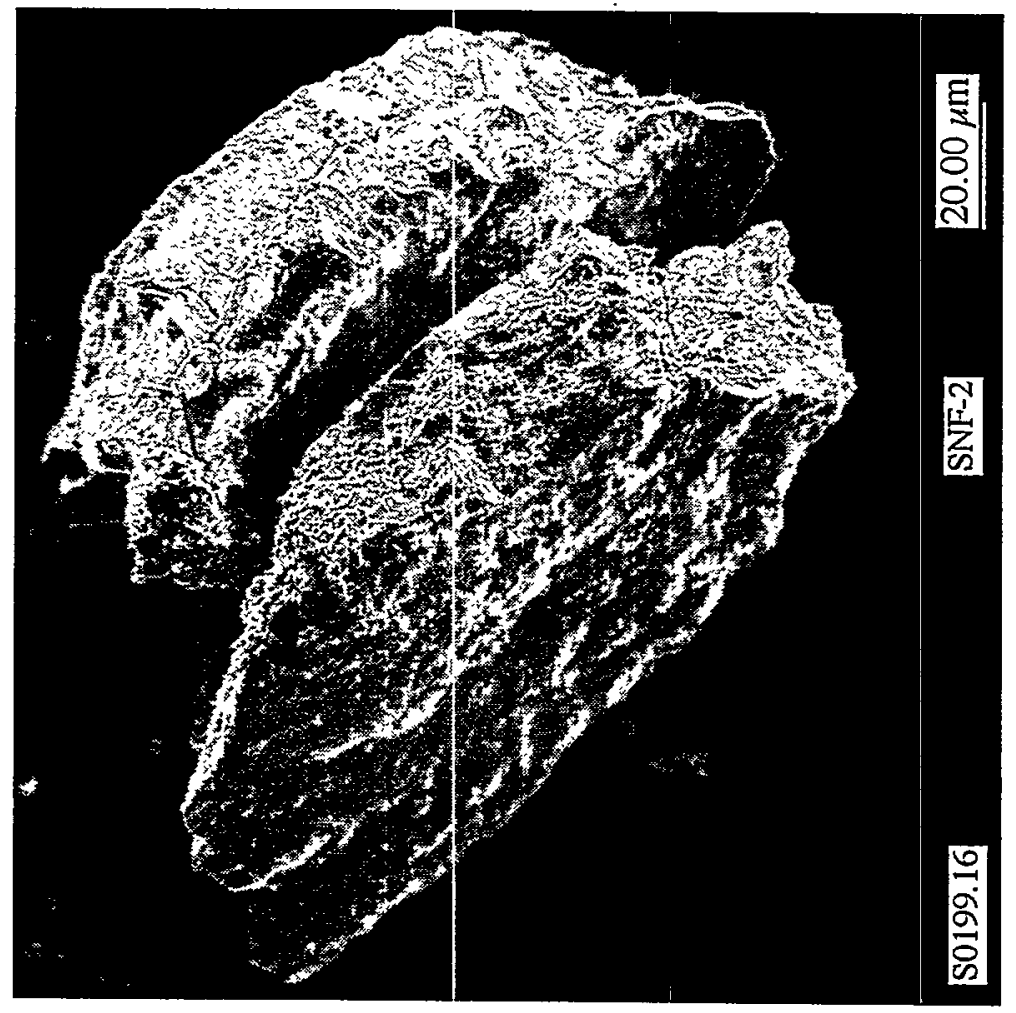




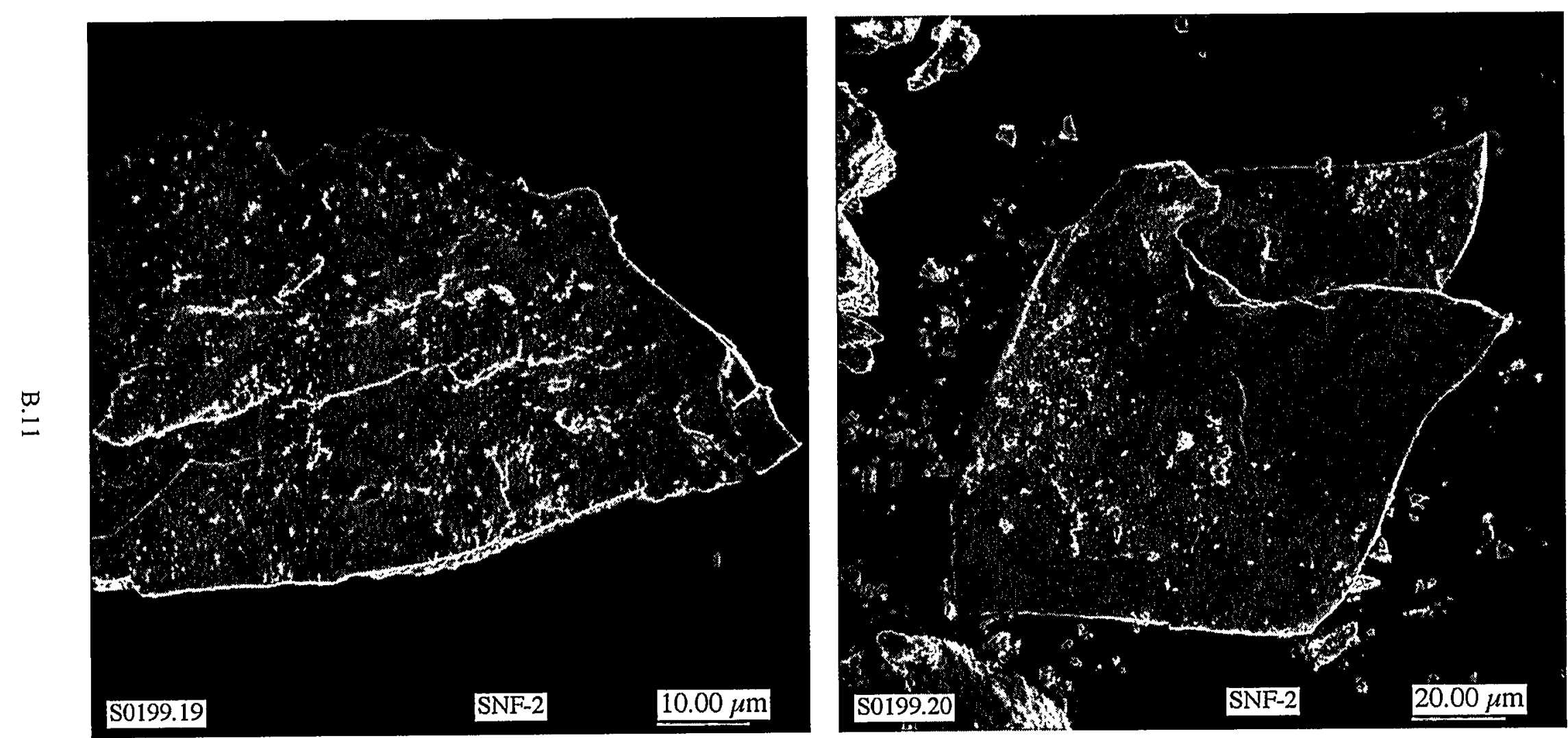

Figure B.11. Photomicrographs of SNF Oxidation Products Showing Sheets of Oxide Particles 


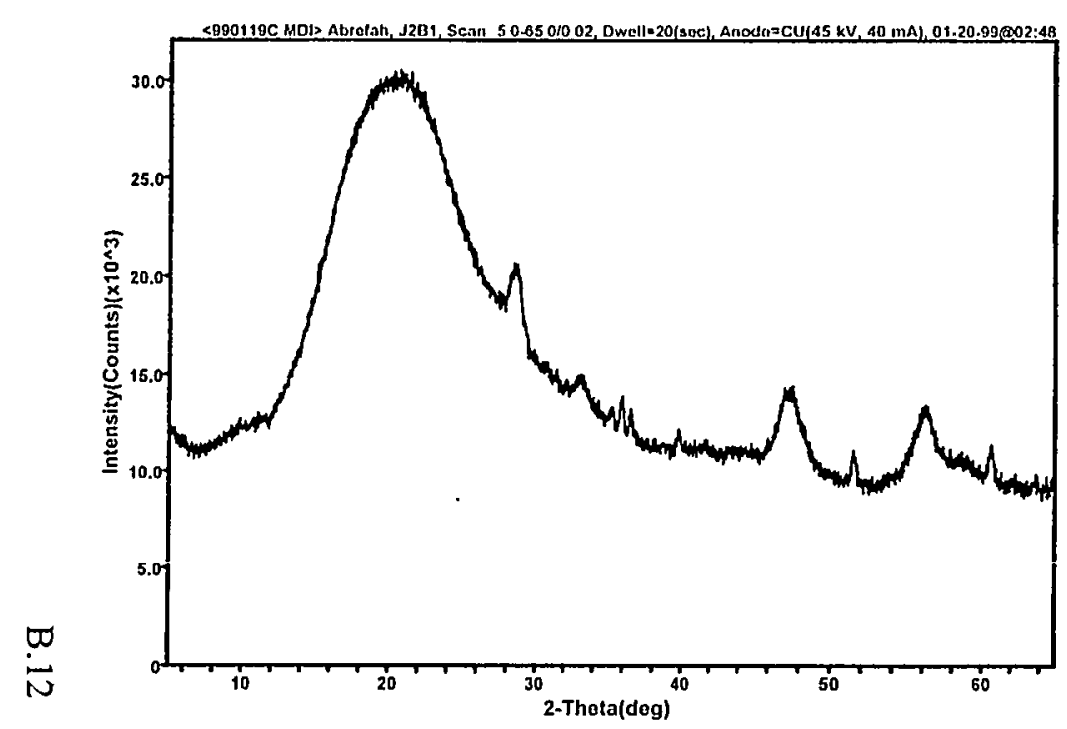

Figure B.12. XRD Spectrum of Disintegrated SNF Sample5-S1A-J2B1 Showing Metallic Uranium Peaks

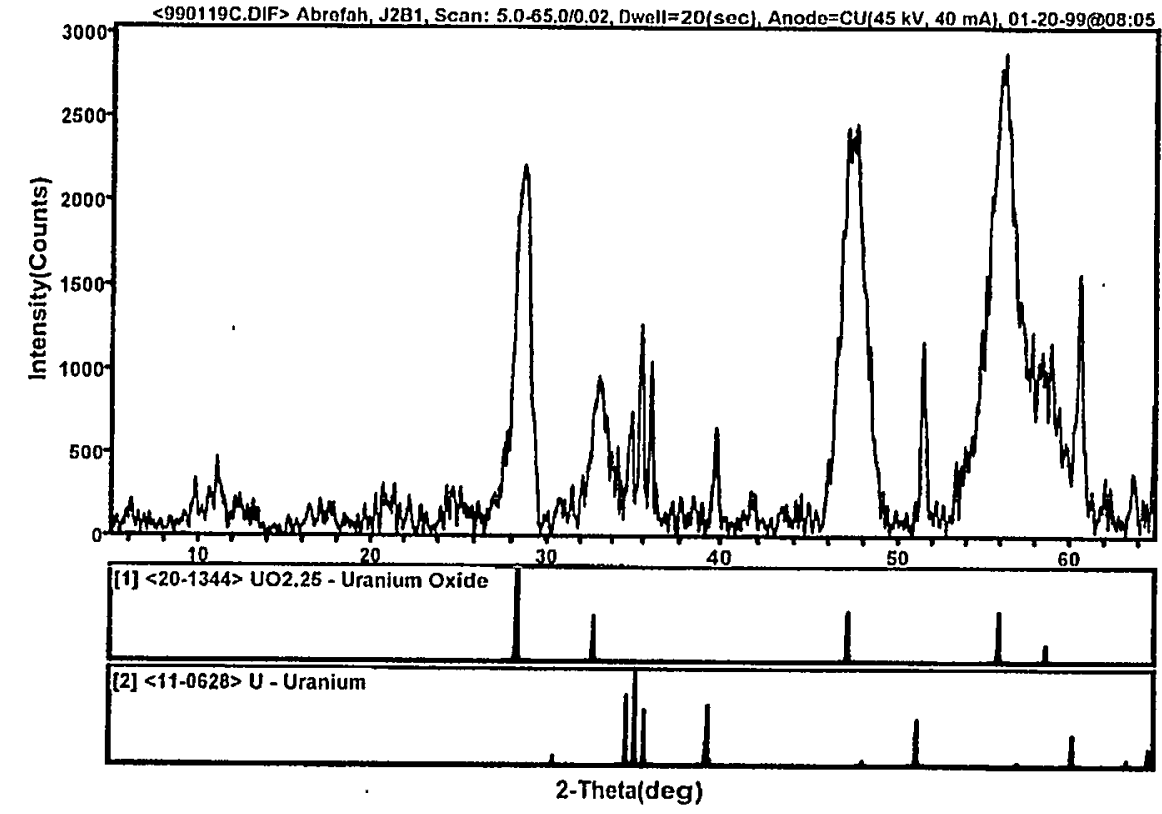

Figure B.13. Background Subtracted XRD Spectrum of the Disintegrated SNF Sample 5-S1A-J2B1.

Stick figures of identified phases are included. 


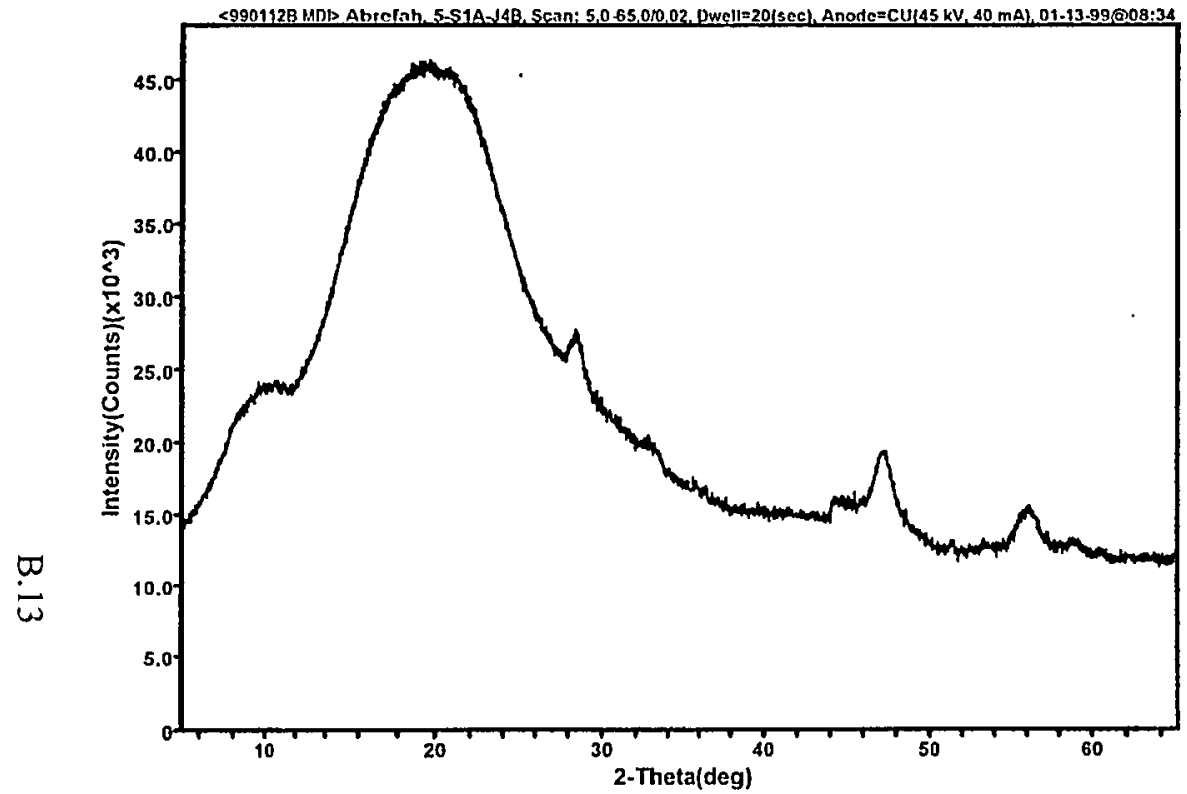

Figure B.14. XRD Spectrum of Disintegrated SNF Sample 5-S1A-J4B Showing Metallic Uranium Peaks

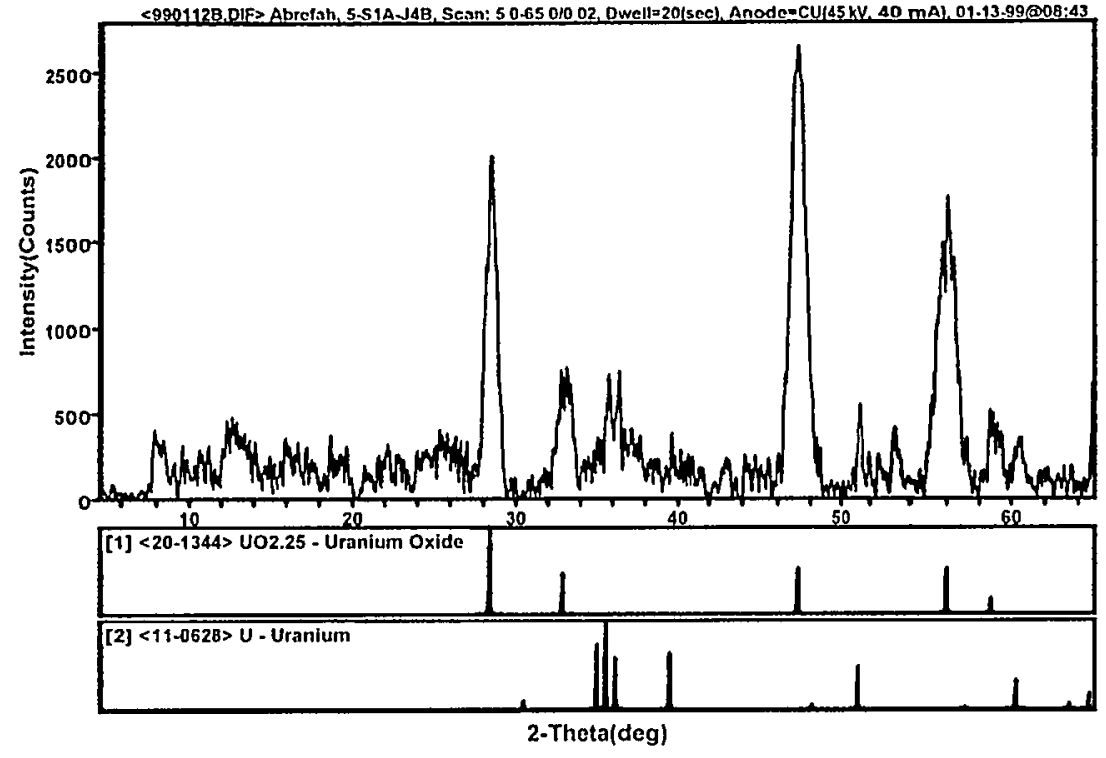

Figure B.15. Background Subtracted XRD Spectrum of Disintegrated SNF Sample 5-S1 A-J4B. Stick figures of identified phases are included. 


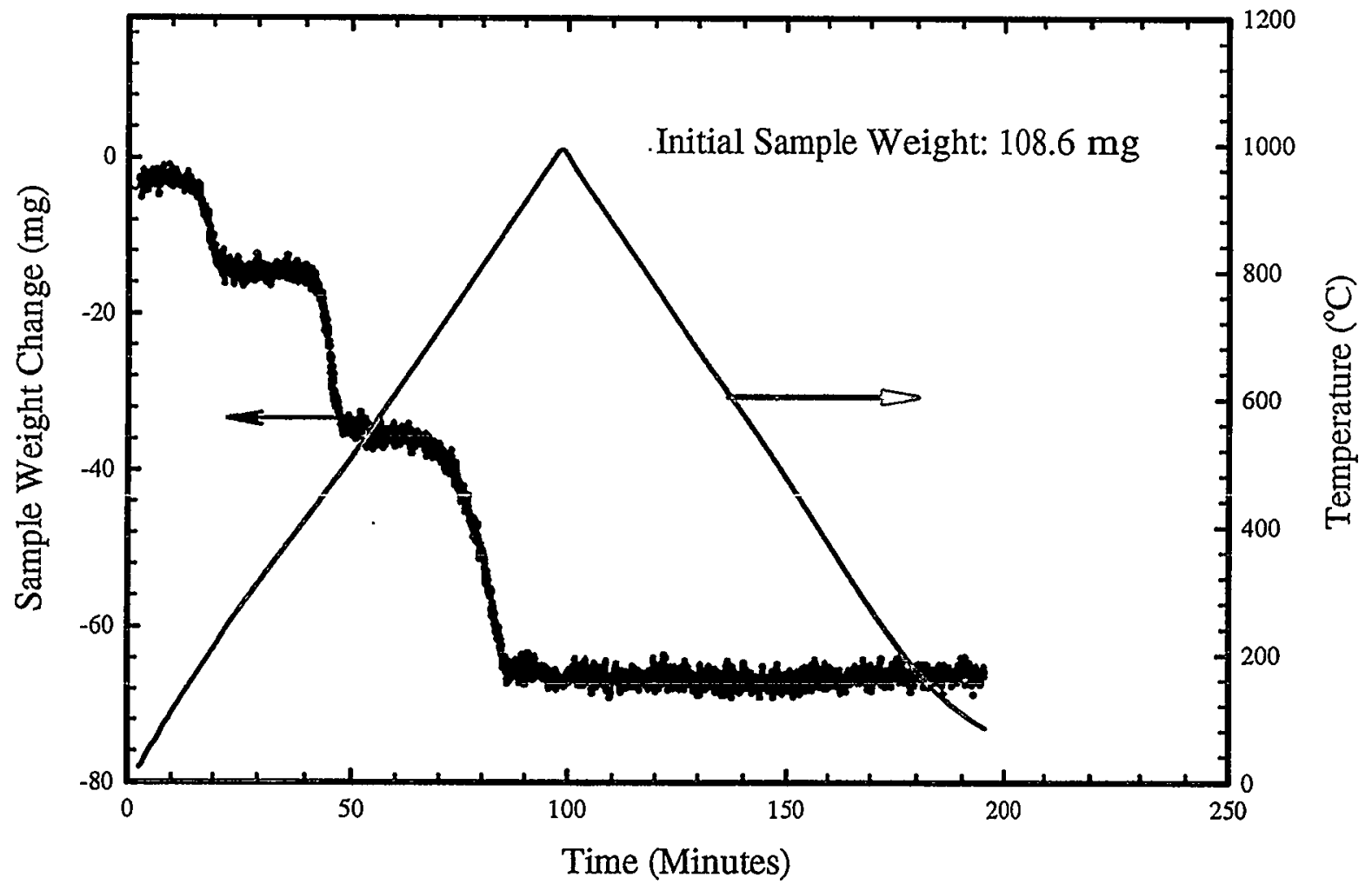

Figure B.16. Drying Results of Calcium Oxalate 


\section{Appendix C}

Statistical Analyses of SNF Oxidation Data 


\title{
Appendix C
}

\section{Statistical Analyses of SNF Oxidation Data}

\author{
Greg Piepel and Sharon Cebula \\ Statistics Resources \\ Pacific Northwest National Laboratory, Richland, WA
}

This report summarizes statistical analyses of data from oxidation of K-West spent nuclear fuel (SNF) in a moist helium environment. Specifically, several Thermogravimetric Analysis (TGA) oxidation tests (defined in terms of temperature, flow rate, and vapor pressure) were performed using K-West SNF samples. The data from these TGA tests were statistically analyzed and compared to unirradiated oxidation rate data from the literature.

\section{C.1 Objectives}

The objectives of the statistical work were to:

1. Estimate, for each TGA test, the unnormalized oxidation rate ( $\mathrm{mg} / \mathrm{min})$ and its uncertainty using weight change $(\mathrm{mg})$ versus time $(\mathrm{min})$ data.

2. Estimate, for each TGA test, the uncertainties in test and sample parameters: temperature $\left({ }^{\circ} \mathrm{C}\right)$, surface area $\left(\mathrm{cm}^{2}\right)$, and vapor pressure $(\mathrm{kPa})$.

3. Propagate, for each TGA test, the uncertainties in unnormalized oxidation rate, surface area, and vapor pressure through the equation

$$
k=r /\left(A \times P^{0.5}\right),
$$

where $k$ is the normalized oxidation rate $\left(\mathrm{mg} / \mathrm{hr} / \mathrm{cm}^{2} / \mathrm{kPa}^{0.5}\right), r$ is the unnormalized oxidation rate $(\mathrm{mg} / \mathrm{min}), A$ is the surface area $\left(\mathrm{cm}^{2}\right)$, and $P$ is the vapor pressure $(\mathrm{kPa})$.

4. Assess whether $\mathrm{K}$-West SNF normalized oxidation rates $k$ are different from literature values.

5. Assess the value of additional TGA tests over a wider temperature range.

Unnormalized oxidation rates (weight gain per unit time) are typically normalized to account for differences in surface area. In this case, they are also normalized with respect to vapor pressure, to allow comparing the oxidation rates of K-West SNF with those from literature data. 
The following sections discuss the statistical work performed to address these objectives.

Specifically, Section C. 2 discusses the estimation of unnormalized oxidation rates and their uncertainties. Section C. 3 discusses the estimation of uncertainties in temperature, vapor pressure, and surface area. Section C.4 presents the error propagation method and results. Section C.5 compares the K-West and literature oxidation rate data, while Section C. 6 assesses the value of performing additional TGA tests over a wider temperature range. Section C.7 provides a brief summary and conclusions of the work.

\section{C.2 Estimating Unnormalized Oxidation Rates for K-West SNF}

Using $\Delta \mathrm{W}=$ weight change $(\mathrm{mg})$ versus $\mathrm{t}=$ time $(\mathrm{min})$ data, "unnormalized" oxidation rates $r$ $(\mathrm{mg} / \mathrm{min})$ and their uncertainties were estimated using least squares regression. Specifically, the linear regression model

$$
\Delta \mathrm{W}=a+r \mathrm{t}
$$

was fit by ordinary (unweighted) least squares regression for all, or various subsets of, the (t, $\Delta \mathrm{W}$ ) data for each TGA test run. The slope coefficient $r$ is the desired estimate of unnormalized oxidation rate $(\mathrm{mg} / \mathrm{min})$. For many of the TGA test runs, it was necessary to truncate a small amount of the early time data corresponding to testing start-up artifacts. In other cases, it was necessary to truncate data beyond a particular time where weight losses (often alternating with periods of weight gain) occurred.

Least squares regression software yields estimates of the coefficients $a$ and $r$ in Eq. C.2, as well as standard deviations of the estimates. Estimates of $r$ and the corresponding standard deviations for each TGA test run are reported in the "Regression of Weight Change vs. Time" portion of Table C.1. The estimates and standard deviations of $a$ are not of interest, and therefore are not reported. Also reported in Table $C .1$ are the $R^{2}$ values for each regression, where $R^{2}$ is a number between 0 and 1 representing the proportion of variation in response values ( $\Delta \mathrm{W}$, in this case) accounted for by the fitted model.

The standard deviations of the $r$ coefficients in Table C. 1 are quite small relative to the $r$ coefficients because of the large number of $(t, \Delta W)$ data points used to fit Eq. C.2 for each TGA run. Also, those standard deviations do not include test sample-to-sample variations or lab-to-lab testing variations. It is expected that these sources of variation will be much larger than the tiny standard deviations of slope $(r)$ estimates for a given regression. One way to estimate these larger sources of variation would be to perform replicate tests (i.e., having the same values of test parameters) on different test samples at different labs. However, no such replicate tests have been performed as part of the TGA testing with the same parameters even though similar experiments were done.

One alternative for obtaining a better estimate of uncertainty in the unnormalized oxidation rate $r$ for a given test sample is to make use of localized time periods of $(t, \Delta \mathrm{W})$ data where the test sample gained weight. Several of the tests showed periods of weight loss (or decreased weight gain), followed by periods of weight gain. Using such localized weight gain data to estimate oxidation rates may be somewhat questionable because of preceding periods of weight loss or slowed weight gain. However, plots of the data showed that such localized areas of weight gain often had slopes (oxidation rates) similar 
Table C-1. Statistical Results for Oxidation Tests of K-West SNF in Moist Helium

\begin{tabular}{|c|c|c|c|c|c|c|c|c|}
\hline \multirow[b]{2}{*}{$\begin{array}{l}\text { TGA } \\
\text { Run } \\
\end{array}$} & \multirow[b]{2}{*}{$\begin{array}{c}A \\
\left(\mathrm{~cm}^{2}\right)\end{array}$} & \multicolumn{2}{|c|}{ Test Parameters } & \multicolumn{2}{|c|}{$\begin{array}{c}\text { Regression of } \\
\text { Weight Change vs. Time }\end{array}$} & \multirow[b]{2}{*}{$\begin{array}{c}\text { Oxidation } \\
\text { Rate } \\
\text { (Slope/A) } \\
\left(\mathrm{mg} / \mathrm{hr} / \mathrm{cm}^{2}\right) \\
\end{array}$} & \multirow[b]{2}{*}{$\begin{array}{c}\text { Oxidation } \\
\text { Rate/(P) } \\
(\mathbf{m g} / \mathrm{hr} / \\
\left.\mathrm{cm}^{2} / \mathrm{kPa}^{0.5}\right)\end{array}$} & \multirow[b]{2}{*}{$\begin{array}{c}\text { Time Range of } \\
\text { Data Used } \\
\text { (min - min) }\end{array}$} \\
\hline & & $\begin{array}{c}\text { Temp. } \\
\text { Mean } \pm \text { SD }\left({ }^{\circ} \mathrm{C}\right)\end{array}$ & $\begin{array}{c}\text { Vapor Press. } \\
\text { Mean } \pm \mathrm{SD}^{(\mathrm{b})} \\
(\mathrm{KPa})\end{array}$ & $\begin{array}{c}\text { Slope } \pm \text { SD } \\
(\mathrm{mg} / \mathrm{min}) \\
\times 10^{-6}\end{array}$ & $\mathrm{R}^{2}$ & & & \\
\hline 80 & 1.24 & $161.04 \pm 0.33^{(a)}$ & $5.58 \pm 0.16$ & $12726.8 \pm 42.1$ & 0.970 & 0.6158 & 0.2607 & $13-2729$ \\
\hline 81 & 1.59 & $\begin{array}{l}160.65 \pm 0.05 \\
161.30 \pm 0.09 \\
160.86 \pm 0.14\end{array}$ & $7.37 \pm 0.16$ & $\begin{array}{c}13879.6 \pm 36.3 \\
12605.7 \pm 67.3 \\
11094.4 \pm 129.5\end{array}$ & $\begin{array}{l}0.998 \\
0.995 \\
0.983\end{array}$ & $\begin{array}{l}0.5238 \\
0.4757 \\
0.4187\end{array}$ & $\begin{array}{l}0.1929 \\
0.1752 \\
0.1542\end{array}$ & $\begin{array}{c}56-279 \\
1000-1175 \\
1275-1400\end{array}$ \\
\hline 82 & 1.94 & $160.45 \pm 0.18^{(a)}$ & $5.76 \pm 0.45$ & $13800.6 \pm 9.0$ & 0.999 & 0.4268 & 0.1778 & $9-2712$ \\
\hline 83 & 1.08 & $\begin{array}{c}100.13 \pm 0.25 \\
100.01 \pm 0.33 \\
99.41 \pm 0.16\end{array}$ & $5.7^{(\mathrm{c})}$ & $\begin{array}{l}1306.6 \pm 7.3 \\
1753.7 \pm 6.6 \\
948.4 \pm 2.4\end{array}$ & $\begin{array}{l}0.981 \\
0.996 \\
0.997\end{array}$ & $\begin{array}{l}0.0726 \\
0.0974 \\
0.0527\end{array}$ & $\begin{array}{l}0.0304 \\
0.0408 \\
0.0221\end{array}$ & $\begin{array}{c}58-672 \\
58-325 \\
1700-2200\end{array}$ \\
\hline 84 & 1.16 & $\begin{array}{l}98.96 \pm 0.11 \\
98.99 \pm 0.10 \\
98.76 \pm 0.22\end{array}$ & $5.58 \pm 0.28$ & $\begin{array}{c}921.9 \pm 7.6 \\
1099.3 \pm 5.0 \\
1226.2 \pm 5.8\end{array}$ & $\begin{array}{l}0.972 \\
0.994 \\
0.988\end{array}$ & $\begin{array}{l}0.0477 \\
0.0569 \\
0.0634\end{array}$ & $\begin{array}{l}0.0202 \\
0.0241 \\
0.0268\end{array}$ & $\begin{array}{c}103-526 \\
103-400 \\
1200-1750\end{array}$ \\
\hline 85 & 2.04 & $\begin{array}{l}98.17 \pm 0.25 \\
98.37 \pm 0.22 \\
98.00 \pm 0.07 \\
98.19 \pm 0.18 \\
98.52 \pm 0.30\end{array}$ & $5.91 \pm 0.22$ & $\begin{array}{c}376.6 \pm 2.3 \\
3608.7 \pm 75.5 \\
447.4 \pm 2.4 \\
757.3 \pm 3.0 \\
1224.7 \pm 6.6\end{array}$ & $\begin{array}{l}0.905 \\
0.922 \\
0.986 \\
0.986 \\
0.991\end{array}$ & $\begin{array}{l}0.0111 \\
0.1061 \\
0.0132 \\
0.0223 \\
0.0360\end{array}$ & $\begin{array}{l}0.0046 \\
0.0437 \\
0.0054 \\
0.0092 \\
0.0148\end{array}$ & $\begin{array}{c}26-2952 \\
26-220 \\
500-1000 \\
1100-2000 \\
2650-2952\end{array}$ \\
\hline 86 & 1.94 & $\begin{array}{l}132.75 \pm 0.11 \\
132.73 \pm 0.04\end{array}$ & $6.10 \pm 0.70$ & $\begin{array}{c}2416.9 \pm 4.8 \\
1585.4 \pm 15.1\end{array}$ & $\begin{array}{l}0.997 \\
0.978\end{array}$ & $\begin{array}{l}0.0747 \\
0.0490\end{array}$ & $\begin{array}{l}0.0303 \\
0.0199\end{array}$ & $\begin{array}{c}91-830 \\
1515-1760\end{array}$ \\
\hline 88 & 1.51 & $\begin{array}{l}162.01 \pm 0.14 \\
162.33 \pm 0.10 \\
162.31 \pm 0.07\end{array}$ & $7.49 \pm 0.19$ & $\begin{array}{l}6635.7 \pm 52.1 \\
3821.3 \pm 28.5 \\
4835.8 \pm 42.3\end{array}$ & $\begin{array}{l}0.985 \\
0.993 \\
0.991 \\
\end{array}$ & $\begin{array}{l}0.2637 \\
0.1518 \\
0.1922 \\
\end{array}$ & $\begin{array}{l}0.0963 \\
0.0555 \\
0.0702 \\
\end{array}$ & $\begin{array}{c}47-295 \\
700-820 \\
1190-1310 \\
\end{array}$ \\
\hline 89 & 1.55 & $\begin{array}{c}163.22 \pm 0.38^{(a)} \\
162.30 \pm 0.83 \\
162.32 \pm 0.65\end{array}$ & $7.40 \pm 0.36$ & $\begin{array}{c}4682.0 \pm 3.4 \\
5885.8 \pm 37.6 \\
4988.1 \pm 31.4\end{array}$ & $\begin{array}{l}0.999 \\
0.991 \\
0.985\end{array}$ & $\begin{array}{l}0.18 \overline{12} \\
0.2278 \\
0.1931\end{array}$ & $\begin{array}{l}0.0666 \\
0.0838 \\
0.0710\end{array}$ & $\begin{array}{c}23-2717 \\
23-250 \\
23-400\end{array}$ \\
\hline 91 & 1.46 & $\begin{array}{l}134.12 \pm 0.13 \\
134.12 \pm 0.14 \\
134.28 \pm 0.10 \\
134.07 \pm 0.11\end{array}$ & $7.27 \pm 0.25$ & $\begin{array}{l}1564.0 \pm 6.8 \\
1706.3 \pm 6.8 \\
2949.5 \pm 5.8 \\
1497.2 \pm 2.5\end{array}$ & $\begin{array}{l}0.974 \\
0.982 \\
0.999 \\
0.997\end{array}$ & $\begin{array}{l}0.0643 \\
0.0701 \\
0.1212 \\
0.0615\end{array}$ & $\begin{array}{l}0.0238 \\
0.0260 \\
0.0450 \\
0.0228\end{array}$ & $\begin{array}{c}39-1452 \\
39-1200 \\
39-300 \\
300-1200\end{array}$ \\
\hline 92 & 1.48 & $\begin{array}{l}105.29 \pm 0.14 \\
105.43 \pm 0.17 \\
105.35 \pm 0.08 \\
105.34 \pm 0.16\end{array}$ & $7.26 \pm 0.18$ & $\begin{array}{c}557.9 \pm 2.0 \\
1997.0 \pm 16.0 \\
764.4 \pm 1.2 \\
920.0 \pm 3.3\end{array}$ & $\begin{array}{l}0.966 \\
0.987 \\
0.998 \\
0.992\end{array}$ & $\begin{array}{l}0.0226 \\
0.0810 \\
0.0310 \\
0.0373\end{array}$ & $\begin{array}{l}0.0084 \\
0.0300 \\
0.0115 \\
0.0138\end{array}$ & $\begin{array}{c}43-2892 \\
43-250 \\
250-1000 \\
1800-2450\end{array}$ \\
\hline$\overline{93}$ & 1.68 & $\begin{array}{l}75.68 \pm 0.08 \\
75.68 \pm 0.07 \\
75.68 \pm 0.08 \\
75.60 \pm 0.06\end{array}$ & $7.18 \pm 0.19$ & $\begin{array}{l}377.5 \pm 2.3 \\
352.1 \pm 1.7 \\
502.0 \pm 4.9 \\
277.9 \pm 1.7\end{array}$ & $\begin{array}{l}0.971 \\
0.983 \\
0.956 \\
0.977\end{array}$ & $\begin{array}{l}0.0135 \\
0.0126 \\
0.0179 \\
0.0099\end{array}$ & $\begin{array}{l}0.0050 \\
0.0047 \\
0.0067 \\
0.0037\end{array}$ & $\begin{array}{c}180-1010 \\
206-961 \\
1150-1990 \\
4580-5230\end{array}$ \\
\hline 94 & 1.70 & $\begin{array}{l}77.26 \pm 0.37 \\
77.75 \pm 0.06 \\
77.09 \pm 0.13\end{array}$ & $6.59 \pm 0.18$ & $\begin{array}{l}294.5 \pm 1.3 \\
616.1 \pm 2.0 \\
473.6 \pm 1.5\end{array}$ & $\begin{array}{l}0.923 \\
0.996 \\
0.985 \\
\end{array}$ & $\begin{array}{l}0.0104 \\
0.0217 \\
0.0167 \\
\end{array}$ & $\begin{array}{l}0.0040 \\
0.0085 \\
0.0065 \\
\end{array}$ & $\begin{array}{l}2897-8667 \\
3500-4000 \\
5000-7000 \\
\end{array}$ \\
\hline 95 & 1.79 & $\begin{array}{l}77.71 \pm 0.21 \\
77.97 \pm 0.12 \\
77.83 \pm 0.21 \\
77.69 \pm 0.08\end{array}$ & $6.38 \pm 0.25$ & $\begin{array}{c}272.0 \pm 1.4 \\
2130.4 \pm 17.1 \\
2176.6 \pm 32.6 \\
452.7 \pm 1.0\end{array}$ & $\begin{array}{l}0.898 \\
0.986 \\
0.968 \\
0.994 \\
\end{array}$ & $\begin{array}{l}0.0091 \\
0.0714 \\
0.0730 \\
0.0152 \\
\end{array}$ & $\begin{array}{l}0.0036 \\
0.0283 \\
0.0289 \\
0.0060 \\
\end{array}$ & $\begin{array}{l}2897-8667 \\
4150-4450 \\
5700-5900 \\
6150-7950 \\
\end{array}$ \\
\hline
\end{tabular}


Table C-1. (Contd)

\begin{tabular}{|c|c|c|c|c|c|c|c|c|}
\hline \multirow[b]{2}{*}{$\begin{array}{l}\text { TGA } \\
\text { Run }\end{array}$} & \multirow[b]{2}{*}{$\begin{array}{c}\mathrm{A} \\
\left(\mathrm{cm}^{2}\right)\end{array}$} & \multicolumn{2}{|c|}{ Test Parameters } & \multicolumn{2}{|c|}{$\begin{array}{c}\text { Regression of } \\
\text { Weight Change vs. Time }\end{array}$} & \multirow{2}{*}{$\begin{array}{c}\text { Oxidation } \\
\text { Rate } \\
\text { (Slope/A) } \\
\left.\text { (mg/hr/cm }{ }^{2}\right) \\
\end{array}$} & \multirow{2}{*}{$\begin{array}{c}\text { Oxidation } \\
\text { Rate } /(\mathbf{P})^{0.5} \\
(\mathrm{mg} / \mathrm{hr} / \\
\left.\mathrm{cm}^{2} / \mathrm{kPa}^{0.5}\right)\end{array}$} & \multirow[b]{2}{*}{$\begin{array}{c}\text { Time Range of } \\
\text { Data Used } \\
\text { (min - min) }\end{array}$} \\
\hline & & $\begin{array}{c}\text { Temp. } \\
\text { Mean } \pm \mathrm{SD}\left({ }^{\circ} \mathrm{C}\right)\end{array}$ & $\begin{array}{l}\text { Vapor Press. } \\
{\text { Mean } \pm \mathrm{SD}^{(\mathrm{b})}}^{(\mathrm{KPa})}\end{array}$ & $\begin{array}{c}\text { Slope } \pm \text { SD } \\
(\mathrm{mg} / \mathrm{min}) \\
\times 10^{-6}\end{array}$ & $\mathbf{R}^{2}$ & & & \\
\hline 96 & 1.79 & $210.66 \pm 2.23$ & $7.15 \pm 0.15$ & $27044.1 \pm 33.8$ & 0.999 & 0.9065 & 0.3390 & $18-498$ \\
\hline 97 & 1.11 & $211.40=0.9 I$ & $7.15 \pm 0.26$ & $15585.9 \pm 37.0$ & 0.997 & 0.8425 & 0.3151 & $24-498$ \\
\hline 98 & 1.18 & $128.80 \pm 0.69$ & $6.86 \pm 0.18$ & $2251.2 \pm 2.7$ & 0.996 & 0.1145 & 0.0437 & I I -2894 \\
\hline \multicolumn{9}{|c|}{$\begin{array}{l}\text { (a) Temperature ramps at the start or end of test runs were truncated prior to computing means and standard deviations. } \\
\text { (b) Vapor pressure ramps at the start (or in one case. the end) of test runs were truncated before computing means and standard deviations. The } \\
\text { time ranges of data used may not match those used for computing means and standard deviations for temperature. or for the regressions of } \\
\text { weight change versus time. } \\
\text { (c) Vapor pressure data for this test were not provided, so the mean and standard deviation could not be calculated. The value reported is the } \\
\text { one provided with the data. }\end{array}$} \\
\hline
\end{tabular}

to slopes for initial portions of the data used for the primary determination of oxidation rate. Hence, using localized areas of weight gain data provides for multiple estimates of oxidation rate for a given test sample, which therefore provides for an estimate of uncertainty of oxidation rate for a given test sample. Such an estimate of uncertainty will not include test sample-to-sample variations or lab-to-lab testing variations. Still, such an estimate of oxidation rate uncertainty should be better than the very small standard deviation of the slope resulting from a regression of weight gain versus time.

Table C.1 reports the multiple estimates of unnormalized oxidation rate for those TGA test runs with multiple localized weight gain periods (i.e., TGA $81,83,84,85,86,88,89,91,92,93,94$, and 95). Other test runs (TGA 82, 96,97, and 98) had consistent linear trends between weight gain and time over substantially the whole test period, so only one estimate of unnormalized oxidation rate is given in Table C. 1 for those runs. For each TGA run, the unnormalized oxidation rate $r$ (slope, $\mathrm{mg} / \mathrm{min}$ ) listed first in Table C.1 is the one corresponding to the largest time period of data deemed reasonable for estimating oxidation rate. Oxidation rates $r$ listed second, third, ... are based on subsets of the initial time period in some cases, or on later subsets in other cases. The "Time Range of Data Used" column in Table C. 1 reports the time ranges (in minutes) of data used to estimate each oxidation rate (slope) via least squares regression.

The multiple unnormalized oxidation rates $r$ for a given TGA test in Table C.1 cannot be considered as resulting from independent random sampling of oxidation rate periods. Still, for TGA tests for which multiple values were available, the multiple values were used to compute standard deviations for each TGA test. These standard deviations were then "pooled" to yield a common estimate of uncertainty in 
oxidation rates across the TGA tests. ${ }^{1}$ Because the unnormalized oxidation rates $r$ span almost two orders of magnitude, standard deviations were computed after taking the natural logarithm (ln) of each $r{ }^{2}$ The standard deviation estimates of $\ln (r)$ for individual TGA runs ranged from 0.11 to 0.54 , excluding TGA 85 (with 0.91) and TGA 95 (with 1.07). Excluding the TGA 85 and 95 standard deviations, the pooled standard deviation of $\ln (r)$ was $0.31 \mathrm{ln}(\mathrm{mg} / \mathrm{min})$, which may also be expressed as $0.31 \mathrm{ln}(\mathrm{mg} / \mathrm{hr}){ }^{3}{ }^{3} \mathrm{This}$ value was deemed appropriate as an estimate of uncertainty in unnormalized oxidation rates for TGA tests $80,81,83,84,86,88,89,91,92,93$, and 94 . As mentioned earlier, TGA runs $82,96,97$, and 98 had only one estimate each of unnormalized oxidation rate, and hence there was no basis for computing a standard deviation of $\ln (r)$ for these runs. It was decided to use $0.12 \ln (\mathrm{mg} / \mathrm{hr})$ as the estimate of the uncertainty of $\ln (r)$ for these runs, because the three smallest standard deviations for the TGA runs with multiple determinations of $r$ had standard deviations close to 0.12 . Although the basis for this value is very limited, it is at least consistent with the expectation that there should be less uncertainty for TGA tests with essentially straight weight gain versus time relationships. Finally, a standard deviation of $1.00 \mathrm{ln}(\mathrm{mg} / \mathrm{min})$ was chosen to represent the uncertainties of the TGA 85 and 95 runs. The $0.31,0.12$, and $1.00 \ln (\mathrm{mg} / \mathrm{min})$ values discussed above are used for the error propagation work in Section C.4.

An advantage of using the natural logarithm transformation is the approximate relationship

$$
\mathrm{SD}[\ln (\mathrm{y})] \cong \mathrm{RSD}(\mathrm{y})
$$

where $\mathrm{y}=\mathrm{a}$ random variable, $\mathrm{SD}=$ standard deviation, and $\mathrm{RSD}=$ relative standard deviation. Hence, the pooled $\mathrm{SD}[\ln (r)]=0.31$ may be interpreted as the unnormalized oxidation rate $r$ having a RSD of 0.31 , or a percent relative standard deviation (\%RSD) of $31 \%$. The $\mathrm{SD}[\ln (r)]$ values of 1.00 for TGA 85 and 95 , and 0.12 for TGA $82,96,97$, and 98 , may be interpreted as $\%$ RSDs of $100 \%$ and $12 \%$, respectively. Hence, there is a considerable range of estimated uncertainties in the TGA unnormalized oxidation rates $r$.

\footnotetext{
' The only purpose of estimating the standard deviation of unnormalized oxidation rate for each TGA run and pooling the estimates is to provide direction for selecting the middle of three variance values to propagate in the error propagation work discussed in Section C.4. Hence, it is not of concern that the usual assumptions of independent random samples for computing sample statistics (such as mean and standard deviation) may not be completely appropriate.

${ }^{2}$ The natural log transformation is commonly applied in statistics to homogenize standard deviations in cases where uncertainties tend to increase as the magnitude of a variable increases.

${ }^{3}$ The standard deviation of $\ln (r)$ is the same regardless of whether $\mathrm{r}$ is expressed in $\mathrm{mg} / \mathrm{min}$ or $\mathrm{mg} / \mathrm{hr}$ units. This is because the units conversion factor is multiplicative, which becomes additive after the natural log transformation. Standard deviations are not affected by the addition of a constant to random variables.
} 
A final alternative for estimating uncertainties in oxidation rates is to use literature data containing replicate tests, and assume the uncertainties for such data also apply to the TGA runs. This alternative provides for capturing test sample-to-sample and lab-to-lab variations. This alternative is discussed in Section C.5.1, which addresses the literature data.

\section{C.3 Uncertainties in Temperature, Vapor Pressure, and Surface Area}

During TGA tests, temperature and vapor pressure were monitored essentially continuously. The data were used to estimate the means and standard deviations of temperature and vapor pressure for each TGA test. For many of the test runs, it was necessary to remove temperature and vapor pressure "ramps" at the beginning or end of the test runs. These "ramps" are an inherent part of test start-up and shutdown, but should not be used to characterize the mean and standard deviations during the bulk of the test. In the case of temperature, means and standard deviations were calculated for the various time periods of data used to estimate local weight gain slopes (unnormalized oxidation rates $r$ ), as discussed in Section C.2. The means and standard deviations for temperature and vapor pressure are reported in Table C.1.

The temperature means reported in Table C.1 range from roughly 76 to $211^{\circ} \mathrm{C}$. The temperature standard deviations range from 0.05 to $0.83^{\circ} \mathrm{C}$, except for a standard deviation of $2.23^{\circ} \mathrm{C}$ for TGA run 96 . Hence, variations in temperature over the course of a test were relatively small. Of course, these estimates of uncertainty only address precision and not accuracy. Accuracy of the measured temperatures cannot be addressed using the data provided.

The vapor pressure means reported in Table $\mathrm{C} .1$ range from roughly 5.6 to $7.5 \mathrm{kPa}$, while the standard deviations range from 0.16 to $0.70 \mathrm{kPa}$. There is no evidence the standard deviation is related to the magnitude of vapor pressure. Hence, the separate estimates of vapor pressure standard deviation for each TGA test were pooled to obtain a combined "average" estimate of uncertainty. This was done by simply averaging the variances (squared standard deviations) for the TGA runs. ${ }^{1}$ The resulting vapor pressure pooled standard deviation was $0.294 \mathrm{kPa}$. This value is referred to in Section C.4.

Surface areas of TGA test samples were calculated using dimensional measurements. The dimensional measurements are subject to very little uncertainty, possibly only 1 mil per dimension (i.e., length, width, and height). If only these very small dimensional measurement uncertainties are considered, the uncertainty in surface area is essentially negligible. Based on irregularities in dimensional shapes, John Abrefah estimated the uncertainty in surface area to range from 1 to $10 \%$. This range is considered to be a range of \% RSD values in Section C. 4 .

1 Because of the large number of data points used to compute vapor pressure standard deviations, it was decided not to use the very large numbers of degrees of freedom to pool the separate standard deviations (as is usually done). The pooled standard deviation estimate was only used as guidance for selecting a range of vapor pressure standard deviations to use for error propagation. 


\section{C.4 Error (Variance) Propagation}

Error propagation methods (sometimes called variance propagation methods) provide for calculating the approximate variance of a function of variables, which are each subject to error (uncertainty). Error propagation methods were applied to propagate uncertainties in unnormalized oxidation rate $(r)$, surface area (A), and vapor pressure (P) through Eq. C.1 to get a combined variance (and standard deviation) of the normalized oxidation rate $k$ for each TGA run. Actually, because of the wide range of $k$ values for the TGA tests, variances and standard deviations of $\ln (k)$ were obtained via error propagation. The first-order error propagation formula

$$
\operatorname{Var}[\ln (k)]=\operatorname{Var}[\ln (r)]+[\operatorname{RSD}(A)]^{2}+\left(1 / 4 P^{2}\right) * \operatorname{Var}(P),
$$

is based on a first-order Taylor-series expansion of Eq. C.1 after a natural logarithm transformation of both sides. The variance terms $\operatorname{Var}[\ln (\mathrm{r})],[\mathrm{RSD}(\mathrm{A})]^{2}$, and $\operatorname{Var}(\mathrm{P})$ in Eq. C.4 represent estimates of uncertainty for $r, A$, and $P$, respectively. Three estimates of uncertainty were used for each of these terms in order to provide a range of estimated variances (and standard deviations). The following paragraphs describe how the three estimates of uncertainty for each variable were obtained.

As mentioned in Section C.2, the $0.31 \mathrm{ln}(\mathrm{mg} / \mathrm{min})$ pooled standard deviation estimate of uncertainty in $\ln (r)$ was deemed applicable to TGA tests $80,81,83,84,86,88,89,91,92,93$, and 94 . For these tests, the estimates $0.15,0.30$, and 0.60 for $S D[\ln (r)]$ were used in the error propagation. The 0.15 value represents approximately one-half of the pooled standard deviation, while 0.60 represents approximately twice this value. These three values span the range of separate estimates of uncertainty seen in the KWest SNF data for TGA tests 81, 83, 84, 86, 88, 89, 91, 92, 93, and 94. As discussed in Section C.2, the standard deviation estimate of uncertainty in $\ln (r)$ was $0.12 \ln (\mathrm{mg} / \mathrm{hr})$ for TGA runs $82,96,97$, and 98 . This led to the choice of estimates $0.06,0.12$, and 0.24 for $S D[\ln (r)]$ to be used in the error propagation for TGA runs 82, 96, 97, and 98. For TGA runs 85 and 95 , the estimates $0.5,1.0$, and 1.5 for $S D[\ln (r)]$ were used in the error propagation.

As mentioned in Section C.3, the combined (across TGA runs) vapor pressure standard deviation was $0.294 \mathrm{kPa}$. The standard deviations of the individual test runs ranged from 0.15 to $0.70 \mathrm{kPa}$. Based on this observation, values of approximately one-half and triple the combined standard deviation were used to cover this range. The vapor pressure standard deviation estimates $0.15,0.3$, and $0.9 \mathrm{kPa}$ were used in the error propagation.

As mentioned in Section C.3, the relative uncertainty associated with surface area is thought to be between $1 \%$ and $10 \%$. $\%$ RSD values of $1 \%, 5 \%$, and $10 \%$ (actually RSD values of $0.01,0.05$, and 0.10 ) were used in the error propagation.

Table C. 2 contains the error (variance) propagation results. The propagated variances associated with the variables unnormalized oxidation rate $(r)$, vapor pressure $(\mathrm{P})$, and surface area $(\mathrm{A})$ are listed in the columns, along with the total variance (Total), total standard deviation (Total Stan. Dev.), and total \%RSD (Total \% RSD) estimates. Note that there are three rows of estimates for each run. The first row 
Table C.2. Results from Propagating Variances of Slope, Vapor Pressure, and Surface Area Through the Equation for Normalized Oxidation Rate $(k)$

\begin{tabular}{|c|c|c|c|c|c|c|c|}
\hline \multirow[b]{2}{*}{ Run } & \multirow[b]{2}{*}{ Levels $^{(2)}$} & \multicolumn{4}{|c|}{ Variance $^{(b)}$} & \multirow[b]{2}{*}{$\begin{array}{l}\text { Total Standard } \\
\text { Deviation }{ }^{(b)}(k) \\
\end{array}$} & \multirow[b]{2}{*}{$\begin{array}{l}\text { Total \% } \\
\text { RSD }(k) \\
\end{array}$} \\
\hline & & Slope $(r)$ & $\begin{array}{c}\text { Vapor } \\
\text { Pressure (P) }\end{array}$ & $\begin{array}{c}\text { Surface } \\
\text { Area (A) }\end{array}$ & Total $(k)$ & & \\
\hline \multirow[t]{3}{*}{80} & smallest & 0.0225 & 0.000181 & 0.0001 & 0.022781 & 0.151 & 15.1 \\
\hline & middle & 0.0900 & 0.000723 & 0.0025 & 0.093223 & 0.305 & 30.5 \\
\hline & largest & 0.3600 & 0.006504 & 0.01 & $0 . \overline{376504}$ & 0.614 & 61.4 \\
\hline \multirow[t]{3}{*}{81} & smallest & 0.0225 & 0.000104 & 0.0001 & 0.022704 & 0.151 & 15.1 \\
\hline & middle & 0.0900 & 0.000414 & 0.0025 & 0.092914 & 0.305 & 30.5 \\
\hline & largest & 0.3600 & 0.003728 & 0.01 & 0.373728 & 0.611 & 61.1 \\
\hline \multirow[t]{3}{*}{82} & smallest & 0.0036 & 0.000170 & 0.0001 & 0.003870 & 0.062 & 6.2 \\
\hline & middle & 0.0144 & 0.000678 & 0.0025 & 0.017578 & 0.133 & 13.3 \\
\hline & largest & 0.0576 & 0.006104 & 0.01 & 0.073704 & 0.271 & 27.1 \\
\hline \multirow[t]{3}{*}{83} & smallest & 0.0225 & 0.000173 & 0.0001 & 0.022773 & 0.151 & 15.1 \\
\hline & middle & 0.0900 & 0.000693 & 0.0025 & $0 . \overline{093193}$ & 0.305 & 30.5 \\
\hline & largest & 0.3600 & 0.006233 & 0.01 & 0.376233 & 0.613 & 61.3 \\
\hline \multirow[t]{3}{*}{84} & smallest & 0.0225 & 0.000181 & 0.0001 & 0.022781 & 0.151 & 15.1 \\
\hline & middle & 0.0900 & 0.000723 & 0.0025 & 0.093223 & 0.305 & 30.5 \\
\hline & largest & 0.3600 & 0.006504 & 0.01 & 0.376504 & 0.614 & 61.4 \\
\hline \multirow[t]{3}{*}{85} & smallest & 0.2500 & 0.000161 & 0.0001 & 0.250261 & 0.500 & 50.0 \\
\hline & middle & 1.0000 & 0.000644 & 0.0025 & 1.003144 & 1.002 & 100.2 \\
\hline & largest & 2.2500 & 0.005798 & 0.01 & 2.265798 & 1.505 & 150.5 \\
\hline \multirow[t]{3}{*}{86} & smallest & 0.0225 & 0.000151 & 0.0001 & 0.022751 & 0.151 & 15.1 \\
\hline & middle & 0.0900 & 0.000605 & 0.0025 & 0.093105 & 0.305 & 30.5 \\
\hline & largest & 0.3600 & $0 . \overline{005442}$ & 0.01 & 0.375442 & 0.613 & 61.3 \\
\hline \multirow[t]{3}{*}{88} & smallest & 0.0225 & 0.0001 & 0.0001 & 0.022700 & $0.15 \mathrm{I}$ & 15.1 \\
\hline & middle & 0.0900 & 0.000401 & 0.0025 & 0.092901 & 0.305 & 30.5 \\
\hline & largest & 0.3600 & 0.00361 & 0.01 & 0.373610 & 0.611 & 61.1 \\
\hline \multirow[t]{3}{*}{89} & smallest & 0.0225 & 0.000103 & 0.0001 & 0.022703 & 0.151 & 15.1 \\
\hline & middle & 0.0900 & 0.000411 & 0.0025 & 0.092911 & $0 . \overline{305}$ & 30.5 \\
\hline & largest & 0.3600 & 0.003698 & 0.01 & 0.373698 & 0.611 & 61.1 \\
\hline \multirow[t]{3}{*}{91} & smallest & 0.0225 & 0.000106 & 0.0001 & 0.022706 & 0.151 & 15.1 \\
\hline & middle & 0.0900 & 0.000426 & 0.0025 & 0.092926 & 0.305 & $30 . \overline{5}$ \\
\hline & largest & 0.3600 & 0.003831 & 0.01 & 0.373831 & 0.611 & 61.1 \\
\hline \multirow[t]{3}{*}{92} & smallest & 0.0225 & 0.000107 & 0.0001 & 0.022707 & 0.151 & 15.1 \\
\hline & middle & 0.0900 & 0.000427 & 0.0025 & 0.092927 & $0 . \overline{305}$ & 30.5 \\
\hline & largest & 0.3600 & 0.003842 & 0.01 & 0.373842 & 0.611 & 61.1 \\
\hline \multirow[t]{3}{*}{93} & smallest & 0.0225 & 0.000109 & 0.0001 & 0.022709 & 0.151 & 15.1 \\
\hline & middle & 0.0900 & 0.000436 & 0.0025 & 0.092936 & 0.305 & 30.5 \\
\hline & largest & 0.3600 & 0.003928 & 0.01 & 0.373928 & 0.611 & 61.1 \\
\hline \multirow[t]{3}{*}{94} & smallest & 0.0225 & 0.00013 & 0.0001 & 0.022730 & 0.151 & 15.1 \\
\hline & middle & $0 . \overline{0900}$ & 0.000518 & 0.0025 & 0.093018 & 0.305 & 30.5 \\
\hline & largest & 0.3600 & 0.004663 & 0.01 & 0.374663 & 0.612 & 61.2 \\
\hline
\end{tabular}


Table C.2. (Contd)

\begin{tabular}{|c|c|c|c|c|c|c|c|}
\hline \multirow[b]{2}{*}{ Run } & \multirow[b]{2}{*}{ Levels $^{(x)}$} & \multicolumn{4}{|c|}{ Variance $^{(b)}$} & \multirow[b]{2}{*}{$\begin{array}{l}\text { Total Standard } \\
\text { Deviation }{ }^{(b)}(k)\end{array}$} & \multirow[b]{2}{*}{$\begin{array}{l}\text { Total \% } \\
\text { RSD }(k)\end{array}$} \\
\hline & & Slope $(r)$ & $\begin{array}{c}\text { Vapor } \\
\text { Pressure (P) }\end{array}$ & $\begin{array}{c}\text { Surface } \\
\text { Area (A) }\end{array}$ & Total $(k)$ & & \\
\hline \multirow[t]{3}{*}{95} & smallest & 0.2500 & 0.000138 & 0.0001 & 0.250238 & 0.500 & 50.0 \\
\hline & middle & 1.0000 & 0.000553 & 0.0025 & 1.003053 & 1.002 & 100.2 \\
\hline & largest & 2.2500 & 0.004975 & 0.01 & 2.264975 & 1.505 & $\overline{150.5}$ \\
\hline \multirow[t]{3}{*}{96} & smallest & 0.0036 & 0.000110 & 0.0001 & 0.003810 & 0.062 & 6.2 \\
\hline & middle & 0.0144 & 0.000440 & 0.0025 & 0.017340 & 0.132 & 13.2 \\
\hline & largest & 0.0576 & 0.003961 & 0.01 & 0.071561 & 0.268 & 26.8 \\
\hline \multirow[t]{3}{*}{97} & smallest & 0.0036 & 0.000110 & 0.0001 & 0.003810 & 0.062 & 6.2 \\
\hline & middle & 0.0144 & 0.000440 & 0.0025 & 0.017340 & 0.132 & 13.2 \\
\hline & largest & 0.0576 & 0.003961 & 0.01 & 0.071561 & 0.268 & 26.8 \\
\hline \multirow[t]{3}{*}{$9 \overline{98}$} & smallest & 0.0036 & 0.000120 & 0.0001 & 0.003820 & 0.062 & 6.2 \\
\hline & middle & 0.0144 & 0.000478 & 0.0025 & 0.017378 & 0.132 & 13.2 \\
\hline & largest & 0.0576 & 0.004303 & 0.01 & 0.071903 & 0.268 & 26.8 \\
\hline \multicolumn{8}{|c|}{$\begin{array}{l}\text { Smallest/middle/largest means the smallest/middle/largest estimates of uncertainty for } \mathrm{r}, \mathrm{A} \text {, and } \mathrm{P} \text { were used. } \\
\text { The total standard deviation has units of } \mathrm{mg} / \mathrm{hr} / \mathrm{cm}^{2} / \mathrm{KPa}^{05} \text {, while the total variance and its component parts each has } \\
\text { units of }\left[\mathrm{mg} / \mathrm{hr} / \mathrm{cm}^{2} / \mathrm{kPa}^{05}\right]^{2} \text {. }\end{array}$} \\
\hline
\end{tabular}

contains the estimates using the smallest levels of uncertainty for each of the variables listed above. The second row contains the estimates using the middle uncertainty levels, and the third row contains the estimates using the largest uncertainty levels. Hence, these combinations of uncertainties span the smallest, middle, and largest total uncertainties possible given the specified low, middle, and high levels of uncertainty for each variable.

The results in Table C.2 are very similar for the three groups of TGA tests for which separate estimates of $\ln (r)$ uncertainty were used. For the group containing TGA runs $80,81,83,84,86,88,89$, $91,92,93$, and 94 , the total standard deviation of the natural $\log$ of normalized oxidation rates $[\ln (k)]$ is estimated to be between approximately 0.15 and 0.61 , with a middle value of approximately 0.31 . This translates to $\%$ RSD values for normalized oxidation rate $k$ ranging from $15 \%$ to $61 \%$, with a middle value of $31 \%$. The results are essentially the same for all TGA tests in the group. However, the smallest uncertainty value may be more appropriate for some TGA tests in the group, while the middle or largest uncertainties may be more appropriate for others.

For the second group, consisting of TGA runs $82,96,97$, and 98 , the $\%$ RSD values for normalized oxidation rate $k$ range from roughly $6 \%$ to $27 \%$, with middle values of $13 \%$. These runs have lower uncertainties than the first group because of the lower estimates of uncertainty used for the unnormalized oxidation rate $(r)$ values in the error propagation. 
For the third group, consisting of TGA runs 85 and 95 , the \%RSD values for normalized oxidation rate $k$ range from roughly $50 \%$ to $151 \%$, with middle values of $100 \%$. These runs have higher uncertainties than the first group because of the higher estimates of uncertainty used for the unnormalized oxidation rate $(r)$ values in the error propagation.

It is clear from the Table C.2 results that the uncertainty in normalized oxidation rates $k$ is dominated by the uncertainty in the unnormalized oxidation rates $r$. Uncertainties in surface area and vapor pressure are small relative to the uncertainty in $r$, and hence contribute little to the uncertainty of $k$.

\section{C.5 Comparison of Literature and TGA Oxidation Rate Data}

The most important objective of this work is to assess whether K-West SNF normalized oxidation rates ( $k$ values per Eq. C.1) are different from literature values for unirradiated uranium. Preliminary plots of $\ln (k)$ versus $1000 / T$ seem to suggest a linear relationship:

$$
\ln (k)=c+d(1000 / \mathrm{T})
$$

where $\ln (k)$ denotes the natural logarithm of the normalized oxidation rate $k\left(\mathrm{mg} / \mathrm{hr} / \mathrm{cm}^{2} / \mathrm{KPa}\right), T$ is temperature in Kelvin, and $c$ and $d$ are the intercept and slope of the line, respectively.

Unfortunately, the TGA test data are over a much narrower temperature range ( 349 to $484 \mathrm{~K}$ ) than are the literature data ( 293 to $1713 \mathrm{~K}$ ). To compare oxidation rates and the oxidation rate-temperature relationship for the literature and TGA tests, it was decided to focus on a truncated portion of the literature data from 293 to $575 \mathrm{~K}$. Over this truncated temperature range, the $\ln (k)$ versus 1000/T relationship for the literature data is approximately linear. The relationship for the TGA tests also appears to be roughly linear, although the relationship is much nosier because of scatter in the small number of ( $T$, $k$ ) data points. Apparently there is reasonable cause to consider omitting some of the TGA data runs, which may reduce the apparent scatter. However, it was beyond the requested scope to consider this in the statistical analyses.

Even though the temperature range for the truncated literature data is much narrower than for the untruncated literature data, it is still wider than the temperature range for the TGA test data. The combination of a narrower temperature range and much smaller number of data points for the TGA test data causes the uncertainty in the slope of the $\ln (\mathrm{k})$ versus $1000 / \mathrm{T}$ linear relationship to be much greater than the uncertainty in the slope for the literature data. This point is illustrated and discussed in Sections C.5.1 and C.5.2. Section C.6 assesses the value that would be added by performing one or two extra TGA tests at temperatures closer to the 293 and $575 \mathrm{~K}$ extremes for the truncated literature data.

In the subsections that follow, the results of various approaches for comparing oxidation rates of literature and TGA test data are presented. 


\section{C.5.1 Linear Relationship Between In(Oxidation Rate) and Inverse Temperature for Truncated Literature Data}

One approach for comparing oxidation rates from literature and TGA test data is to: (i) fit and assess a linear relationship between $\ln (k)$ and $1000 / \mathrm{T}$ for the literature data, (ii) compute $95 \%$ prediction intervals for normalized oxidation rate $k$ on each of the TGA tests using the fitted relationship, and (iii) determine whether the "measured" oxidation rate $k$ for each TGA test is within its corresponding $95 \%$ prediction interval. This approach assumes that the uncertainty in oxidation rates for the literature data is representative of the uncertainty in oxidation rates for the TGA test data.

The results of fitting Eq. C.5 to the truncated literature data are given in Table C. 3 and shown in Figure C.1. Note that 167 data points provided 166 total degrees of freedom, of which 113 were used to estimate pure error and 52 were available to statistically test lack-of-fit. The lack-of-fit F-statistic had a

Table C.3. Results of Fitting the Line $\ln (k)=c+d(1000 / \mathrm{T})$ to Literature and TGA Test Data

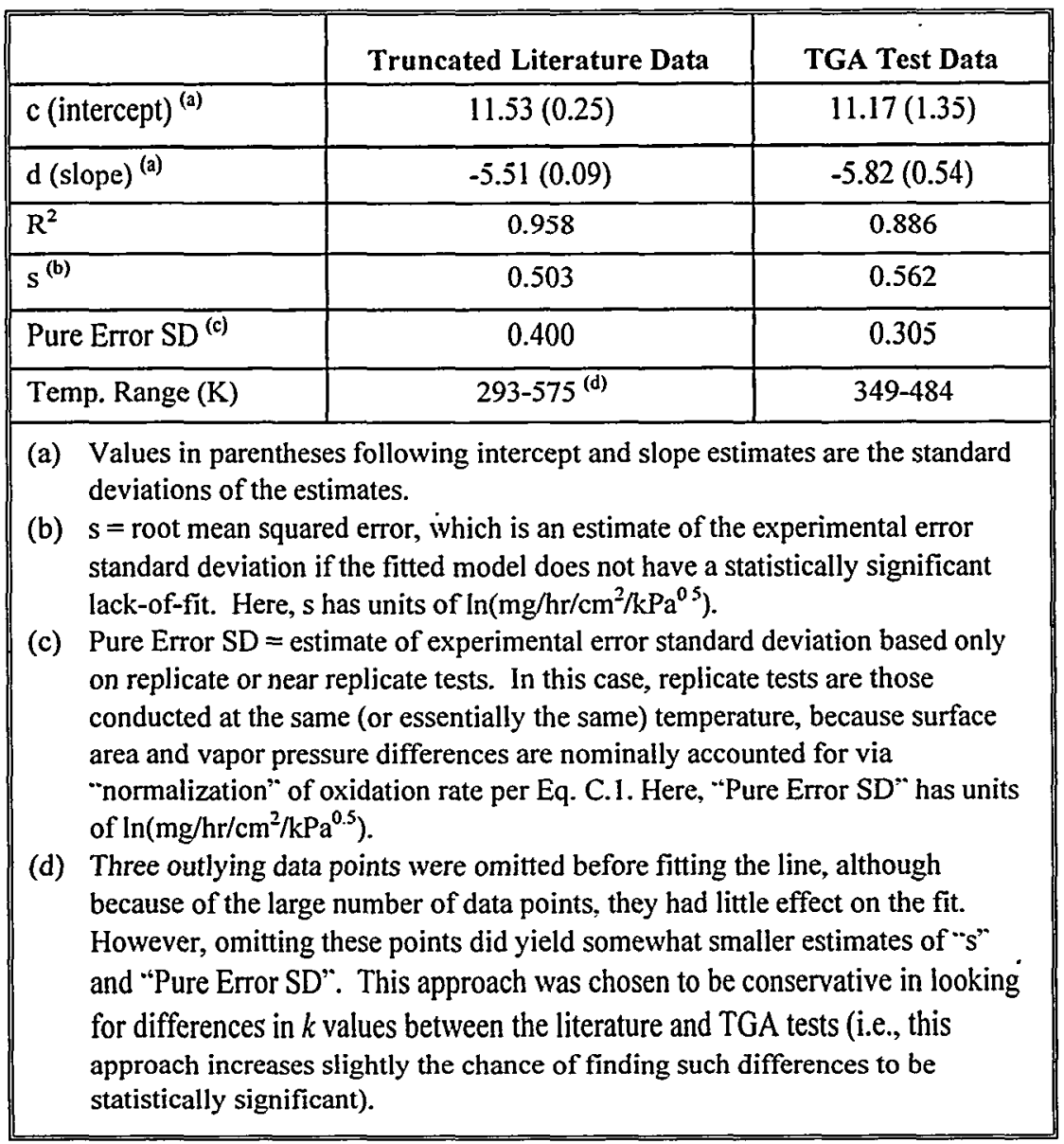




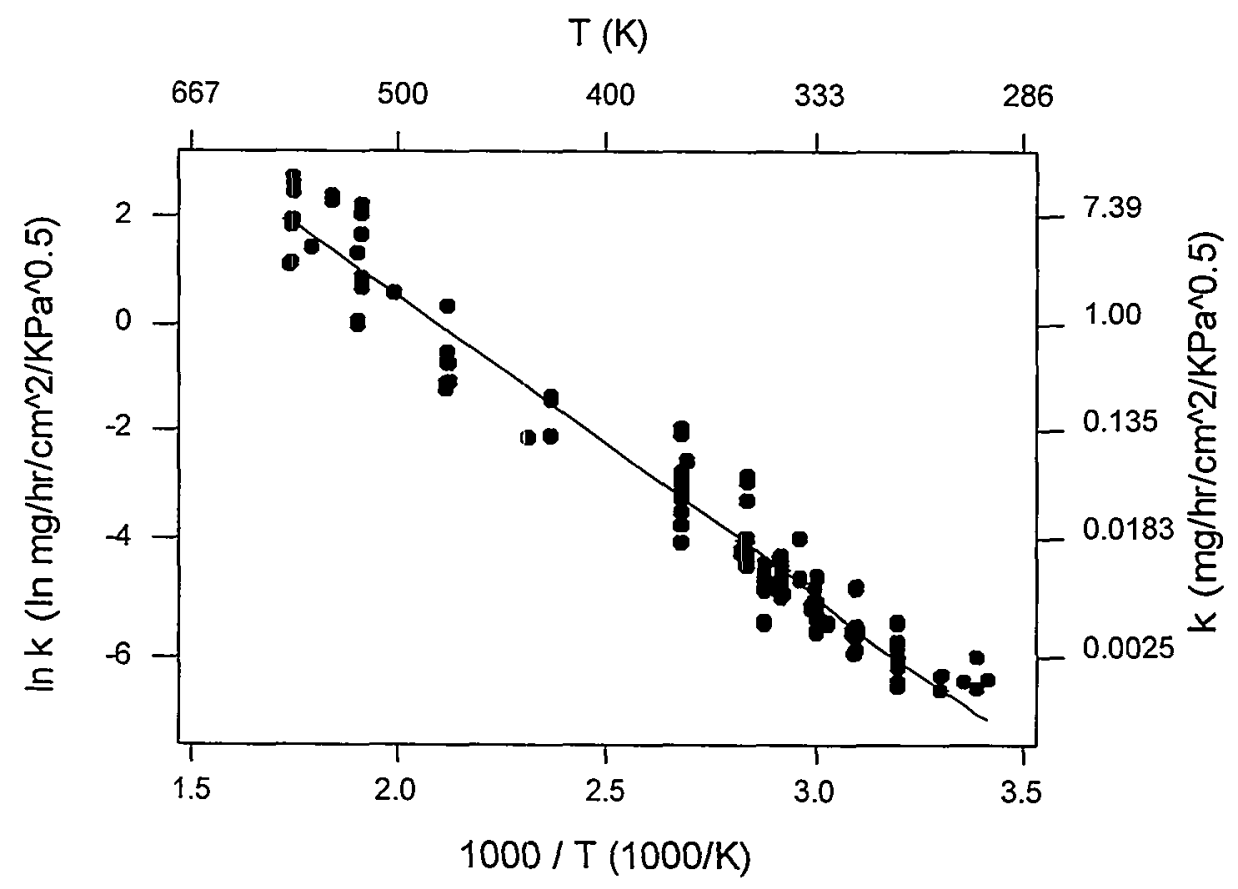

Figure C.1. Truncated Literature Oxidation Rate Data for Unirradiated Uranium Between 293 and $575 \mathrm{~K}$ and the Fitted Least Squares Line

value of 2.85 , which was highly statistically significant $(>99.9 \%)$ because of the large degrees of freedom. However, from a practical standpoint, a line fits the $\ln (k)$ versus $1000 / T$ truncated literature data quite well (as seen in Figure C.1). Hence, it was deemed appropriate to proceed with using the fitted line to make predictions and $95 \%$ prediction intervals for the TGA tests.

The "Pure Error SD" value of 0.400 for the truncated literature data (see Table C.3) can be interpreted (per the approximation in Eq. C.3) as normalized oxidation rate $k$ having $\% \mathrm{RSD}=40.0 \%$. This estimate of uncertainty for $k$ includes test sample-to-sample variations and lab-to-lab testing variations. The $\% \mathrm{RSD}=40.0$ estimate from the literature data may be contrasted with the error propagation estimates of uncertainty in TGA $k$ values summarized in Table C.2. The propagated uncertainties for TGA $k$ values do not contain any sample-to-sample or lab-to-lab sources of variation, and yet have \%RSD values from error propagation in the ranges 6 to $28 \%, 15$ to $61 \%$, or 50 to $150 \%$ depending on the group each TGA test was in. These results suggest the TGA test data may be subject to more uncertainty than the test data from the literature. However, there are other possible explanations. Because the uncertainty in unnormalized oxidation rates was dominant in the error propagation results, the ad-hoc method of using localized weight gain data to estimate uncertainty may have yielded overestimates. Another explanation is that there could be differences in uncertainty in literature tests of unirradiated uranium versus TGA tests of K-West SNF. It was beyond the scope of this statistical analysis to address such issues. 
The line in Eq. C.5 fitted to the truncated literature data was used to make a prediction and $95 \%$ twosided prediction interval on $k$ for each of the TGA tests. The results are given in Table C.4. For a given TGA test, if the range of "measured" $k$ values is within the corresponding $95 \%$ prediction interval, then the TGA results cannot be declared significantly different from the mean $k$ value for the literature data at that temperature. If the range of "measured" $k$ values for a given TGA test is outside the corresponding 95\% prediction interval, the TGA results are declared significantly different from the mean $k$ value for the literature data at that temperature. In the long run, such "significantly different" conclusions would be correct $95 \%$ of the time given that a $95 \%$ prediction interval was used. If the range of "measured" $k$ values for a given TGA test is partly inside and partly outside the corresponding $95 \%$ prediction interval, it is borderline whether there is a statistically significant difference.

Table C. 4 shows, that of the 17 TGA tests, 6 have ranges of "measured" $k$ values that are completely outside the $95 \%$ prediction intervals. In all 6 of these cases, the range of "measured" $k$ values is below the lower limit of the $95 \%$ prediction interval. Another 6 TGA runs had their ranges of "measured" $k$ values overlap the $95 \%$ prediction intervals, always on the lower end of the $95 \%$ prediction intervals. The remaining 5 TGA tests $(80,81,82,83$, and 84$)$ had their $k$ ranges completely inside the corresponding $95 \%$ prediction intervals. However, the $k$ ranges tended to fall within the lower portions of the $95 \%$ prediction intervals. Finally, if the K-West SNF tests were performed in the order of their TGA numbers, it is worth noting that the first 5 tests had "measured" $k$ ranges within the corresponding $95 \%$ prediction intervals, while the final 12 tests did not.

Table C.4. Comparison of "Measured" $k$ Values for TGA Tests to Predictions and 95\% Prediction Intervals Obtained from Fitting Eq. C.5 to Truncated Literature Data

\begin{tabular}{|c|c|c|c|}
\hline $\begin{array}{l}\text { TGA } \\
\text { Test }\end{array}$ & $\begin{array}{c}\text { Predicted } k \\
\left(\mathrm{mg} / \mathrm{hr} / \mathrm{cm}^{2} / \mathrm{KPa}^{0.5}\right)\end{array}$ & $\begin{array}{l}\text { 95\% Prediction Interval on } k \\
\left(\mathrm{mg} / \mathrm{hr} / \mathrm{cm}^{2} / \mathrm{kPa}^{0.5}\right)\end{array}$ & $\begin{array}{c}\text { Range of "Measured" } k^{(\text {(a) }} \\
\left(\mathrm{mg} / \mathrm{hr} / \mathrm{cm}^{2} / \mathrm{kPa}^{0.5}\right)\end{array}$ \\
\hline 80 & 0.312 & $0.1149-0.8477$ & 0.2607 \\
\hline 81 & 0.312 & $0.1149-0.8477$ & $0.1542-0.1929$ \\
\hline 82 & 0.303 & $0.1115-0.8232$ & 0.1778 \\
\hline$\overline{83}$ & 0.039 & $0.0144-0.1061$ & $0.0221-0.0408$ \\
\hline 84 & 0.038 & $0.0139-0.1020$ & $0.0202-0.0268$ \\
\hline 85 & 0.036 & $0.0133-0.0980$ & $0.0054-0.0437^{*}$ \\
\hline 86 & 0.130 & $0.0479-0.3527$ & $0.0199-0.0303^{* *}$ \\
\hline 88 & 0.321 & $0.1182-0.8729$ & $0.0555-0.0963^{* *}$ \\
\hline 89 & 0.321 & $0.1182-0.8729$ & $0.0666-0.0838^{* *}$ \\
\hline 91 & 0.134 & $0.0496-0.3647$ & $0.0228-0.0450^{* *}$ \\
\hline 92 & 0.048 & $0.0176-0.1290$ & $0.0084-0.0300^{*}$ \\
\hline 93 & 0.014 & $0.0052-0.0384$ & $0.0037-0.0067 *$ \\
\hline$\overline{94}$ & 0.015 & $0.0055-0.0402$ & $0.0040-0.0085^{*}$ \\
\hline 95 & 0.016 & $0.0057-0.0421$ & $0.0036-0.0289 *$ \\
\hline 96 & 1.158 & $0.4244-3.1573$ & $0.3390^{* *}$ \\
\hline 97 & 1.158 & $0.4244-3.1573$ & 0.3151 ** \\
\hline 98 & 0.114 & $0.0419-0.3081$ & $0.0437^{*}$ \\
\hline \multicolumn{4}{|c|}{$\begin{array}{l}\text { (a) An * indicates the range of "measured" } k \text { values overlaps the corresponding } 95 \% \\
\text { prediction interval (PI), while ** indicates the range of "measured" } k \text { values is } \\
\text { completely outside the corresponding } 95 \% \mathrm{PI} \text {. }\end{array}$} \\
\hline
\end{tabular}


The results in Table C.4 strongly suggest that the TGA tests tend to have lower normalized oxidation rates $k$ than do literature tests. There are two possible explanations for this. One possible explanation is that the K-West SNF actually oxidizes at a slower rate than do the various unirradiated uranium samples represented in the literature data. Another possible explanation is that the TGA testing process yieIds normalized oxidation rates $k$ that are biased low compared to the testing processes used to produce the literature data. One possible explanation for the first 5 TGA tests showing less "bias" relative to the literature data than the subsequent 12 tests is that the bias was changing over time. Presumably there are other possible explanations. Whether or not the TGA testing process yields estimates of $k$ that are biased low must be addressed on the basis of knowledge of the testing process, and thus is not discussed further here.

\section{C.5.2 Linear Relationships Between In(Oxidation Rate) and Inverse Temperature for TGA Test Data}

The results of fitting Eq. C.5 to the TGA test data are given in Table C.3 and displayed in Figure C.2. The results from fitting Eq. C.5 to the literature data are also contained in Table C. 3 to facilitate comparisons. The line fitted to the TGA data had $R^{2}=0.886$, which is smaller than the $R^{2}=0.958$ value for the line fitted to the literature data. The smaller $R^{2}$ value could be due to larger scatter of the TGA data about the fitted line (see Figure C.2). The larger scatter tends to support the earlier conjecture that the TGA test data may be subject to more uncertainty than the literature data. The lower $\mathrm{R}^{2}$ value could

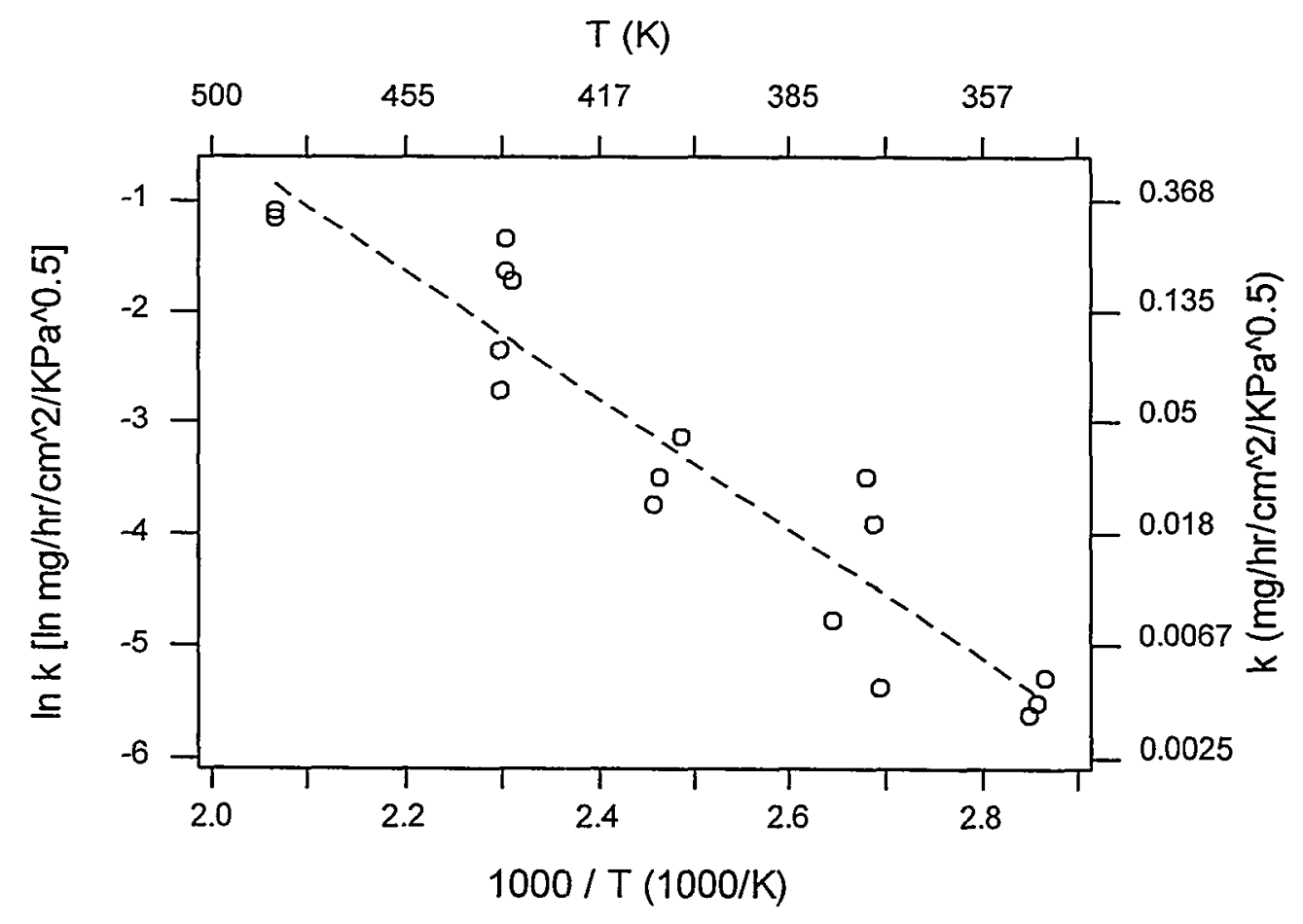

Figure C.2. K-West SNF Oxidation Rate Data and the Fitted Least Squares Line 


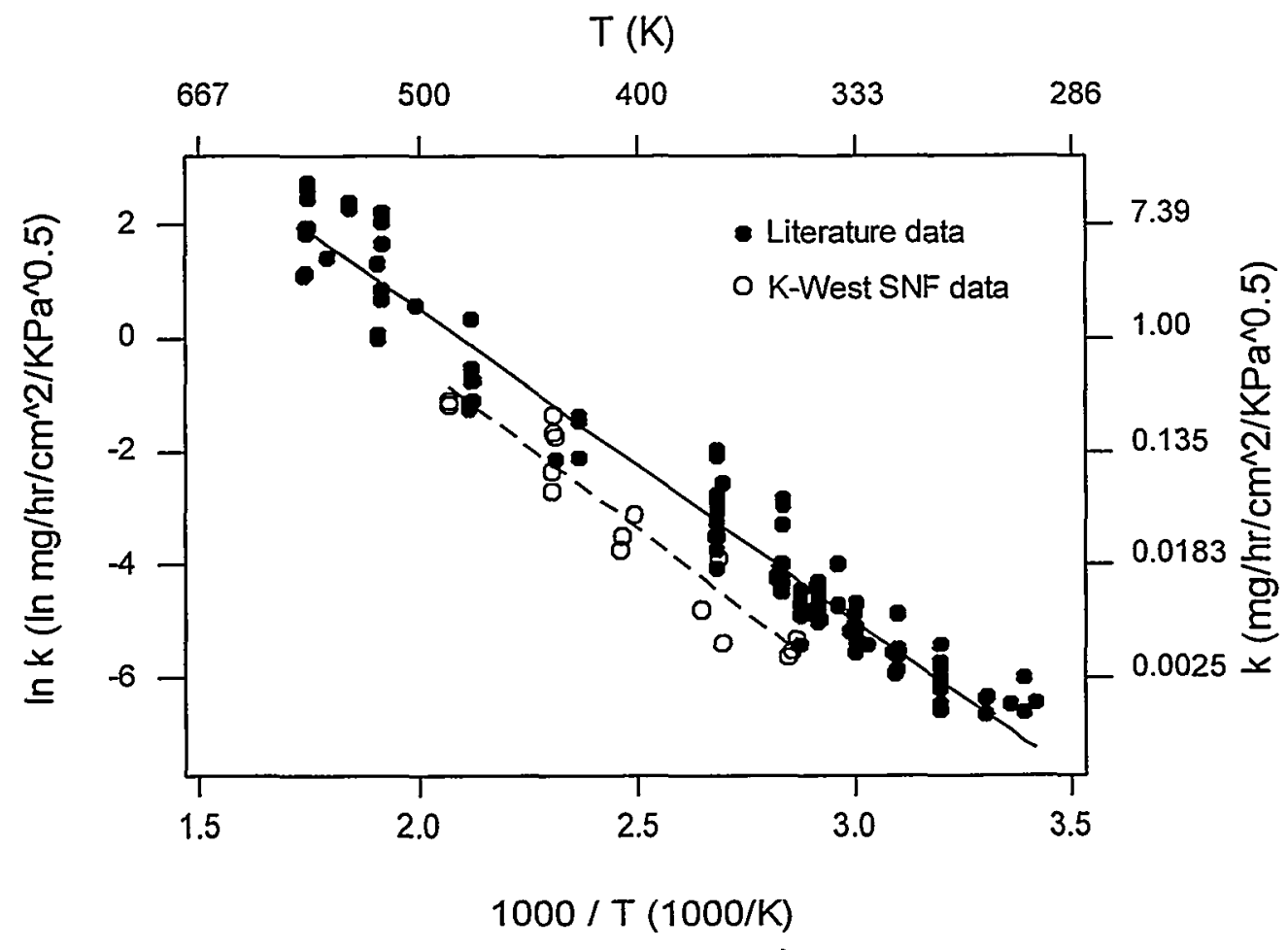

Figure C.3. K-West SNF and Literature Unirradiated Uranium Oxidation Rate Data and the Respective Fitted Least Squares Lines

also be due to the narrower temperature range of data for the TGA tests compared to the literature data. The estimate of "Pure Error SD" for the TGA tests given in Table C.3 is based on near-replicate TGA data (tests at nearly the same temperature). The "Pure Error SD" estimate of 0.305 for the TGA tests is somewhat smaller than the corresponding estimate of 0.400 for the literature data. However, the pure error standard deviations (SDs) at different TGA test temperatures varied widely, with some small values lowering the combined estimate.

An important question is whether the slopes of the $\ln (k)$ versus 1000/T relationship are different for the TGA and literature data. If the slopes are different, that would indicate K-West SNF could have higher normalized oxidation rates for some values of $T$ than unirradiated uranium samples from the literature data. Figure C.3 displays the TGA and literature data and their corresponding fitted lines. From Table C.3 and Figure C.3, it is seen that the slopes of the $\ln (k)$ versus $1000 /$ T relationship are very close for the literature and TGA data sets. Given the uncertainties in the slopes (see Table C.3), there is no statistically significant difference between them. Neither is there a statistically significant difference between the two intercepts. However, in the temperature range of the TGA data, Figure C.3 clearly shows the TGA line is lower than the literature line. This difference agrees with earlier indications of normalized oxidation rates for the TGA tests being lower than for the literature tests. 


\section{C.6 Value of Additional TGA Tests Over Wider Temperature Range}

It was noted in Section C.5 that the TGA test data covers a narrower temperature range than the truncated literature data. This raises the question as to the added value of conducting additional TGA tests over a wider temperature range. Additional TGA tests over a wider temperature range will reduce the SD for the slope of $\ln (k)$ versus 1000/T. In other words, a more precise estimate of the slope would be obtained for the TGA data. In turn, it would be easier to detect a difference between the slopes of the $\ln (k)$ versus $1000 / T$ relationship for the TGA and literature data.

The SD of the slope for the TGA data was recalculated assuming data were collected at one or two additional temperature values. Additional temperature values were selected near the smallest (293K) and largest $(575 \mathrm{~K})$ temperature values from the truncated literature data. The calculation of the new SDs (after adding one or two new temperature values) assumes there is no change in the mean squared error of the linear fit of $\ln (k)$ versus $1000 / \mathrm{T}$. The selected new temperature values and the corresponding new SDs are listed in Table C.5.

Table C. 5 shows that the slope SD is reduced from 0.540 to 0.410 by including additional points at $\mathrm{T}=325$ and $550 \mathrm{~K}$. The $\mathrm{SD}$ is reduced from 0.540 to 0.366 by including points at $300 \mathrm{~K}$ and $575 \mathrm{~K}$. Adding more than two additional data points, or even replicating some data points, would reduce the $\mathrm{SD}$ further. The question is whether the reduction in SD of the slope for the TGA data would be sufficient to declare the slope significantly different than the slope for the literature data.

Table C.3 shows a slope of -5.51 for the literature data, and -5.82 for the TGA data. Assuming the TGA slope would remain the same after adding additional temperature data points, the question becomes whether the reduction in standard error would be sufficient to declare -5.82 significantly different from 5.51. Because the difference in these two slopes $(0.31)$ is so small, the reduction in SD from adding one

Table C.5. Value of Performing Additional TGA Tests Over a Wider Temperature Range

\begin{tabular}{|l|c|}
\hline $\begin{array}{c}\text { T (K) Value of } \\
\text { Point(s) Added }\end{array}$ & $\begin{array}{c}\text { Standard Deviation } \\
\text { of Slope }\end{array}$ \\
\hline no point(s) added & 0.540 \\
\hline 325 & 0.474 \\
\hline 550 & 0.458 \\
\hline 325 and 550 & 0.410 \\
\hline & \\
\hline no points added & 0.540 \\
\hline 300 & 0.424 \\
\hline 575 & 0.442 \\
\hline 300 and 575 & 0.366 \\
\hline
\end{tabular}


or two additional points would not be enough to declare the difference statịstically significant. Of course, there is always the possibility that additional TGA tests at temperatures more extreme than studied so far would yield a slope for the TGA data with a larger difference compared to the slope for the literature data. It is possible to perform statistical power analyses to determine the probability of declaring statistically significant slope differences of different magnitudes given various numbers of TGA data points.

However, such a power analysis was not performed because of the lack of strong evidence that the TGA tests of K-West SNF have a different slope compared to literature data.

\section{C.7 Summary and Conclusions}

Several statistical analyses were performed to achieve the primary goals of: 1) estimating normalized oxidation rates $k\left(\mathrm{mg} / \mathrm{hr} / \mathrm{cm}^{2} / \mathrm{kPa}^{0.5}\right)$ and their uncertainties for TGA tests of K-West SNF in a moist helium atmosphere, 2) comparing $k$ values for literature unirradiated uranium tests and K-West SNF tests, and 3) assessing the value of performing additional TGA tests on K-West SNF.

The statistical analyses did not find any evidence of K-West SNF having higher oxidation rates compared to literature data. Rather, there was strong statistical evidence that K-West SNF has lower oxidation rates than the literature data, or that the TGA tests performed on K-West SNF somehow yield oxidation rates that are biased low compared to the literature tests.

Oxidation rates obtained from TGA testing of K-West SNF may be subject to higher uncertainty than the literature data. This statement requires some explanation, because fewer sources of uncertainty may be present in the K-West SNF data compared to the literature data. The literature data presumably includes unirradiated uranium sample-to-sample and lab-to-lab variations, whereas the TGA tests of $\mathrm{K}$-West SNF were performed in the same lab with possibly less variation in SNF samples. Replicate literature data (multiple normalized oxidation rate values at the same temperature) provided an estimate of $40 \%$ RSD. Error propagation results for the TGA K-West SNF tests indicated uncertainties could be in the 6 to $150 \%$ RSD range depending on the specific TGA test and uncertainties in the quantities used to calculate normalized oxidation rate. The error propagation results were dominated by the uncertainties estimated for unnormalized oxidation rates, which were determined using localized portions of weight gain versus time data. These uncertainties in unnormalized oxidation rates may be overestimates of the true uncertainty, which is a possible explanation for the larger estimates of uncertainties in TGA test results for normalized oxidation rate.

Finally, it is recommended that if additional TGA tests are performed in the future, statistical experimental design principles and methods be employed so as to be able to adequately assess and account for the effects of test and sample parameters on oxidation rate. Also, including several replicates in the experimental design would provide for better estimates of oxidation rate uncertainty. 


\section{Appendix D}

\section{Data Integrity Review Team (DIRT) Activity Summary}




\section{Appendix D}

\section{Data Integrity Review Team (DIRT) Activity Summary}

\section{D.1 Purpose}

The purpose of the Data Integrity Review Team was to help ensure the quality of results obtained in laboratory studies to assess the kinetics of K-Basin spent fuel in a moist, inert gas environment. The team was asked to review the entire experimental approach to evaluation. of spent fuel oxidation kinetics, identifying vulnerabilities that could impact the quality of experimental results. Where appropriate, the committee was to suggest modifications to experimental methods and possibly additional tests that would lead to an improved understanding of the kinetics of spent fuel oxidation under anticipated storage conditions.

The DIRT team was composed of the following:

G. Scott Barney - Babcock and Wilcox

Albin L. Pajunen - Duke Engineering Services

Larry R. Pederson - Pacific Northwest National Laboratory

Joel M: Tingey - Pacific Northwest National Laboratory

Each of the team members has expertise in the development and use of reaction rate data. The team was assembled by and reported to DW Bergmann and JR Fredrickson, Duke Engineering Services. The team met at least once weekly beginning in early November 1998 with J Abrefah, the cognizant PNNL scientist for moist, inert gas oxidation studies.

It is the opinion of the DIRT that the experimentally determined oxidation rates for K-Basin spent fuel are of high quality and accurately reflect the behavior of that fuel in a moist, inert gas environment. Within identified limits, the use of thermogravimetric analysis to study spent fuel oxidation is appropriate for this study. The origin of each sample used in the tests and experimental rate data corresponding to each sample are well documented. Uncertainties associated with these measurements were carefully considered. The reported results are in good agreement with literature values. 


\section{D.2 Issues Considered by DIRT}

A wide range of issues was discussed by the DIRT that could potentially affect the quality of experimentally determined spent fuel oxidation rates in moist helium. These issues are summarized below.

Degree That Chosen Samples Are Representative of K-Basin Spent Fuel: All seventeen samples on which TGA tests were performed were taken from the damaged end of one K-West Basin fuel element. Constraints of time and budget precluded examination of additional elements. Samples sectioned from the spent fuel element contained varying degrees of matrix damage due to corrosion, ranging from minor to severe. Somewhat higher oxidation rates were obtained for severely corroded samples, but the obtained rates did not exceed literature results. Since samples were cut from the damaged fuel element, present studies did not address the effect on oxidation kinetics of the presence of a surface corrosion layer formed during fuel storage in the K-Basins.

Applicability of the TGA Method: The DIRT has concluded that the TGA approach to studying spent fuel oxidation is appropriate. Advantages include the ability to measure even very small weight gains due to oxidation in a controlled atmosphere in real time and the ability to use small samples. Reaction temperatures can be controlled precisely. However, even a very sensitive technique such as thermogravimetric analysis has limitations in its applicability, which was established in the present study through a series of background drift measurements and a careful analysis of error.

Surface Area: Oxidation rates are based on the exposed surface area of the spent fuel sample, not on initial sample weight. Dimensional irregularities due to sample cutting, etc., could result in a surface area greater than the geometric sample area used in data reduction, conservatively estimated at $10 \%$. Microcracks in damaged spent fuel samples will also result in a higher surface area than the geometric value and will contribute to experimental scatter. Such enhanced rates due to microcracks merely reflect the properties of the spent fuel. While rates determined for severely damaged samples were somewhat greater than obtained for mildly damaged samples, the determined rates did not exceed that reported in the literature.

Actual Surface Temperature versus Furnace Temperature: We expect that the actual sample temperature and the indicated temperature in the TGA will be essentially identical, even though oxidation reactions produce heat. Differences in actual sample and indicated temperatures will be minimized by small sample size, good thermal conductivity of the sample and TGA hardware, and relatively slow reaction rates in the temperature range studied.

Sample Loss: Irradiation-induced strains in spent fuels can result in spallation of the oxidation product. The oxidation product was partially lost from the sample cup in initial tests, leading to irregular weight gain curves and an underestimate of oxidation kinetics. The addition of platinum screen covers to the sample cup effectively minimized this problem, preventing substantial oxidation product loss. 
Mass Transfer Limitations: If the potential oxidation rate of spent fuel exceeded the rate of reactant flow in the TGA, reaction rates would be biased low. The use of platinum screens to minimize oxidation product loss could somewhat exacerbate this possible problem. Experimental results do not support mass transfer limitations, given that there was no dependence of reaction rate on gas flow rate, and that the temperature dependence of oxidation kinetics followed simple Arrhenius behavior.

Sample Fragmentation: Some of the most damaged spent fuel samples fragmented during TGA tests, particularly at temperatures equal to or greater than $160^{\circ} \mathrm{C}$. Whether the samples fragmented or not during the tests was well documented. Three tests that resulted in sample fragmentation at $160^{\circ} \mathrm{C}$ yielded oxidation rates somewhat higher than a test at the same temperature where the sample' did not fragment. Experimental scatter due to fragmentation was similar to that of literature results.

Balance Drift: Drifts in the background of the TGA signal could add or subtract from actual weight gains due to oxidation. Balance drift can exceed that of oxidative weight gain at low temperatures where the reaction rate is very small. Extensive blank runs were performed over time periods and temperatures similar to those used in oxidation tests to ensure that balance drift did not significantly alter results. Background runs were also performed where moisture was introduced into the carrier stream after first equilibrating in dry helium. Such background runs helped to establish a minimum experimental temperature at which meaningful kinetic data could be obtained.

Possible Oxygen Poisoning: It is possible that oxygen could have been present in the range of 30 to 80 $\mathrm{ppm}$ in the TGA, based on measurement of oxygen concentrations in the outlet gas from the TGA. Oxygen levels above $\approx 25 \mathrm{ppm}$ are known to suppress the oxidation rate of uranium metal in moist inert gas; reductions in rate by a factor of 7 to 8 have been observed for an oxygen concentration of $150 \mathrm{ppm}$. Test configuration limitations may have led to the introduction of small concentrations of oxygen. Infiltration of air downstream of the test chamber is the most probable source. Oxygen concentration measurements were made downstream of the most likely infiltration point, so the actual oxygen concentrations could well have been less than $80 \mathrm{ppm}$. When reaction rate results are adjusted for the maximum effect of oxygen poisoning, reaction rate data for K-Basin spent fuel did not significantly exceed the literature results for unirradiated uranium.

Uncertainty Analysis: From the earliest meetings of the DIRT, it was recommended that an extensive analysis of experimental uncertainties be conducted. Preliminary propagation of error analyses conducted by the team led to an estimate that the lowest temperature for which meaningful results could be obtained was approximately $70^{\circ} \mathrm{C}$. The minimum experimental temperature below which results were deemed unreliable was revised upward, based on the results of a series of background tests conducted by $J$. Abrefah and R. Sell. These tests included some where the balance was first equilibrated in dry helium followed by moisture introduction. At the completion of the tests, a careful statistical analysis of spent fuel oxidation results was conducted by G. Piepel and S. Cebula, PNNL, which is attached to this report as Appendix C. It was concluded from this statistical analysis that there was no evidence for K-West Basin spent fuel to exhibit higher oxidation rates than given in the literature. 


\section{D.3 Summary}

The DIRT is satisfied that oxidation rate data obtained for K-West Basin spent fuel in moist helium are of high quality and accurately represent the behavior of the fuel. The experimental approach used in this study, thermogravimetric analysis, is appropriate for the study. After an examination of the results of initial tests, modifications to the TGA were made to minimize measurement artifacts - specifically, the loss of oxidation product from the sample vessel. From a thorough and careful analysis of measurement uncertainties, the temperature range of applicability of the TGA technique was established. The experimental results showed conclusively that oxidation rates of the examined K-West Basin fuel element did not exceed that of literature results. 


\section{Distribution}

No. of

Copies

\section{OFFSITE}

C. L. Bendixsen

Idaho National Engineering and

Environmental Laboratory

P.O. Box 1625

Mail Stop 3135

Idaho Falls, ID 83415

A. W. Conklin

Washington State Department of Health

Airdustrial Park

Building 5, Mail Stop LE-13

Olympia, WA 98504-0095

M. A. Ebner

Idaho National Engineering and

Environmental Laboratory

P.O. Box 1625

Mail Stop 3114

Idaho Falls, ID 83415

A. R. Griffith

U.S. Department of Energy, Headquarters

19901 Germantown Rd (EM-65)

Germantown, MD 20585-1290

T. J. Hull

U.S. Department of Energy, Headquarters

19901 Germantown Road (EH-34)

Germantown, MD 20874-1290

M. R. Louthan

Savamnah River Technology Center

Materials Technology Center

Aiken, SC 29808
No. of

Copies

T. E. Madey

Rutgers University

Bldg. 3865

136 Freylinghuysen $\mathrm{Rd}$

Piscataway, NJ 08854

B. K. Nelson

U.S. Department of Energy, Headquarters 19901 Germantown Road (EM-65)

Germantown, MD 20874-1290

R. G. Pahl, Jr.

Argonne National Laboratory

P. O. Box 2528

Idaho Falls, ID 83403

R. S. Rosen

Lawrence Livermore National Laboratory 20201 Century Blvd., $1^{\text {ST }}$ Floor

Germantown, MD 20874

D. Silver

Washington State Department of Ecology

P.O. Box 47600

Olympia, WA $98504-7600$

T. A. Thornton

Yucca Mountain Project M\&O Contractor

SUM1/423

1261 Town Center Drive

Las Vegas, NV 89134 
No. of

\section{Copies}

\section{ONSITE}

6 DOE Richland Operations Office
R. M. Hiegel
S7-41
P. G. Loscoe
S7-41
C. R. Richins
K8-50
E. D. Sellers
S7-41
J-S. Shuen
G. D. Trenchard
S7-41
S7-41

23 Duke Engineering and Services,

\section{Hanford, Inc.}

C. B. Aycock

R3-11

R. B. Baker

D. W. Bergmann

HO-40

$\mathrm{X} 3-79$

\section{Fluor Daniel Hanford}

\section{Fluor Daniel Northwest}

S. A. Chastain

D. R. Duncan

J. R. Frederickson

L. H. Goldmann

S. L. Hecht

B. J. Makenas

R. P. Omberg

A. L. Pajunen

R. W. Rasmussen

A. M. Segrest

J. A. Swenson

C. A. Thompson

D. J. Trimble (5)

D. J. Watson

J. H. Wicks, Jr.

SNF Project Files

E. W. Gerber

R3-11

D. A. Smith

M. J. Wiemers

HO- 40

R3-86

R3-86

R3-86

H0-40

HO- 40

H0-40

R3-86

X3-85

R3-11

R3-11

R3-86

HO- 40

X3-79

X3-74

R3-11

T4-13

R3-11

L. J. Garvin

R3-26

G. A. Ritter
No. of

Copies

7 Numatec Hanford Company

G. P. Chevrier

H5- 25

T. Choho

R3-86

E. R. Cramer

HO-34

T. A. Flament

H5-25

J. J. Irwin

R3-86

C. R. Miska

R3-86

J. P. Sloughter

H5-49

\section{Technical Advisory Group}
J. C. Devine
R3-11
R. F. Williams
R3-11

36 Pacific Northwest National Laboratory

J. Abrefah (7) P7-27

S. T. Cebula K5-12

J. P. Cowin K8-88

S. R. Gano K2-12

W. J. Gray P7-27

B. D. Hanson P7-27

G. S. Klinger P7-22

D. K. Kreid K7-80

P. J. MacFarlan P7-27

S. C. Marschman (5) P7-27

B. M. Oliver P7-22

T. M. Orlando K8-88

L. R. Pederson K2-44

G. F. Piepel K5-12

R. L. Sell (2) P7-25

J. K. Tarantino K9-41

J. M. Tingey P7-25

J. C. Wiborg K7-74

Information Release (7)

1 B. \& W. Hanford

G. S. Barney

T5-12 